

\section{An Evaluation of Several Cryogenic Turbine Flowmeters}

U.S.

PARTMENT

OF

OMMERCE

National

$Q$

○。

5753

0.624

972 


\section{NATIONAL BUREAU OF STANDARDS}

The National Bureau of Standards ${ }^{1}$ was established by an act of Congress March 3, 1901. The Bureau's overall goal is to strengthen and advance the Nation's science and technology and facilitate their effective application for public benefit. To this end, the Bureau conducts research and provides: (1) a basis for the Nation's physical measurement system, (2) scientific and technological services for industry and government, (3) a technical basis for equity in trade, and (4) technical services to promote public safety. The Bureau consists of the Institute for Basic Standards, the Institute for Materials Research, the Institute for Applied Technology, the Center for Computer Sciences and Technology, and the Office for Information Programs.

THE INSTITUTE FOR BASIC STANDARDS provides the central basis within the United States of a complete and consistent system of physical measurement; coordinates that system with measurement systems of other nations; and furnishes essential services leading to accurate and uniform physical measurements throughout the Nation's scientific community, industry, and commerce. The Institute consists of a Center for Radiation Research, an Office of Measurement Services and the following divisions:

Applied Mathematics-Electricity-Heat-Mechanics-Optical Physics-Linac Radiation ${ }^{2}$ - Nuclear Radiation ${ }^{2}$ - Applied Radiation ${ }^{2}$ - Quantum Electronics ${ }^{3}$ Electromagnetics ${ }^{3}$ - Time and Frequency ${ }^{3}$-Laboratory Astrophysics ${ }^{3}$ - Cryogenics ${ }^{3}$.

THE INSTITUTE FOR MATERIALS RESEARCH conducts materials research leading to improved methods of measurement, standards, and data on the properties of well-characterized materials needed by industry, commerce, educational institutions, and Government; provides advisory and research services to other Government agencies; and develops, produces, and distributes standard reference materials. The Institute consists of the Office of Standard Reference Materials and the following divisions:

Analytical Chemistry-Polymers-Metallurgy-Inorganic Materials-Reactor Radiation-Physical Chemistry.

THE INSTITUTE FOR APPLIED TECHNOLOGY provides technical services to promote the use of available technology and to facilitate technological innovation in industry and Government; cooperates with public and private organizations leading to the development of technological standards (including mandatory safety standards), codes and methods of test; and provides technical advice and services to Government agencies upon request. The Institute also monitors NBS engineering standards activities and provides liaison between NBS and national and international engineering standards bodies. The Institute consists of a Center for Building Technology and the following divisions and offices:

Engineering Standards Services-Weights and Measures-Invention and Innovation-Product Evaluation Technology-Electronic Technology-Technical Analysis-Measurement Engineering-Fire Technology-Housing Technology ${ }^{4}$ -Federal Building Technology ${ }^{4}$-Building Standards and Codes Services ${ }^{4}$ Building Environment ${ }^{4}$-Structures, Materials and Life Safety ${ }^{4}$-Technical Evaluation and Application ${ }^{4}$.

THE CENTER FOR COMPUTER SCIENCES AND TECHNOLOGY conducts research and provides technical services designed to aid Government agencies in improving cost effectiveness in the conduct of their programs through the selection, acquisition, and effective utilization of automatic data processing equipment; and serves as the principal focus within the executive branch for the development of Federal standards for automatic data processing equipment, techniques, and computer languages. The Center consists of the following offices and divisions:

Information Processing Standards-Computer Information-Computer Services - Systems Development-Information Processing Technology.

THE OFFICE FOR INFORMATION PROGRAMS promotes optimum dissemination and accessibility of scientific information generated within NBS and other agencies of the Federal Government; promotes the development of the National Standard Reference Data System and a system of information analysis centers dealing with the broader aspects of the National Measurement System; provides appropriate services to ensure that the NBS staff has optimum accessibility to the scientific information of the world, and directs the public information activities of the Bureau. The Office consists of the following organizational units:

Office of Standard Reference Data-Office of Technical Information and Publications-Library-Office of International Relations.

Headquarters and Laboratories at Gaithersburg, Maryland, unless otherwise noted; mailing address Washington, D.C. 20234

Part of the Center for Radiation Research.

${ }^{3}$ Located at Boulder, Colorado 80302.

- Part of the Center for Building 'Technology. 


\section{An Evaluation of Several Cryogenic Turbine Flowmeters}

J. A. Brennan

R. W. Stokes

D. B. Mann

C. H. Kneebone

\section{Cryogenics Division}

Institute for Basic Standards

National Bureau of Standards

Boulder, Colorado 80302

Co-sponsored by

The Compressed Gas Association

500 Fifth Avenue

New York, New York 10036

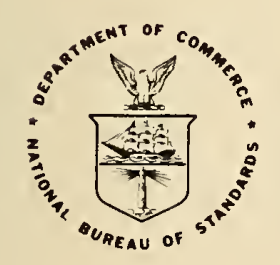

U.S. DEPARTMENT OF COMMERCE, Peter G. Peterson, Secretary NATIONAL BUREAU OF STANDARDS, Lawrence M. Kushner, Acting Director Issued October 1972 
National Bureau of Standards Technical Note 624

Nat. Bur. Stand. (U.S.), Tech. Note 624, 90 pages (Oct. 1972)

CODEN: NBTNAE 


\section{PREFACE}

The comments in this report, the use of descriptive phrases, or the actual performance of the meters do not in any way constitute endorsement either expressed or implied by the National Bureau of Standards.

It is the policy of the National Bureau of Standards to use the International System of Units (SI) in its reports unless this usage would lead to confusion or a lack of understanding. In this report SI units have not been used because it is standard practice in the industry to use English units and the use of SI units would be unduly cumbersome. The following conversions are given so the reader can convert the values in the report if he desires.

$$
\begin{aligned}
& \text { feet }{ }^{3} \times 0.028317=\text { meter }^{3} \\
& \text { gallons } \times 0.0037854=\text { meters }^{3} \\
& \text { gallons } / \text { minute } \times 0.00006309=\text { meters }^{3} / \text { second } \\
& \text { inches } \times 0.0254=\text { meters } \\
& \text { pounds } \times 0.45359=\text { kilograms } \\
& \text { pounds / inch }{ }^{2} \times 6894.757=\text { newtons } / \text { meter }^{2} \\
& \text { The authors wish to thank Dr. Peter Tryon of the NBS Statistical Engineering } \\
& \text { Laboratory for his assistance in this program. The test schedules he prepared and the } \\
& \text { assistance in analyzing the data have been invaluable. }
\end{aligned}
$$


ABSTRACT

1. Introduction .

2. Cryogenic Flow Research Facility

3. Meter Description

4. Method of Meter Evaluation

5. Data Analysis

6. Meter Performance Summary

7. Flowmeter Methodology

8. References

APPENDIX A. Rangeability Test Plan.

APPENDIX B. Performance of an Inferred Mass Turbine Meter System

(Meters $\mathrm{N}$ and $\mathrm{O}$ ) . . . . . . . . . . . . . . . . B-1

APPENDIX C. Performance of a Volumetric Turbine Meter (Meters P and Q) • • • C-1

APPENDIX D. Performance of a Volumetric Turbine Meter (Meters R and S) • • • D-1

APPENDIX E. Performance of Volumetric Turbine Meter (Meter V) • • • • • • E-l

APPENDIX F. Performance of an Inferred Mass Turbine Meter System

(Meter Z)

F-1

\section{LIST OF FIGURES}

Figure 1.

Figure $1 \mathrm{~B}$.

Figure 2B.

Figure $3 \mathrm{~B}$.

Figure $4 \mathrm{~B}$.

Figure 5B.

Figure 6B.

Figure 7B.

Figure $8 \mathrm{~B}$.

Figure 9B.

Figure 10B.

Figure $11 \mathrm{~B}$.
Schematic of Flow Loop.

Volumetric Meter N, First Rangeability Test . . . . . . . B-5

Volumetric Meter N, First Rangeability Test . . . . . . . . B-6

Volumetric Meter N, Boundary Test . . . . . . . . . B-7

Volumetric Meter N, Stability Test. . . . . . . . . . B-8

Volumetric Meter N, Second Rangeability Test . . . . . . . B-9

Volumetric Meter N, Second Rangeability Test . . . . . . B-10

Mass Meter N, Variable Flow Test. . . . . . . . . . . B-1l

Volumetric Meter O, First Rangeability Test . . . . . . . B-12

Volumetric Meter O, First Rangeability Test . . . . . . . B-13

Mass Meter O, Variable Flow Test. . . . . . . . . . . B-14

Meters $\mathrm{N}$ and $\mathrm{O}$, Pressure Drop............. . B-15 
LIST OF FIGURES (continued)

Figure 1C. Meter P, Variable Flow Test. . . . . . . . . . . . . . C-4

Figure 2C. Meter P, Variable Flow Test . . . . . . . . . . . . C-5

Figure 3C. Meter P, First Rangeability Test . . . . . . . . . . . C-6

Figure 4C. Meter P, First Rangeability Test . . . . . . . . . . C-7

Figure 5C. Meter P, Boundary Test . . . . . . . . . . . . . C-8

Figure 6C. Meter P, Stability Test . . . . . . . . . . . . . C-9

Figure 7C. Meter P, Second Rangeability Test. . . . . . . . . . . C-10

Figure 8C. Meter P, Second Rangeability Test . . . . . . . . . . . C-11

Figure 9C. Meter Q, First Rangeability Test . . . . . . . . . . C-12

Figure 10C. Meter Q, First Rangeability Test ............... C-13

Figure 11C. Meters P and Q, Pressure Drop . . . . . . . . . . . C-14

Figure 1D. Meter R, Variable Flow Test. . . . . . . . . . . . . D-4

Figure 2D. Meter R, Variable Flow Test. . . . . . . . . . . . D-5

Figure 3D. Meter R, First Rangeability Test. . . . . . . . . . . . D-6

Figure 4D. Meter R, First Rangeability Test. . . . . . . . . . . . D-7

Figure $5 \mathrm{D}$. Meter R, Boundary Test. . . . . . . . . . . . D-8

Figure 6D. Meter R, Stability Test . . . . . . . . . . . . D-9

Figure 7D. Meter S, First Rangeability Test. . . . . . . . . . . . D-10

Figure $8 \mathrm{D}$. Meter S, First Rangeability Test.............. D-11

Figure 9D. Meters R and S, Pressure Drop . . . . . . . . . . . D-12

Figure 1E. Meter V, First Rangeability Test . . . . . . . . . . . . E-3

Figure 2E. Meter V, First Rangeability Test. . . . . . . . . . . . . E-4

Figure 3E. Meter V, First Rangeability Test . . . . . . . . . . . E-5

Figure 4E. Meter V, Variable Flow Test . . . . . . . . . . . . . E-6

Figure 5E. Meter V, Variable Flow Test . . . . . . . . . . . . E-7

Figure 6E. Meter V, Pressure Drop. . . . . . . . . . . . . . . E-8

Figure 1F. Volumetric Meter Z, First Rangeability Test . . . . . . . . F-5

Figure 2F. Volumetric Meter Z, First Rangeability Test . . . . . . . . F-6

Figure 3F. Volumetric Meter Z, Boundary Test . . . . . . . . . . F-7

Figure 4F. Volumetric Meter Z, Stability Test . . . . . . . . . . F-8

Figure 5F. Volumetric Meter Z, Second Rangeability Test. . . . . . . . F-9

Figure 6F. Volumetric Meter Z, Second Rangeability Test. . . . . . . F-10

Figure 7F. Mass Meter Z, First Rangeability Test . . . . . . . . . F-11

Figure 8F. Mass Meter Z, First Rangeability Test . . . . . . . . . . F-12

Figure 9F. Mass Meter Z, Boundary Test.................F-13

Figure 10F. Mass Meter Z, Stability Test . . . . . . . . . . . . F-14 


\section{LIST OF FIGURES (continued)}

Figure 11F. Mass Meter Z, Second Rangeability Test F-15

Figure $12 \mathrm{~F}$. Mass Meter Z, Second Rangeability Test F-16

Figure $13 \mathrm{~F}$. Volumetric Meter Z, Pressure Drop

\section{LIST OF TABLES}

Table 1.

Descriptive Meter Cha racteristics

Table 2. Meter Test Record.

Table 3. Turbine Meter Performance Summary .

Table 1A. Rangeability Random Test Plan

A-2

Table 2A. Rangeability Test Schedule

A- 3

Table $1 \mathrm{~B}$.

Fit of Model to Meter N, First Rangeability Test Data

B-2

Table $2 \mathrm{~B}$.

Fit of Model to Meter N, Second Rangeability Test Data

B-2

Table $3 \mathrm{~B}$.

Fit of Model to Meter N, Variable Flow Test Data.

B - 3

Table $4 \mathrm{~B}$.

Fit of Model to Meter O, Rangeability Test Data.

B-3

Table 5B.

Fit of Model to Meter O, Variable Flow Test Data.

Table 1C.

Fit of Model to Meter P, Variable Flow Test Data for Flow

Rates above $40 \mathrm{gpm}(2.5 \mathrm{l} / \mathrm{s})$

Table 2C. Fit of Model to Meter P, First Rangeability Test Data for Flow Rates above $40 \mathrm{gpm}(2.5 \mathrm{l} / \mathrm{s})$

Table 3C. Fit of Model to Meter P, Second Rangeability Test Data for Flow Rates above $40 \mathrm{gpm}(2.5 \mathrm{l} / \mathrm{s})$

Table 4C. Fit of Model to Meter Q, Rangeability Test Data for Flow Rates above $40 \mathrm{gpm}(2.5 \mathrm{l} / \mathrm{s})$. . . . . . . . . . . . C $\mathrm{C}-3$

Table 1D. Fit of Model to Meter R, Variable Flow Test Data . . . . . . . D-1

Table 2D. Fit of Model to Meter R, Rangeability Test Data . . . . . . . . D-2

Table 3D. Fit of Model to Meter S, Rangeability Test Data . . . . . . . D-3

Table 1E. Fit of Model to Meter V, Rangeability Test Data . . . . . . . E-1

Table 2E. Fit of Model to Meter V, Variable Flow Test Data . . . . . . . E-2

Table 1F. Fit of Model to Meter Z (Volumetric System), First Rangeability Test Data . . . . . . . . . . . . . . . . . F-2

Table 2F. Fit of Model to Meter Z (Volumetric System), Second Rangeability Test Data

Table 3F. Fit of Model to Meter Z (Mass System), First Rangeability Data, for Flow Rates above $4 \mathrm{lbs} / \mathrm{s}(1.8 \mathrm{~kg} / \mathrm{s})$

Table 4F. Fit of Model to Meter Z (Mass System), Second Rangeability Test Data 


\section{AN EVALUATION OF SEVERAL CRYOGENIC TURBINE FLOWMETERS}

\section{J. A. Brennan, R. W. Stokes, D. B. Mann, and C. H. Kneebone}

The National Bureau of Standards (NBS) and the Compressed Gas Association (CGA) have jointly sponsored a research program on cryogenic flow measurement. A cryogenic flow research facility was constructed and has been used to evaluate cryogenic flowmeters operating on several different principles.

The operation and the accuracy of the flow facility is briefly described. The performance of the flowmeters in liquid nitrogen is described by reporting the precision and bias of the meters before and after an 80-hour stability test and by defining the existence of temperature, pressure, flow rate, subcooling, and time order (wear) dependencies. Meters were evaluated with flow rates ranging from 20 to $210 \mathrm{gpm}$ (1. 3 to $13.2 \mathrm{l} / \mathrm{s}$ ), pressures ranging from 32 to 112 psia $(0.22$ to 0.77 $\mathrm{MN} / \mathrm{m}^{2}$ ), and with temperatures ranging from 72 to $90 \mathrm{~K}$.

Key Words: Cryogenic; flow; liquid nitrogen; mass; mass flowmeters; measurement; turbine flowmeters; volume flowmeters.

\section{Introduction}

The National Bureau of Standards and the Compressed Gas Association have jointly sponsored a program of cryogenic flow research. A dynamic gravimetric flow facility has been constructed at NBS Boulder and flowmeters operating on several principles have been evaluated. This report describes the results of the evaluation of several volumetric and mass cryogenic turbine type flowmeters. This group represents those meters or meter systems which have not been widely used commercially in the United States either because they are new or not readily obtainable in this country. The group includes flowmeters from England and Germany, as well as domestic flowmeters. The commercial meters commonly used in the United States have been tested and reporied earlier by Brennan et al. [1971].

Meters were submitted for testing as a result of joint recommendations of the Compressed Gas Association Subcommittee on Cryogenic Liquid Flowmetering and the National Bureau of Standards, Cryogenics Division. The meters were intended to be representative of those available from industry. The results presented in this report only show the capability of each individual meter tested to measure flow of liquid nitrogen.

\section{Cryogenic Flow Research Facility}

A continuous flow loop has been constructed that allows the dynamic gravimetric measurement of liquid nitrogen flow. The continuous flow loop, shown schematically in figure 1, allows the establishment of constant pressures, temperatures, and flow rates over a long period of time. Liquid is pumped out of the catch tank through a heat exchanger where the pump and heat energy are removed. Liquid then passes through the 
test section, weigh tank, and back to the catch tank. A measurement is taken by closing the flow diverter valve, weighing the fluid that passes through a meter under test located in the test section, recording the meter registration, and timing the test interval. When the tank is filled to a preset level the flow diverter valve is opened automatically without interrupting the flow. A more complete discussion of the design of the facility is given by Dean et al. [ 1969].

The principle operating criteria of the flow research facility during the period of these meter evaluations were:

1) Ability to establish and maintain thermal and pressure equilibrium during test.

2) Operation with temperatures ranging from 72 to $90 \mathrm{~K}$ and with pressures from 32 to $112 \mathrm{psia}\left(0.22\right.$ to $\left.0.77 \mathrm{MN} / \mathrm{m}^{2}\right)$.

3) Usable weigh tank volume from 50 to 100 gallons (189 to $379 \mathrm{l}$ ).

4) Flow rates cover the volume flow range from 20 to $210 \mathrm{gpm}(1.3$ to $13.2 \mathrm{l} / \mathrm{s}$ ).

A detailed description of the accuracy statement for the flow facility has been presented by Dean et al. [1971]. In that report the uncertainty of the measurement of total mass flow was estimated to be \pm 0.18 percent. This figure includes an allowance of \pm 0.12 percent for known sources of systematic errors, plus an allowance of \pm 0.06 percent for random error. The estimated uncertainty due to random error was based on three times the standard deviation calculated from 23 applications of the calibrated masses over a period of three months. An additional uncertainty was specified for total volume flow which was caused by the uncertainty in the thermodynamic properties data. However, when a consistent set of data is used by all meter users this additional uncertainty need not be considered.

Continued analysis of the system has not revealed any reasons for changing the uncertainty values at this time. The random error determination can now be based on many more applications of the calibration masses but the values are approximately the same as reported by Dean.

\section{Meter Description}

Test results are presented for eight meters representing five different manufactuerers. In most cases, more than one meter of the same size and model was submitted for testing. A brief description of each meter type is included in the following text. A detailed description is presented in the appendices.

Five of the turbine meters were standard volumetric meters. Three were standard volumetric meters combined with a compensation device that measured or inferred the fluid density at the flow conditions whereby the volumetric output from the turbine meter was converted to a mass output. 


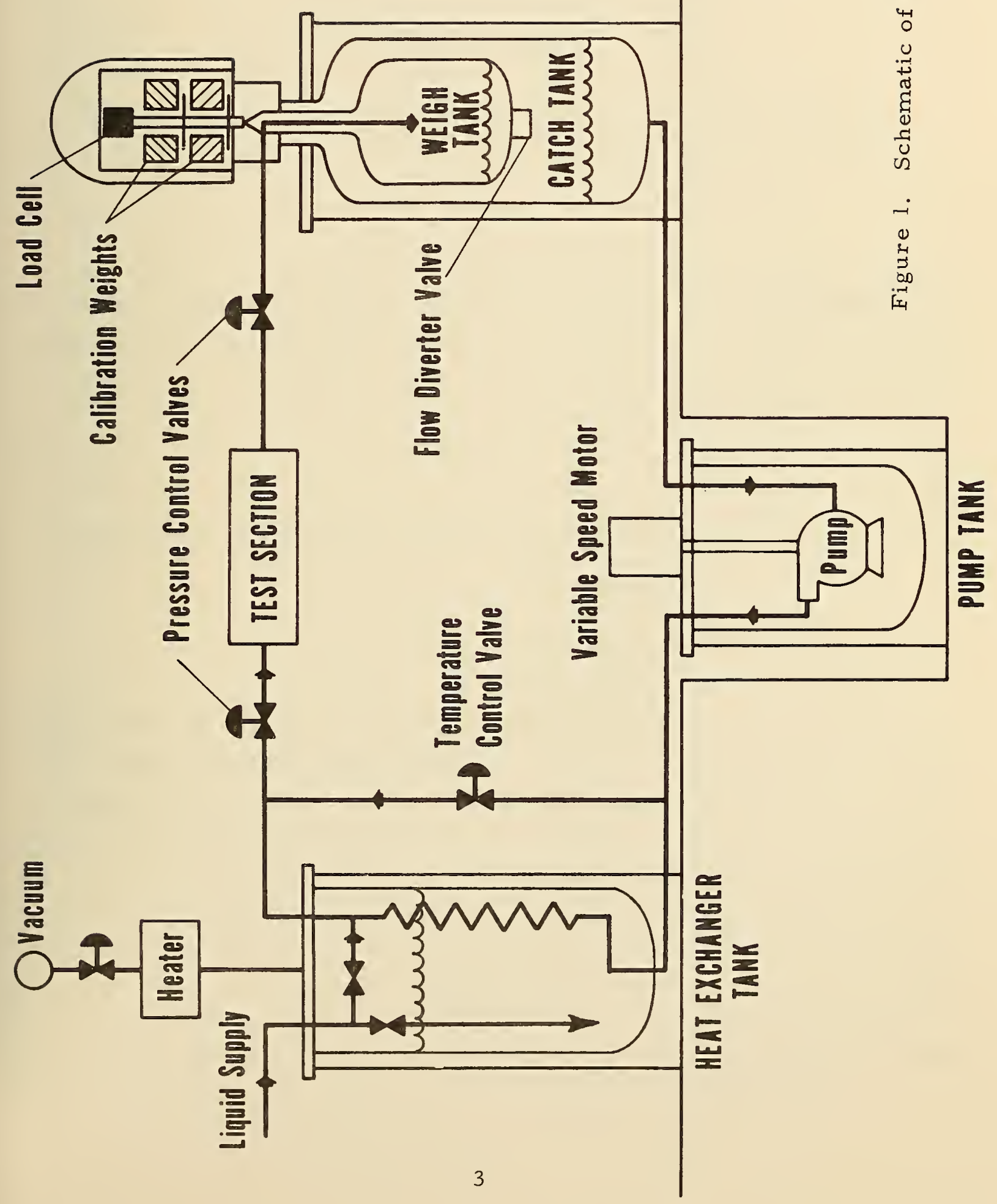


A summary of descriptive meter characteristics is presented in table 1.

Table 1. Descriptive Meter Cha racteristics

$\begin{array}{cclclc}\begin{array}{c}\text { Manu- } \\ \text { facturer }\end{array} & \begin{array}{c}\text { Meter } \\ \text { Designation }\end{array} & \begin{array}{l}\text { Operating } \\ \text { Principle }\end{array} & \begin{array}{c}\text { Size } \\ \text { in }(\mathrm{cm})\end{array} & \begin{array}{l}\text { Primary } \\ \text { Element }\end{array} & \text { Register } \\ 1 & \mathrm{~N}, \mathrm{O} & \begin{array}{l}\text { Compensated } \\ \text { Turbine }\end{array} & 1 \frac{1}{4}(3.2) & \text { Volume } & \text { Mass } \\ 2 & \mathrm{P}, \mathrm{Q} & \text { Turbine } & 1 \frac{1}{2}(3.81) & \text { Volume } & \text { Volume } \\ 3 & \mathrm{R}, \mathrm{S} & \text { Turbine } & 1 \frac{1}{2}(3.81) & \text { Volume } & \text { Volume } \\ 4 & \mathrm{~V} & \text { Turbine } & 2(5.08) & \text { Volume } & \text { Volume } \\ 5 & \mathrm{Z} & \text { Compensated } & 1 \frac{1}{2}(3.81) & \text { Volume } & \text { Mass } \\ & & \text { Turbine } & & & \end{array}$

4. Method of Meter Evaluation

The performance of each meter was evaluated by comparing the amount of liquid registered by the meter over the test interval to the liquid mass accumulated in the weigh tank for a wide range of liquid conditions. The mass of liquid metered by the volumetric meters was calculated from the expression.

$$
M_{R}=P \cdot V_{K} \cdot \rho
$$

where

$$
\begin{aligned}
& M_{R}=\text { mass calculated from the volume registered by the meter (lb) } \\
& P \quad=\text { pulses, or meter counts } \\
& V_{K}=\text { volume meter factor }(\mathrm{gal} / \mathrm{P}) \\
& \mathrm{P}=\text { liquid density (lb/gal). }
\end{aligned}
$$

The volume meter factor, $\mathrm{V}_{\mathrm{K}}$, is the volume registered by the meter per count. The volume meter factor normally used in this calculation was supplied by the meter manufacturer. Usually the factors were determined in a non-cryogenic fluid such as water or oil. The measurement of the liquid mass accumulated in the weigh tank was started and terminated on integer meter counts.

The mass of liquid registered by the mass meters tested was calculated from the expression

$$
M_{R}=P \cdot M_{K}
$$

where

$$
M_{K}=\text { mass meter factor }(1 b / P)
$$


The mass calculated from the meter pulses is then compared to the mass accumulated in the weigh tank and the percent deviation calculated as follows:

$$
\text { percent deviation }=\frac{M_{R}-M_{N B S}}{M_{N B S}} \cdot 100
$$

where

$$
\begin{aligned}
& M_{R}=\text { mass calculated from the meter pulses } \\
& M_{N B S}=\text { mass measured by NBS. }
\end{aligned}
$$

The Cryogenic Liquid Flowmetering Subcommittee of the CGA and NBS jointly decided to subject each meter to three types of test: a rangeability test, a long term stability test, and a boundary test. Another test, the variable flow test, is used in some cases for special purposes.

The purpose of the rangeability test is to subject the meter to a variety of conditions and to observe the response of the meter to these conditions. This test was statistically designed so the effect of various parameters could be separated. The temperature range explored was from 80 to $90 \mathrm{~K}$ in $2.5 \mathrm{~K}$ increments. The pressure range was 62 to 112 psia $\left(0.427\right.$ to $\left.0.772 \mathrm{MN} / \mathrm{m}^{2}\right)$ in increments of $12.5 \mathrm{psi}\left(0.86 \mathrm{MN} / \mathrm{m}^{2}\right)$. Flow rates depended on the meter capacity with the flow range being divided into four equal increments if the meter did not have significant flow rate dependencies. The flow range was divided into twelve equal increments in most cases where it was necessary to closely examine these dependencies. A schedule of variables, based on a table of random numbers, was selected for all meters. A typical schedule is given in Appendix A.

An 80-hour stability test was designed to determine the effect of wear on the meter performance. The stability test was run in eight hour shifts at flow rates near the maximum rated capacity and at a convenient temperature near $80 \mathrm{~K}$. The meter was allowed to warm up overnight between shifts.

The boundary test was performed with the liquid conditions at the bounds of what the Cryogenic Liquid Flowmetering Subcommittee and NBS judged to be well beyond the normal operating range for most meters and within economic operation of the flow facility. The upper boundary was set at a pressure of $112 \mathrm{psia}\left(0.772 \mathrm{MN} / \mathrm{m}^{2}\right)$ with the temperature varying from about 72 to $85 \mathrm{~K}$. The lower pressure boundary was set at 32 psia (0. $22 \mathrm{MN} / \mathrm{m}^{2}$ ) with the temperature ranging from $72 \mathrm{~K}$ to a temperature as close to the saturation temperature as could be obtained without excessive cavitation occurring in the meter. The purpose of these bounds was to establish a wide range of liquid subcooling conditions. 
A first rangeability test is conducted for each type of meter before the 80 -hour stability test is performed, and a second rangeability test is generally performed at the conclusion of the stability test. The boundary test is performed before the start of the stability test. In certain situations where a retest of a meter did not warrant a complete rangeability test, a variable flow test was used. In this test only the flow rate is varied over the flow range and all other parameters are held constant.

\section{Data Analysis}

The criteria for evaluating meter performance are the precision and bias of the meter and the existence of flow rate, temperature, subcooling, pressure and time order (an indication of meter wear) dependencies. The bias is defined as the mean percent deviation from the measured NBS mass for repeated measurements at a specified set of flow conditions. The precision is a measure of the ability of the meter to reproduce the same bias for repeated measurements at the same flow conditions. The precision is reported as three times the standard deviation and, for a meter with no significant order, flow rate or temperature dependencies, is calculated from the following expression:

$$
\sigma=3\left[\frac{\sum_{i=1}^{n}\left(y-a_{i}\right)^{2}}{n-1}\right]^{\frac{1}{2}} 100
$$

where

$$
\begin{aligned}
\sigma= & \text { standard deviation (percent) } \\
\mathrm{n}= & \text { the number of separate measurements over a range of flow conditions } \\
\mathrm{y}= & \text { mean bias of the repeated measurements over the same conditions } \\
& \text { (percent) } \\
\mathrm{a}_{\mathrm{i}}= & \text { bias of each single measurement (percent). }
\end{aligned}
$$

For a meter that has significant dependencies, the precision is reported as three times the residual standard deviation after the data have been fitted to a mathematical model. The residual standard deviation represents the precision at a single set of conditions, whereas, the standard deviation represents the precision over a range of conditions. The reported bias of the meter was obtained by evaluating the mathematical model at the rated maximum flow rate of the meter under test at a temperature of $80 \mathrm{~K}$. The bias may also be calculated from the mathematical model for any desired combination of parameters that are within the range of the experimental data.

The mathematical model for a mass flowmeter is

$$
y=\mu+a T+b T^{2}+\operatorname{cin}+d \dot{m}^{2}+e \theta
$$


where

$$
\begin{aligned}
& \mathrm{y}=\text { bias in percent } \\
& \mu=\text { constant } \\
& \mathrm{T}=\text { temperature } \\
& \dot{\mathrm{m}}=\text { mass flow rate in } \mathrm{lb} / \mathrm{s} \\
& \theta=\text { time order term. }
\end{aligned}
$$

The coefficients $a, b, c, d$, and e give an indication of the dependency of the corresponding terms and are reported for each rangeability test when they are significant. This model can be used for volumetric meters by substituting the volume flow rate, $q$ in gallons per minute, for the mass flow rate terms. Pressure terms a re not included in the model since, on examination, the data did not indicate a dependency for any of these meters. In the case where terms did not prove to be significant, they were removed from the model. In the majority of cases, reduced linear models have been used.

A subcooling term has not been included in the model. The subcooling effect may be seen by examining the boundary test data. Similarly, the effect of wear is best seen by examining the stability test data.

When the meters showed a strong flow rate dependency at the low or high extremes of the flow range, that portion of the data was not fitted to the model. The model then can be considered a mathematical expression of the bias over the useable flow range of each meter. The primary criterion in determining the significance of each parameter was the residual standard deviation after fitting. If the standard deviation did not change by more than 0.02 , then the parameter was not considered significant.

\section{Meter Performance Summary}

A meter test record is presented as table 2. This represents the meters whose performance is reported. As will be noted in the appendices, meters $H$, I, and $Y$ were submitted and partially tested, but the results are not reported.

The general CGA-NBS committee policy is to have two meters available for testing. One of the two is subjected to the first rangeability test, the boundary test, the stability test, and the second rangeability test. The second meter is subjected only to a rangeability test. By then comparing the rangeability tests of the two meters an insight is gained into the meter manufacturers ability to reproduce his meters.

There are exceptions to this policy. Meter $V$ was not solicited through the normal procedures. It was obtained by NBS as a transfer meter for a liquefied natural gas flowmeter calibration facility. Since the liquid nitrogen tests, which were subsequently done, were of interest to the Compressed Gas Association, the results are reported. 
Table 2. Meter Test Record

$\begin{array}{ccccccc}\begin{array}{c}\text { Meter } \\ \text { Manacturer } \\ \text { Number }\end{array} & \text { Meter } & \begin{array}{c}\text { Variable } \\ \text { Flow }\end{array} & \begin{array}{r}\text { First } \\ \text { Range }\end{array} & \text { Boundary } & \text { Stability } & \begin{array}{r}\text { Second } \\ \text { Range }\end{array} \\ 1 & \mathrm{~N} & \mathrm{X} & \mathrm{X} & \mathrm{X} & \mathrm{X} & \mathrm{X} \\ 1 & \mathrm{O} & \mathrm{X} & \mathrm{X} & & & \\ 2 & \mathrm{P} & \mathrm{X} & \mathrm{X} & \mathrm{X} & \mathrm{X} & \mathrm{X} \\ 2 & \mathrm{Q} & & \mathrm{X} & & & \\ 3 & \mathrm{R} & \mathrm{X} & \mathrm{X} & \mathrm{X} & \mathrm{X} & \\ 3 & \mathrm{~S} & & \mathrm{X} & & & \\ 4 & \mathrm{~V} & \mathrm{X} & \mathrm{X} & & \mathrm{X} & \mathrm{X} \\ 5 & \mathrm{Z} & & \mathrm{X} & \mathrm{X} & \mathrm{X}\end{array}$

A detailed description of the meters and their performance is given in the appendices. Wherever possible meter performance is plotted using a six percent range in deviation. This range was chosen since the tentative code for Cryogenic Liquid Measuring Devices adopted at the 1972 Conference on Weights and Measures (4) specifies a maintenance tolerance of +2 percent and -4 percent. The deviation was calculated from the $\mathrm{K}$-factor supplied with the meter which resulted in some meters having a large bias. This bias can be changed, of course, by using the proper $\mathrm{K}$-factor. As long as the meters operated normally, all reported here had sufficient precision to satisfy the tentative code. A summary of the meter performance is given in table 3. The precision reported is three times the residual standard deviation calculated from the data taken during the rangeability test. The precision at the start is calculated from the first rangeability test data taken before the stability test, while the precision at the end is calculated from the second rangeability test data taken after the stability test. The meter bias is reported for each rangeability test. The minimum subcooling required for consistent meter performance, as determined in the boundary test, is reported.

\section{Flowmeter Methodology}

The accuracy that may be achieved with each of these meters is dependent to some degree on the manner with which they are used. An effort was made during the testing of these meters to observe and record any operational procedures or circumstances that may have a detrimental effect on the accuracy. Those observations are included here.

All meters tested showed a tendency toward overregistration and a loss of precision as the subcooling was decreased. With the exception of meter $\mathrm{N}$, they required from 14 


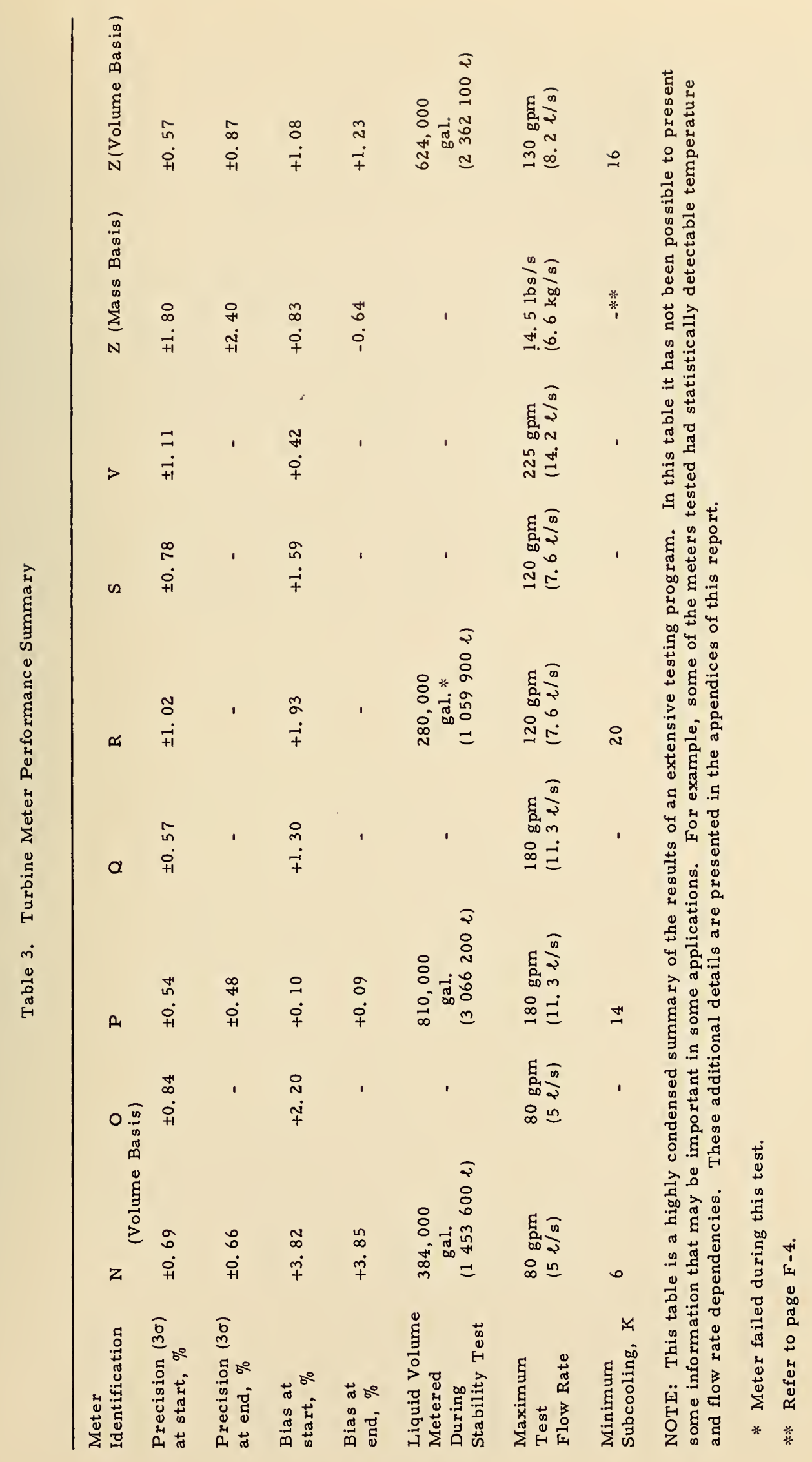


to $20 \mathrm{~K}$ minimum subcooling. Meter $\mathrm{N}$ showed only a slight loss of precision down to $6 \mathrm{~K}$ subcooling although considerable cavitation was observed downstream of the meter.

Turbine meters are sensitive to overspeeding during cooldown and if this situation is not considered during installation, damage to the bearings may occur. All meters were installed so that they could be cooled down to liquid nitrogen temperature before any fluid passed through them.

Turbine meters are known to exhibit $\mathrm{K}$-factor shifts when the meters are operated in fluids other than liquid nitrogen. It has also been observed during these tests that the $\mathrm{K}$-factor will shift from meter to meter in the same fluid. It, therefore, should be noted that if these meters are to be operated at the maximum accuracy inherent in them, they must be individually calibrated with the fluid in which they will be used. 


\section{References}

1. J. W. Dean, J. A. Brennan, and D. B. Mann, "Cryogenic Flow Research Facility of the National Bureau of Standards, "Advances in Cryogenic Engineering, Vol. 14 (Plenum Press, New York 1969), p. 299.

2. J. W. Dean, J. A. Brennan, D. B. Mann, and C. H. Kneebone, "Cryogenic Flow Research Facility Provisional Accuracy Statement, "National Bureau of Standards, Tech. Note 606 (1971).

3. J. A. Brennan, J. W. Dean, D. B. Mann, and C. H. Kneebone, "An Evaluation of Positive Displacement Cryogenic Volumetric Flowmeters, "National Bureau of Standards, Tech. Note 605 (1971).

4. 57th National Conference on Weights and Measures, Wa shington, D. C. , July 10-14, 1972. To be published in "Specifications, Tolerances, and Other Technical Requirements for Commercial Weighing and Measuring Devices, "National Bureau of Standards, Handbook 44,1972 edition. 

APPENDIX A. Rangeability Test Plan

The purpose of the rangeability test is to investigate the performance of cryogenic liquid flowmeters when the flowmeters are subjected to the following conditions:

1) Temperature varying from 80 to $90 \mathrm{~K}$.

2) Pressure varying from 50 to $100 \mathrm{psig}\left(0.427\right.$ to $0.772 \mathrm{MN} / \mathrm{m}^{2}$ ).

3) Flow rates from $20 \mathrm{gpm}(1.3 \mathrm{l} / \mathrm{s})$ to the maximum rated capacity in either four or twelve steps.

4) Average barometric pressure of 12.0 psia $\left(82.7 \mathrm{kN} / \mathrm{m}^{2}\right)$.

The liquid density resulting from the chosen pressure and temperature ranges from $6.7 \mathrm{lbs} / \mathrm{gal}(0.803 \mathrm{~kg} / \mathrm{l})$ to $6.2 \mathrm{lbs} / \mathrm{gal}(0.743 \mathrm{~kg} / \ell)$.

In addition, it is desired to keep the subcooling, which is a function of temperature and pressure, above $8 \mathrm{~K}$.

It is time consuming and inefficient to change the temperature of the flow system, so temperature changes consequently are kept to a minimum. Pressure changes also a re kept at a minimum to conserve helium. The flow rate may be changed easily and quickly.

An example of a test plan is presented in table 1A. This particular plan was designed for a meter with a flow range from $20 \mathrm{gpm}(1.3 \mathrm{l} / \mathrm{s})$ to $130 \mathrm{gpm}(8.2 \mathrm{l} / \mathrm{s})$. The flow range has been divided into twelve equal increments in this example; however, a similar plan has been used that divides the flow range into four equal increments. The test draft weight was included as a parameter and was varied as shown in four increments. Points at high temperatures and low pressures are not included because of the subcooling requirement.

Numbers and arrows at the top of each column indicate the sequence in which the columns were executed and the points were taken.

The test plan was then used to generate an operator test schedule which is presented in table 2A. In order to conserve time, the approximate values of these parameters are set and held constant. The actual values are then measured and recorded. 


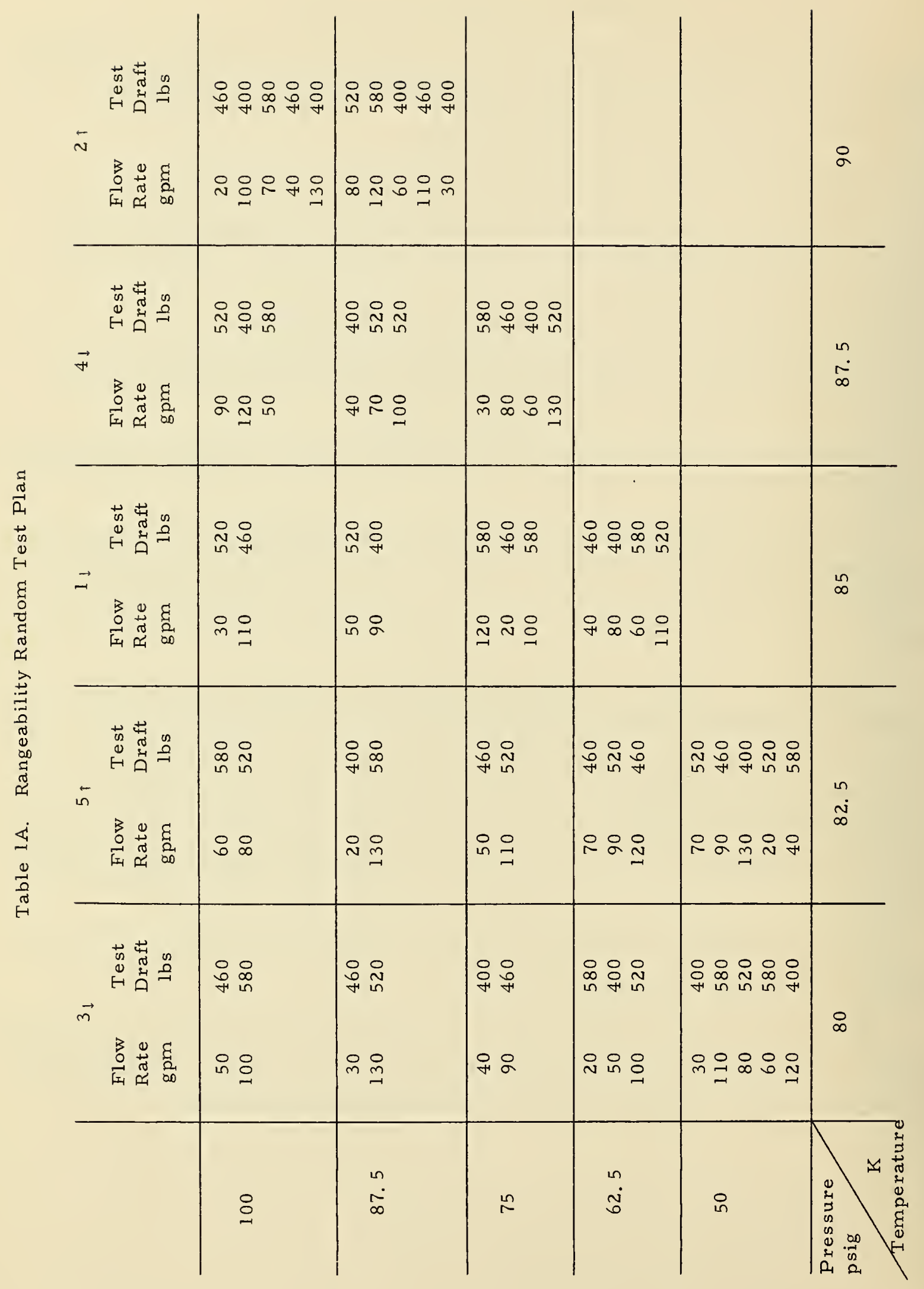


Table 2A. Rangeability Test Schedule

$\begin{array}{ccccr}\begin{array}{c}\text { Run } \\ \text { Number }\end{array} & \begin{array}{c}\text { Temperature } \\ \text { K }\end{array} & \begin{array}{c}\text { Pressure } \\ \text { psig }\end{array} & \begin{array}{c}\text { Test Draft } \\ \text { lbs }\end{array} & \begin{array}{c}\text { Flow Rate } \\ \text { gpm }\end{array} \\ & & & & \\ 1 & 85 & 100 & 520 & 30 \\ 2 & 85 & 100 & 460 & 110 \\ 3 & 85 & 87.5 & 520 & 50 \\ 4 & 85 & 87.5 & 400 & 90 \\ \vdots & \vdots & \vdots & \vdots & \vdots \\ 56 & 82.5 & 87.5 & 580 & 130 \\ 57 & 82.5 & 87.5 & 400 & 20 \\ 58 & 82.5 & 100 & 520 & 80 \\ 59 & 82.5 & 100 & 580 & 60\end{array}$

A- 3 



\section{APPENDIX B. Performance of an Inferred Mass Turbine} Meter System (Meters $\mathrm{N}$ and $\mathrm{O}$ )

This meter system consists of a standard turbine meter, a platinum resistance thermometer that is mounted upstream of the meter in the liquid stream, and an electronics package. The turbine meter rotor speed is monitored by a pickup coil mounted on the turbine housing. The volumetric flow rate is then a function of the frequency generated by the pickup coil. This frequency is an input to the electronic package. The other input is provided by the thermometer whose resistance is a function of the liquid temperature and, consequently, density. The influence of pressure on the density is neglected. The electronics package converts the input volumetric frequency and the temperature to a pulse output that reads directly in mass units.

The meter manufacturer specifications are:

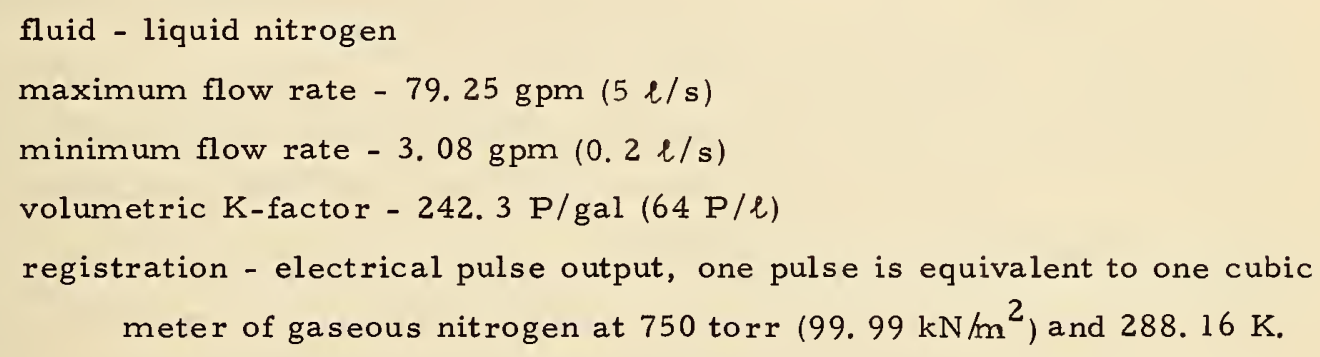

Initially the flowmeter electronics package was not compatible with the NBS electronics system. Since the functioning of the mechanical system depends almost entirely on the performance of the turbine meter, volumetric tests were performed first on both turbine meter's without temperature compensation. Once the electronics problems were resolved, additional variable flow tests were performed on both meters to determine the ability of the meter systems to register inferred mass. Only one thermometer and one electronics package was tested. No adjustment was made in the electronics to take into account the different volumetric $\mathrm{K}$-factors of the two meters.

\section{Meter $\mathrm{N}$}

This meter was subjected to a first rangeability test, a boundary test, a stability test, and a second rangeability test. These were volumetric tests involving only the turbine meter. These tests were followed by a variable flow test, which as previously explained,was designed to test the system as an inferred mass meter.

The results of the first rangeability test are shown in figures $1 \mathrm{~B}$ and $2 \mathrm{~B}$. These data were fitted to the mathematical model and the results are shown in table $1 B$. 
Table 1B. Fit of Model to Meter N, First Rangeability Test Data

$$
\begin{aligned}
& \text { Model } y=3.82 \\
& \text { Bias, } y=+3.82 \% \\
& \text { Standard Deviation }= \pm 0.23 \% \\
& \text { Number of Points }=45
\end{aligned}
$$

There were no significant dependencies observed during this test. The bias of these data is $+3.82 \%$ and the precision based on three times the standard deviation $+0.69 \%$.

The results of the boundary test are shown in figure 3B. There was no significant loss of accuracy down to six degrees of subcooling. At this point there was extensive vapor formation downstream of the turbine meter as observed during the test through the sapphire window in the flow system. Since the vapor was not affecting the performance of the turbine, it was being formed in the piping downstream of the turbine.

The results of the stability test are shown in figure 4B. Approximately 384000 gallons ( $1453600 \mathrm{l}$ ) of liquid nitrogen were metered during this test. There was no indication of wear occurring during that period.

The results of the second rangeability test are shown in figures $5 \mathrm{~B}$ and $6 \mathrm{~B}$. These data were fitted to the model and the results are shown in table $2 \mathrm{~B}$.

Table 2B. Fit of Model to Meter N, Second Rangeability

Test Data

Model $y=3.85$

Bias, $y=3.85 \%$

Standard Deviation $= \pm 0.22 \%$

Number of Points $=57$

There were no significant dependencies observed during this test. The bias of these data is $+3.85 \%$ and the precision based on three times the standard deviation is $\pm 0.66 \%$.

It should be mentioned that there was no significant change in the precision or bias of this meter after having metered 384000 gallon ( 1453600 l) of liquid nitrogen.

The last test performed on this meter was the variable flow test of the mass system. The test was done by initially establishing a temperature of $80 \pm 0.2 \mathrm{~K}$ and a pressure of $92 \pm 5$ psia. The flow rate was then varied over the meter range while holding all other parameters constant. The sequence was then repeated at a temperature of $90 \pm 0.2 \mathrm{~K}$. This test provided an insight into the ability of the system to register mass over a range 
of flow rates and the temperature extremes of the rangeability test. The results are shown in figure $7 \mathrm{~B}$. These data were fitted to the model and the results are shown in table $3 \mathrm{~B}$.

Table 3B. Fit of Model to Meter N, Variable Flow Test Data.

Model $\mathrm{y}=-6.786+0.06197 \mathrm{~T}+0.6307 \dot{\mathrm{m}}-0.03766 \dot{\mathrm{m}}^{2}$
Bias at $\dot{\mathrm{m}}=8.8 \mathrm{lbs} / \mathrm{s}$ and $\mathrm{T}=80 \mathrm{~K}, \mathrm{y}=+0.80 \%$
Residual Standard Deviation $= \pm 0.24 \%$
Number of Points $=16$

This mass meter system shows significant dependencies on temperature, $T$, mass flow rate, $\dot{m}$ in $\mathrm{lbs} / \mathrm{s}$, and mas flow rate squared. The bias at a flow rate of $8.8 \mathrm{lbs} / \mathrm{s}$ and a temperature of $80 \mathrm{~K}$ is +0.80 percent. The precision based on three times the residual standard deviation is \pm 0.72 percent.

The mean bias of these data without fitting them to the model is +0.56 percent. The standard deviation of these data without the model is \pm 0.65 percent and the precision based on three times the standard deviation is \pm 1.95 percent.

Since this meter has significant dependencies, the bias must be calculated from the model to obtain the precision of \pm 0.72 percent. If the bias is not calculated from the model then the precision can be no better than \pm 1.95 percent.

\section{Meter $\mathrm{O}$}

This meter was subjected to a rangeability test and a variable flow test. As previously explained the rangeability test was performed only on the turbine meter. It was a volumetric test. The variable flow test was performed on the mass system.

The results of the rangeability test are shown in figures $8 \mathrm{~B}$ and $9 \mathrm{~B}$. These data were fitted to the model and the results are shown in table $4 \mathrm{~B}$.

Table 4B. Fit of Model to Meter O, Rangeability Test Data

$$
\begin{aligned}
& \text { Model } y=2.20 \\
& \text { Bias, } y=+2.20 \% \\
& \text { Standard Deviation }= \pm 0.28 \% \\
& \text { Number of Points }=56
\end{aligned}
$$

There were no significant dependencies observed during this test. The bias of these data is +2.20 percent and the precision based on three times the standard deviation is \pm 0.84 percent. 
The results of the variable flow test are shown in figure 10B. The test was done. by initially establishing a temperature of $80 \pm 0.2 \mathrm{~K}$ and a pressure of $94 \pm 10$ psia. The flow rate was then varied over the meter range while holding all other parameters constant The sequence was then repeated at a temperature of $90 \pm 0.1 \mathrm{~K}$. These data were fitted to the model and the results are shown in table 5B.

Table 5B. Fit of Model to Meter O, Variable Flow Test Data

$$
\begin{aligned}
& \text { Model } y=-2.691+0.5852 \dot{m}-0.04023 \dot{m}^{2} \\
& \text { Bias at } \dot{m}=8.8 \mathrm{lbs} / \mathrm{s}, y=-0.66 \% \\
& \text { Residual Standard Deviation }= \pm 0.31 \% \\
& \text { Numter of Points }=16
\end{aligned}
$$

This mass meter system has significant dependencies on mass flow rate, $\dot{m}$ in 1 bs / and mass flow rate squared. The bias at a flow rate of $8.8 \mathrm{lbs} / \mathrm{s}$ is -0.66 percent. The precision based on three times the residual standard deviation is \pm 0.93 percent.

The mean bias of these data without fitting them to the model is -0.92 percent. The standard deviation of these data without the model is \pm 0.47 percent and the precision based on three times the standard deviation is \pm 1.41 percent.

Since this meter has significant dependencies, the bias must be calculated from the model to obtain the precision of \pm 0.93 percent. If the bias is not calculated from the mode the precision can be no better than \pm 1.95 percent.

Typical pressure drop data are shown in figure $11 \mathrm{~B}$ for both meters $\mathrm{N}$ and $\mathrm{O}$. 


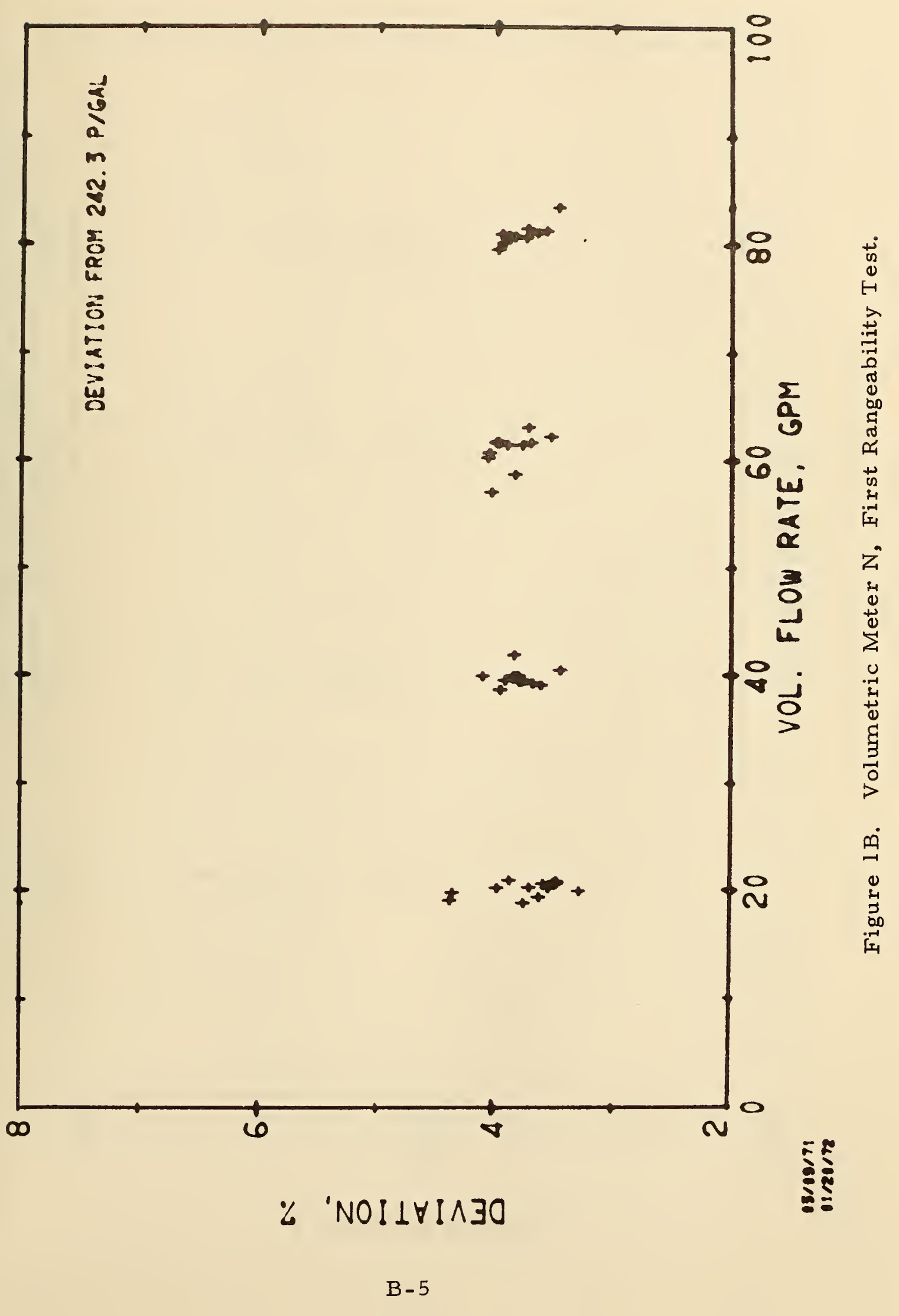




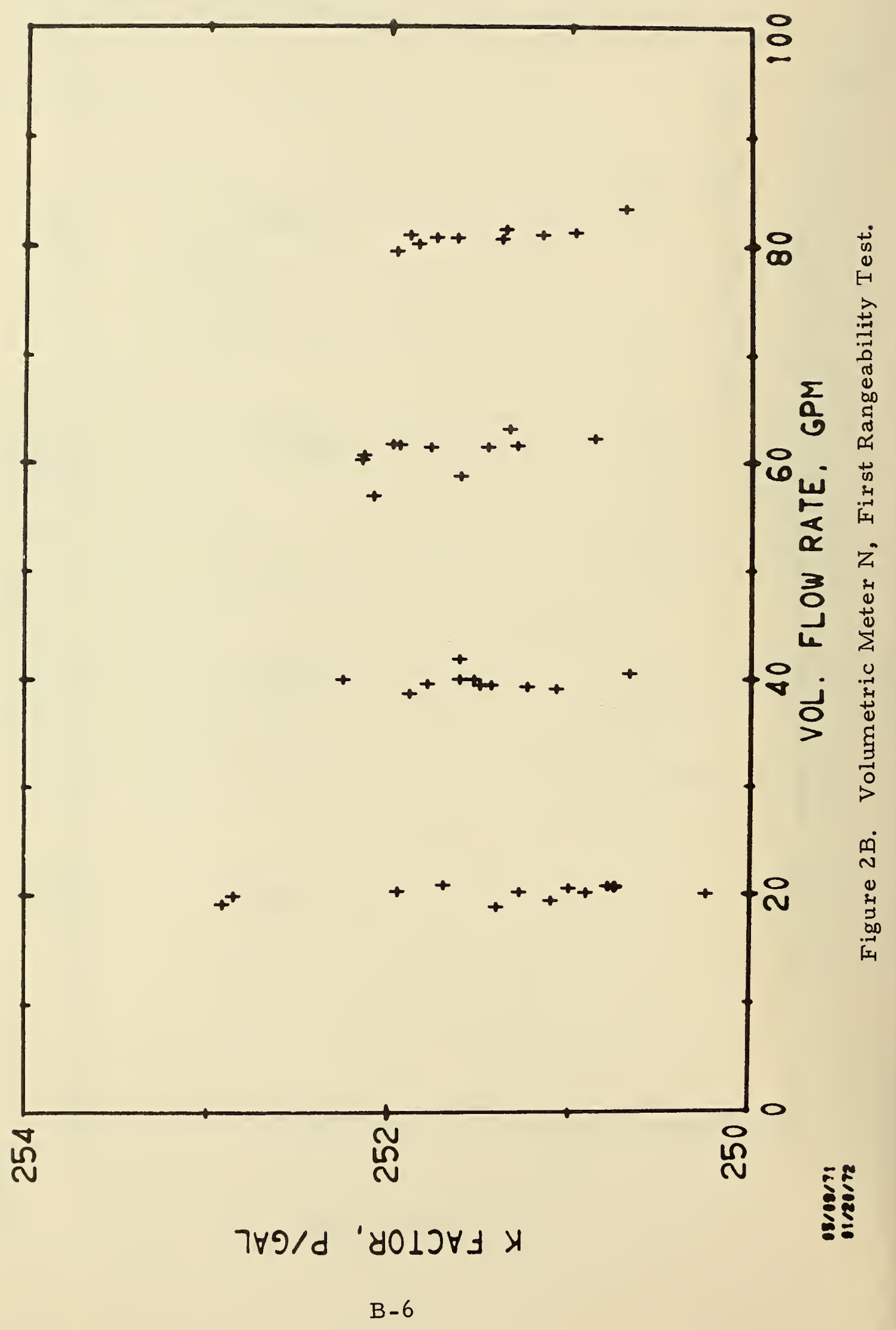




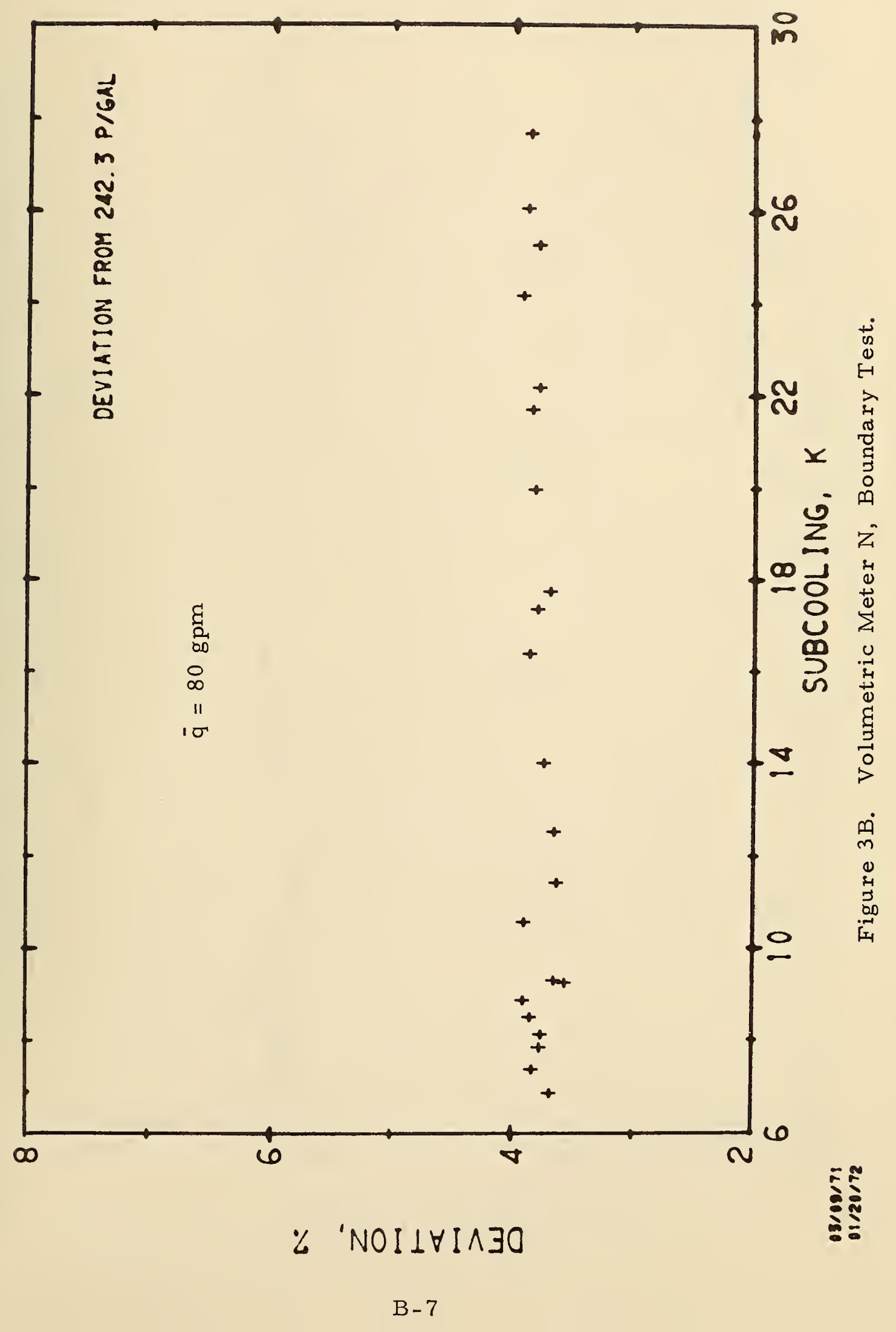




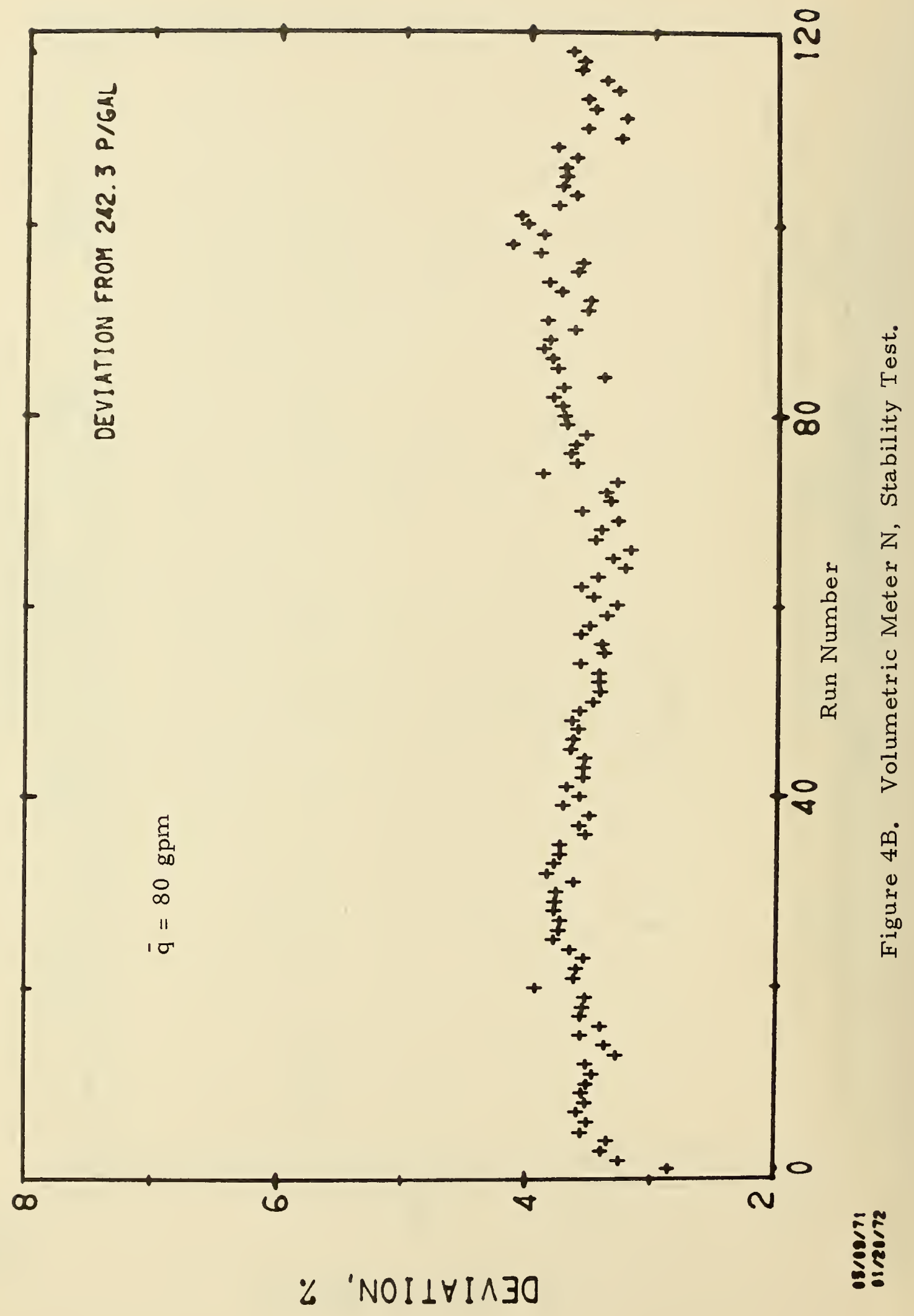

B -8 


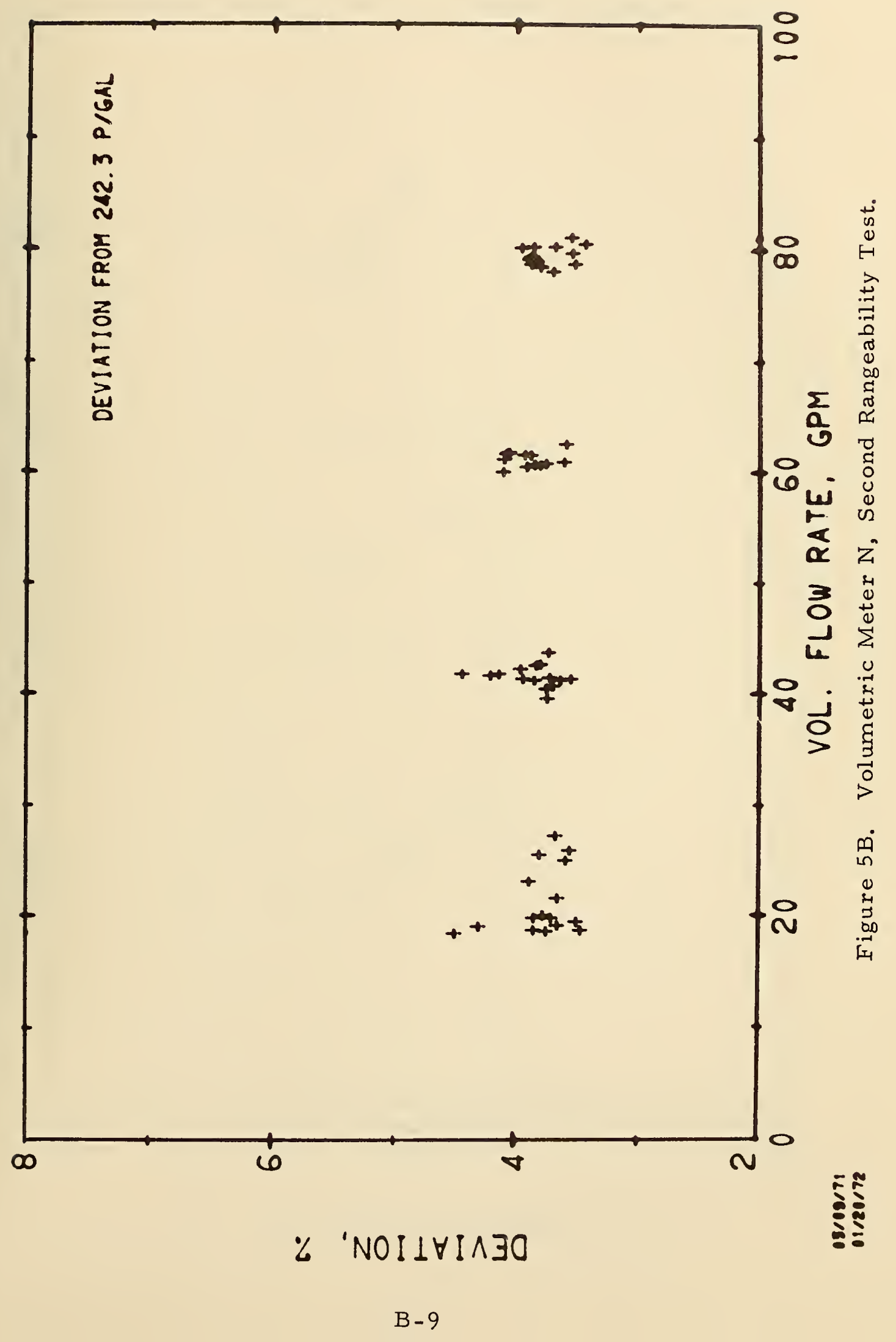




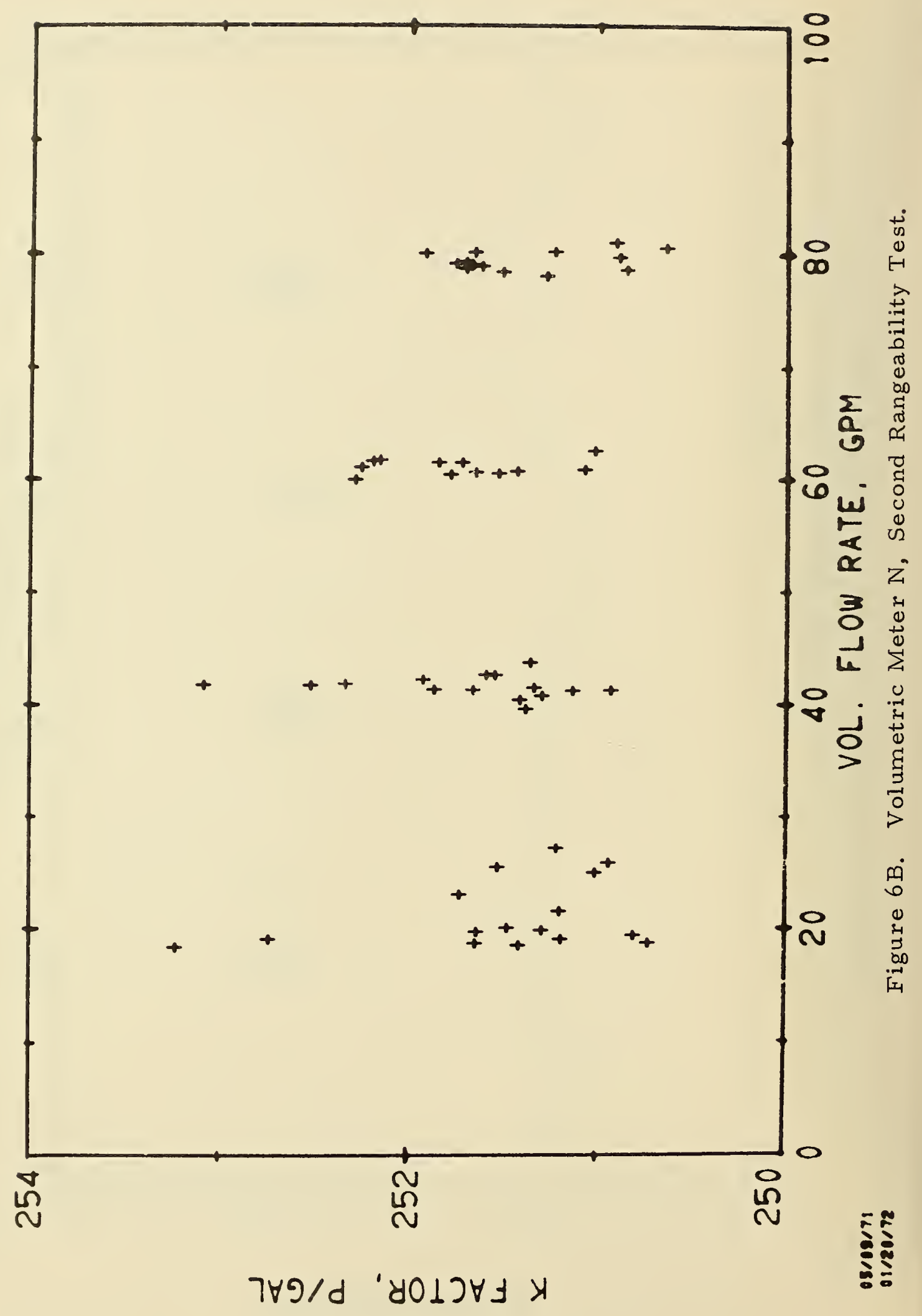




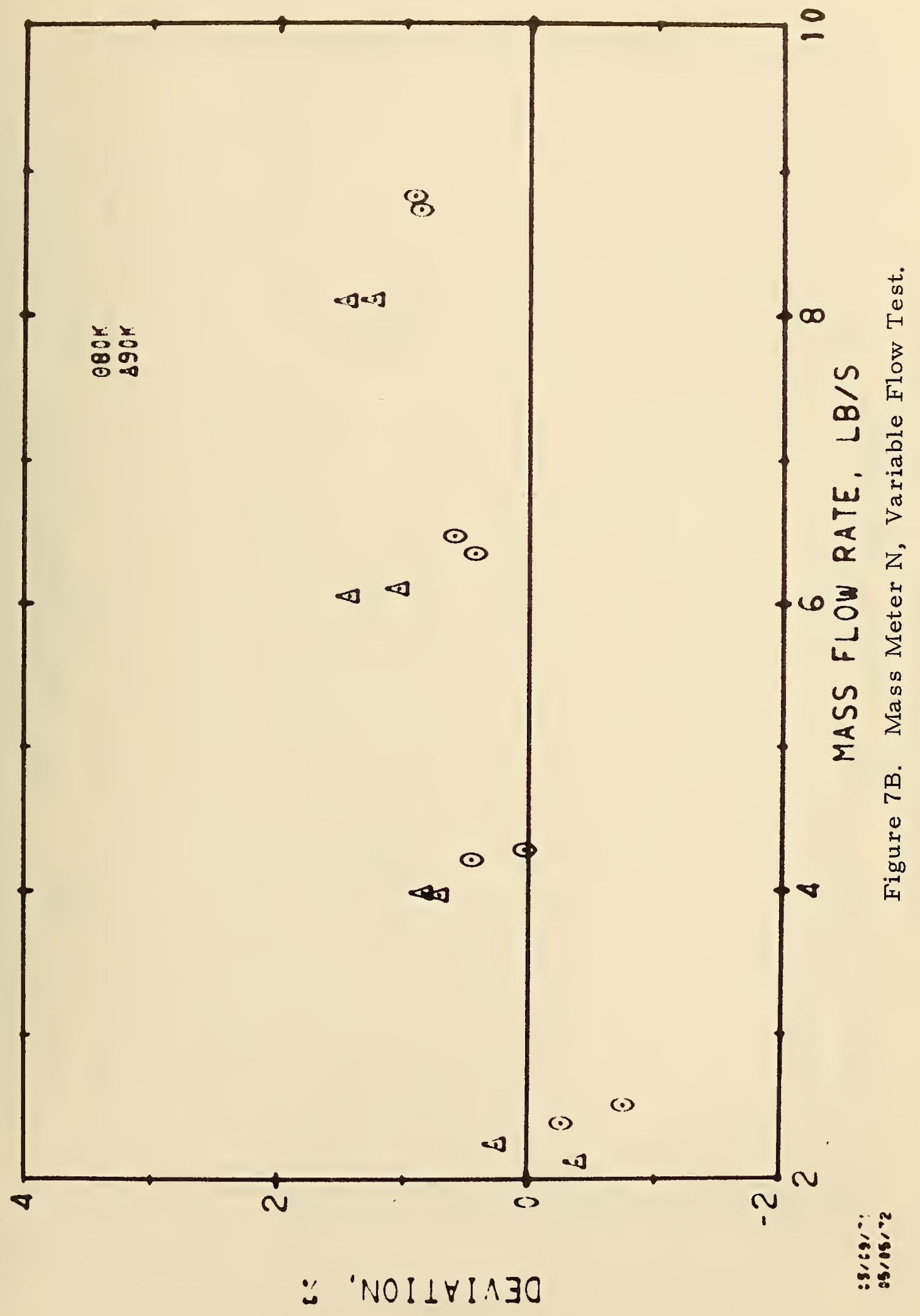

B -11 


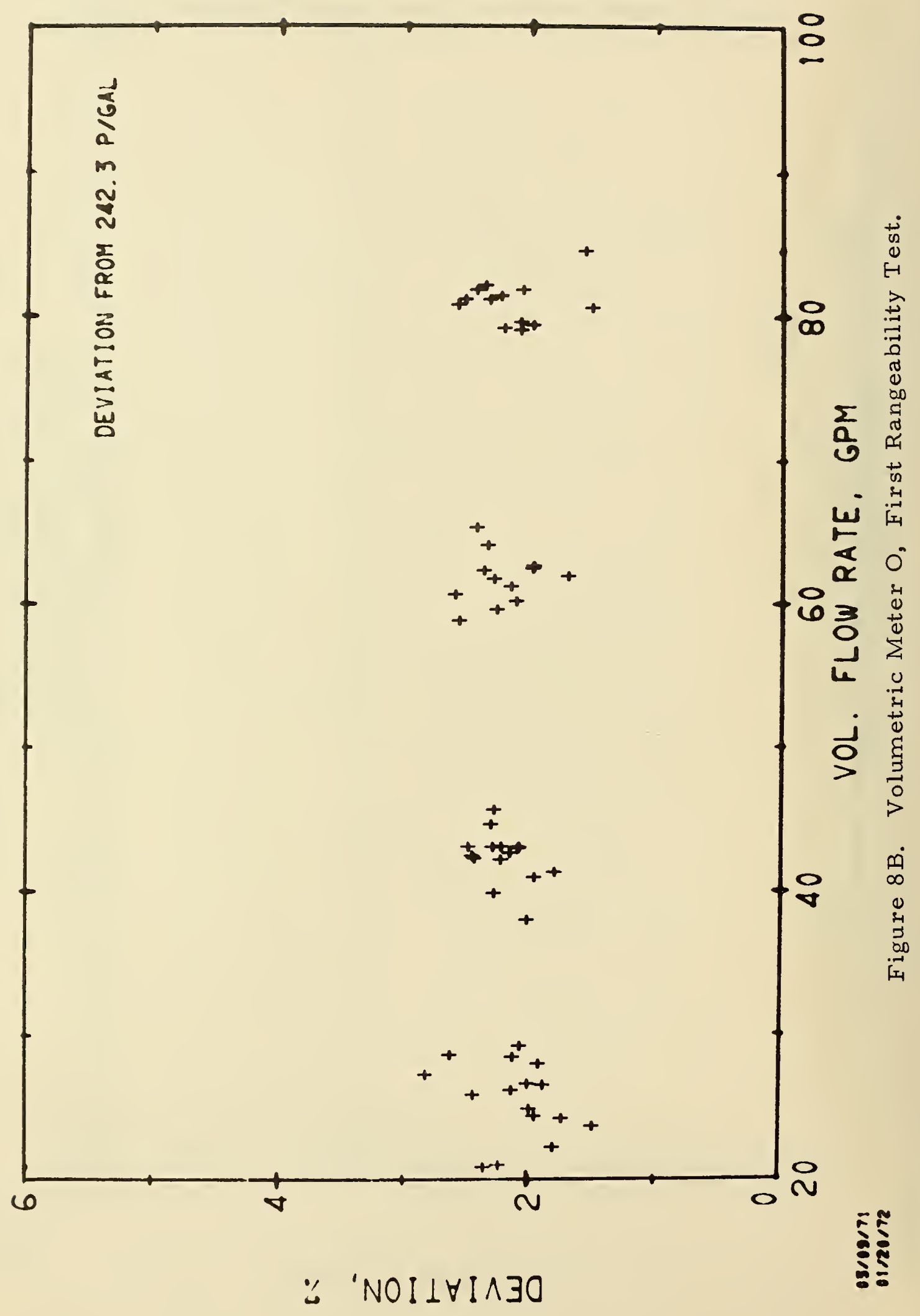




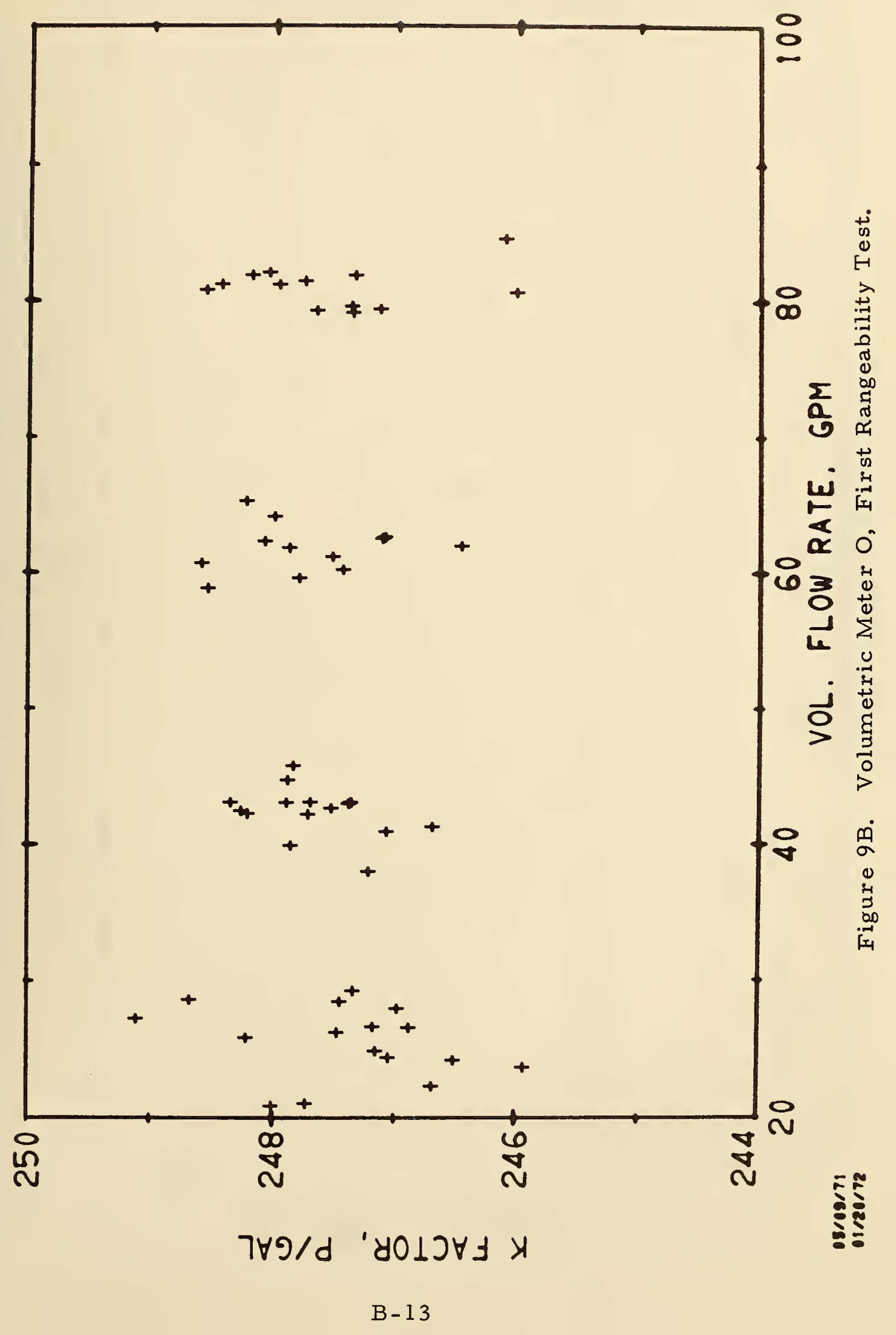




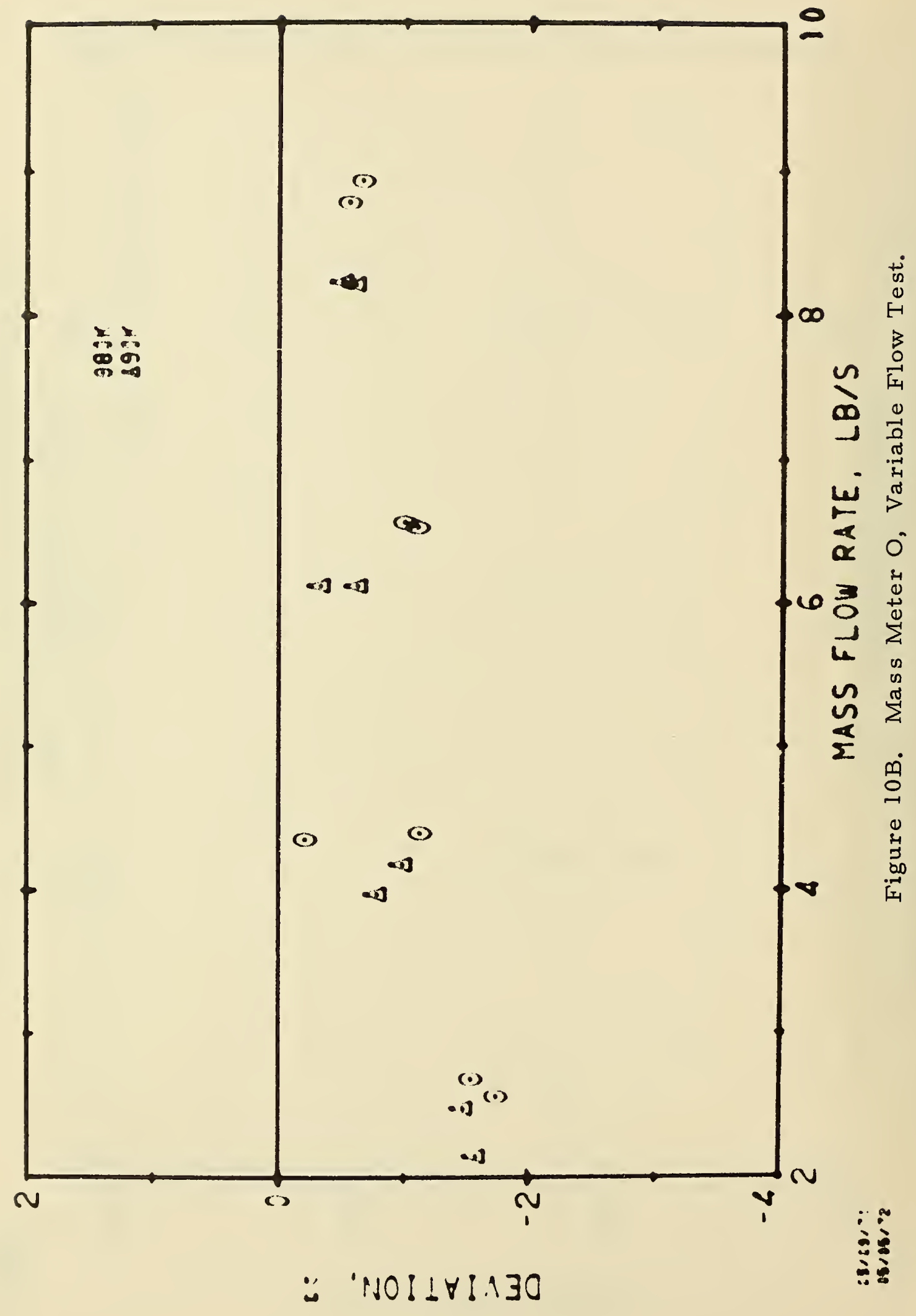




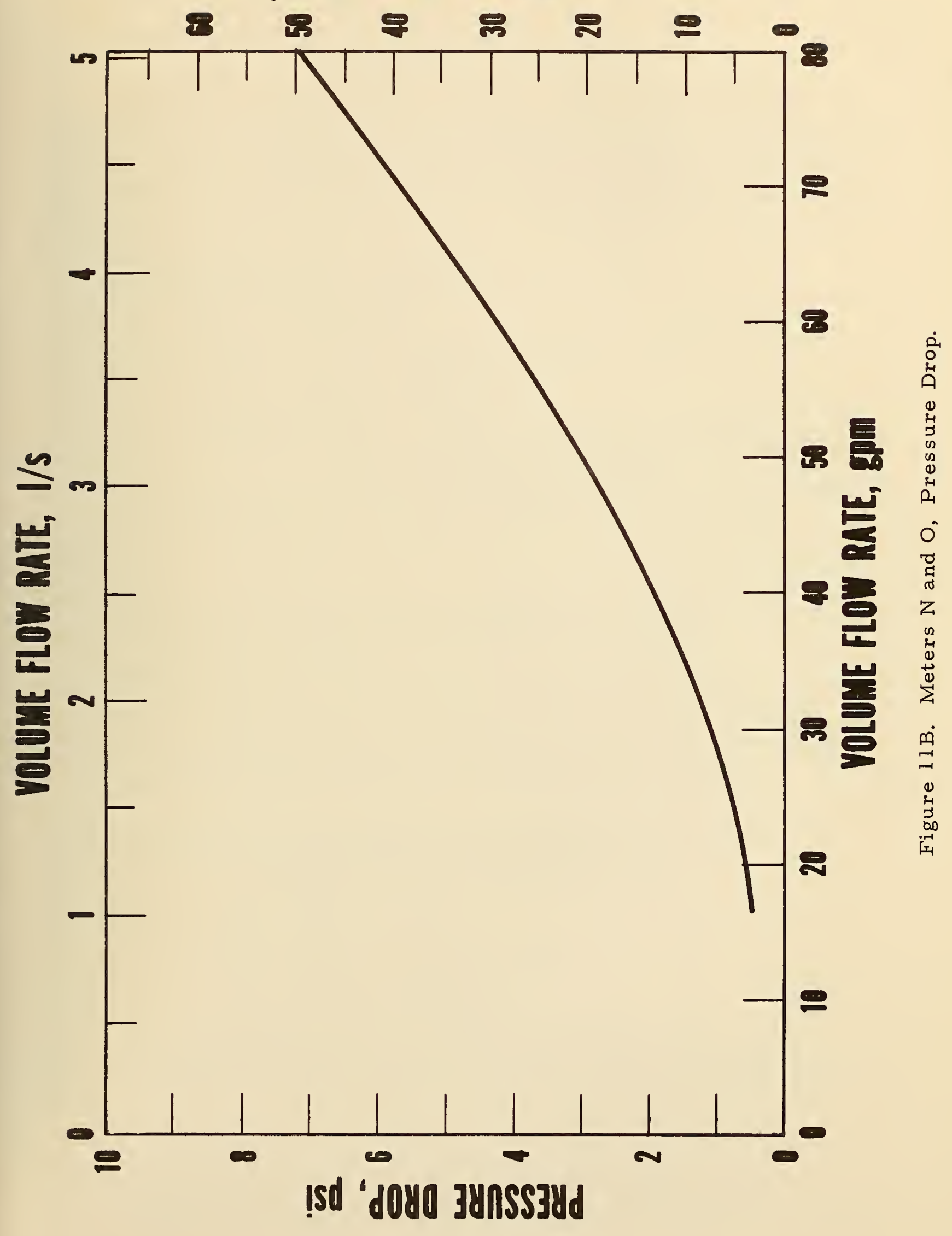



APPENDIX C. Performance of a Volumetric

Turbine Meter (Meters $P$ and $Q$ )

This meter is a standard turbine flowmeter in which a rotor is actuated by the moving liquid. The volumetric flow rate is a function of the speed of rotation of the rotor. The rotor revolutions a re translated into voltage pulses by a pickup coil mounted on the meter housing. These pulses are then counted by means of an electro-mechanical digital totalizer.

The meter manufacturer's specifications are:

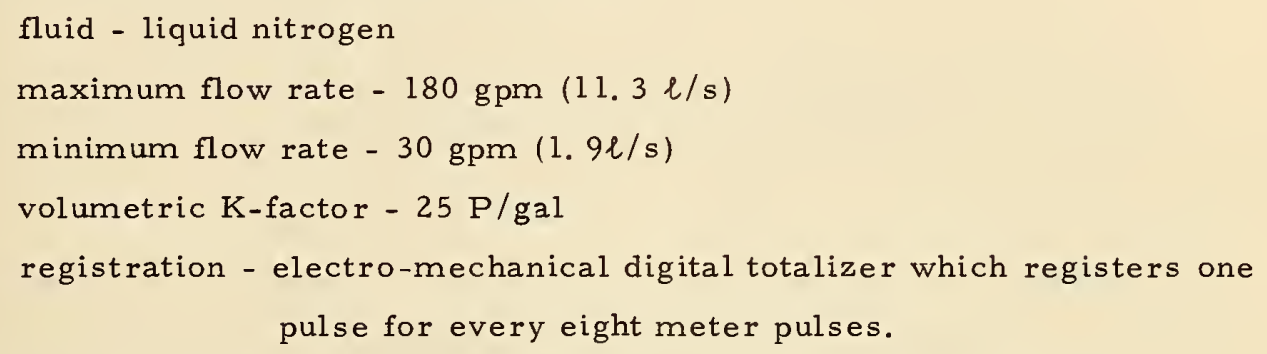

Two meters ( $P$ and $Q$ ) were tested and exhibited similar characteristics.

\section{Meter P}

This meter was subjected to a first rangeability test, a boundary test, a stability test, a second rangeability test, and a variable flow test in that order.

The results of the variable flow test are shown in figures $1 \mathrm{C}$ and $2 \mathrm{C}$. The temperature was $80 \pm 0.5 \mathrm{~K}$, and the pressure was $98 \pm 5$ psia during this test. The figures show a strong underregistration tendency below $40 \mathrm{gpm}(2.5 \mathrm{l} / \mathrm{s})$. The data above $40 \mathrm{gpm}$ $(2.5 \mathrm{l} / \mathrm{s})$ were fitted to the flow model and the results are shown in table $1 \mathrm{C}$.

Table 1C. Fit of Model to Meter P, Variable Flow Test Data for flow rates above $40 \mathrm{gpm}(2.5 \mathrm{l} / \mathrm{s})$

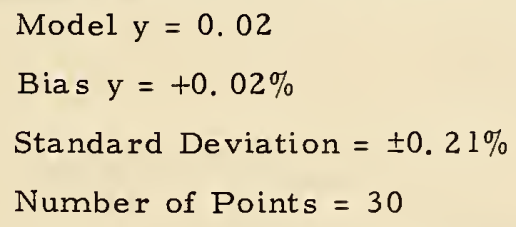

There were no significant dependencies above $40 \mathrm{gpm}(2.5 \mathrm{l} / \mathrm{s})$. The bias of these data is \pm 0.02 percent and the precision based upon three times the standard deviation is \pm 0.63 percent.

The results of the first rangeability test a re shown in figures $3 \mathrm{C}$ and $4 \mathrm{C}$. Three points were removed from these plots. They were very low deviation points and it was felt that something was retarding the rotor that could have been attributed to the system. 
The data above $40 \mathrm{gpm}(2.5 \mathrm{l} / \mathrm{s})$ were fitted to the flow model and the results are shown in table $2 \mathrm{C}$.

Table 2C. Fit of Model to Meter P, First Rangeability Test Data for flow rates above $40 \mathrm{gpm}(2.5 \mathrm{l} / \mathrm{s})$

$$
\begin{aligned}
& \text { Model } \mathrm{y}=0.10 \\
& \text { Bias } \mathrm{y}=+0.10 \% \\
& \text { Standard Deviation }= \pm 0.18 \% \\
& \text { Number of Points }=39
\end{aligned}
$$

There were no significant dependencies above $40 \mathrm{gpm}(2.5 \mathrm{l} / \mathrm{s})$. The bias of these data is +0.10 percent and the precision based on three times the standard deviation is \pm 0.54 percent.

The results of the boundary test are shown in figure $5 \mathrm{C}$. A loss of precision and a tendency to overregister is evident below fourteen degrees of subcooling. The probable cause was the formation of vapor in the meter or the flow system which was observed during this test through the sapphire window downstream of the flowmeter. No explanation can be given for the high deviation at $25 \mathrm{~K}$.

The results of the stability test are shown in figure 6C. Approximately 810000 gallons ( $3066200 \mathrm{l}$ ) were metered during this test. The meter did not show any wear during that period.

The results of the second rangeability test are shown in figures $7 \mathrm{C}$ and $8 \mathrm{C}$. The data above $40 \mathrm{gpm}(2.5 \mathrm{l})$ were fitted to the flow model and the results are shown in table $3 \mathrm{C}$.

Table 3C. Fit of Model to Meter P, Second Rangeability Test Data for flow rates above $40 \mathrm{gpm}(2.5 \mathrm{l} / \mathrm{s})$

$$
\begin{aligned}
& \text { Model } y=0.09 \\
& \text { Bias, } y=+0.09 \\
& \text { Standard Deviation }= \pm 0.16 \% \\
& \text { Number of Points }=41
\end{aligned}
$$

There were no significant dependencies above $40 \mathrm{gpm}(2.5 \mathrm{l} / \mathrm{s})$. The bias of these data is +0.09 percent and the precision based on three times the standard deviation is \pm 0.48 percent.

It should be noted that there was no significant change in the precision or bias of this meter after having metered 810000 gallons ( 3066200 l) of liquid nitrogen. 
The pressure drop data for meter $\mathrm{P}$ are shown in figure $1 \mathrm{lC}$.

\section{Meter $Q$}

This meter was subjected only to a rangeability test. The results of this test are shown in figures $9 \mathrm{C}$ and $10 \mathrm{C}$. The data above $40 \mathrm{gpm}(2.5 \mathrm{l} / \mathrm{s})$ were fit to the flow model and the results are shown in table $4 \mathrm{C}$. The five low deviation points above $40 \mathrm{gpm}$ (2. $5 \mathrm{l} / \mathrm{s}$ ) were removed from those points included in the fit. As the points were in consecutive order it was felt the possibility existed that something was retarding the rotor that could be attributed to the system.

Table 4C. Fit of Model to Meter Q, Rangeability Test Data for flow rates above $40 \mathrm{gpm}(2.5 \mathrm{l} / \mathrm{s})$

$$
\begin{aligned}
& \text { Model } \mathrm{y}=0.8468+0.002510 \mathrm{q} \\
& \text { Bias at } \mathrm{q}=180 \mathrm{gpm}, \mathrm{y}=+1.30 \% \\
& \text { Residual Standard Deviation }= \pm 0.19 \% \\
& \text { Number of Points }=37
\end{aligned}
$$

Meter $Q$ was dependent on the volume flow rate, $q$ in $g \mathrm{pm}$, as the model indicates. The precision based on three times the residual standard deviation is \pm 0.57 percent and the bias at a flow rate of $180 \mathrm{gpm}(11.3 \mathrm{l} / \mathrm{s})$ is +1.30 percent.

The mean bias of these data without fitting them to the model is +1.16 percent. The standard deviation of these data without the model is \pm 0.22 percent, and the precision based on three times this standard deviation is \pm 0.66 percent.

Since this meter has a signficant flow rate dependency, the bias must be calculated from the model to obtain the precision of \pm 0.57 percent. If the bias is not calculated from the model, then the precision can be no better than \pm 0.66 percent. 


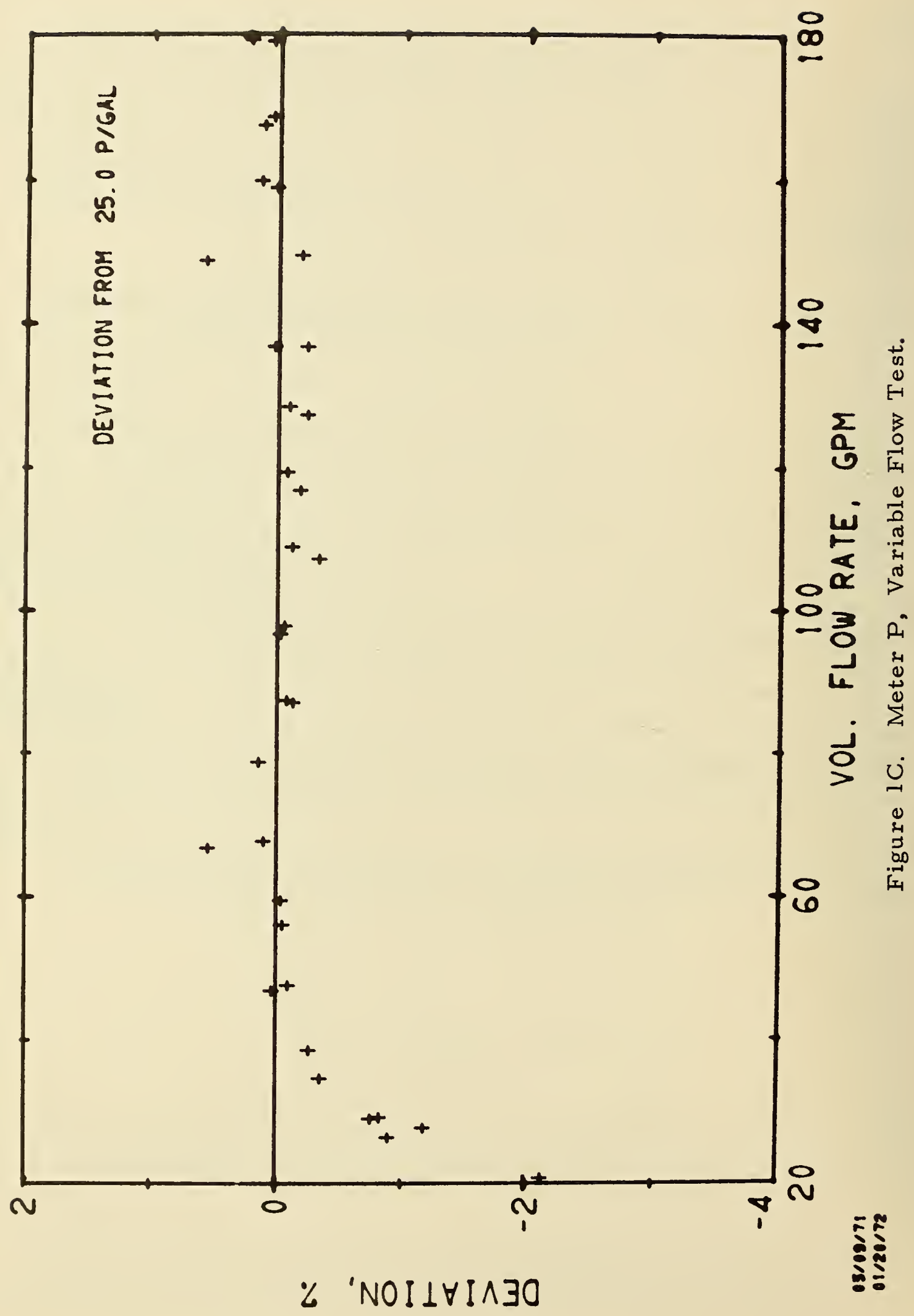

C - 4 


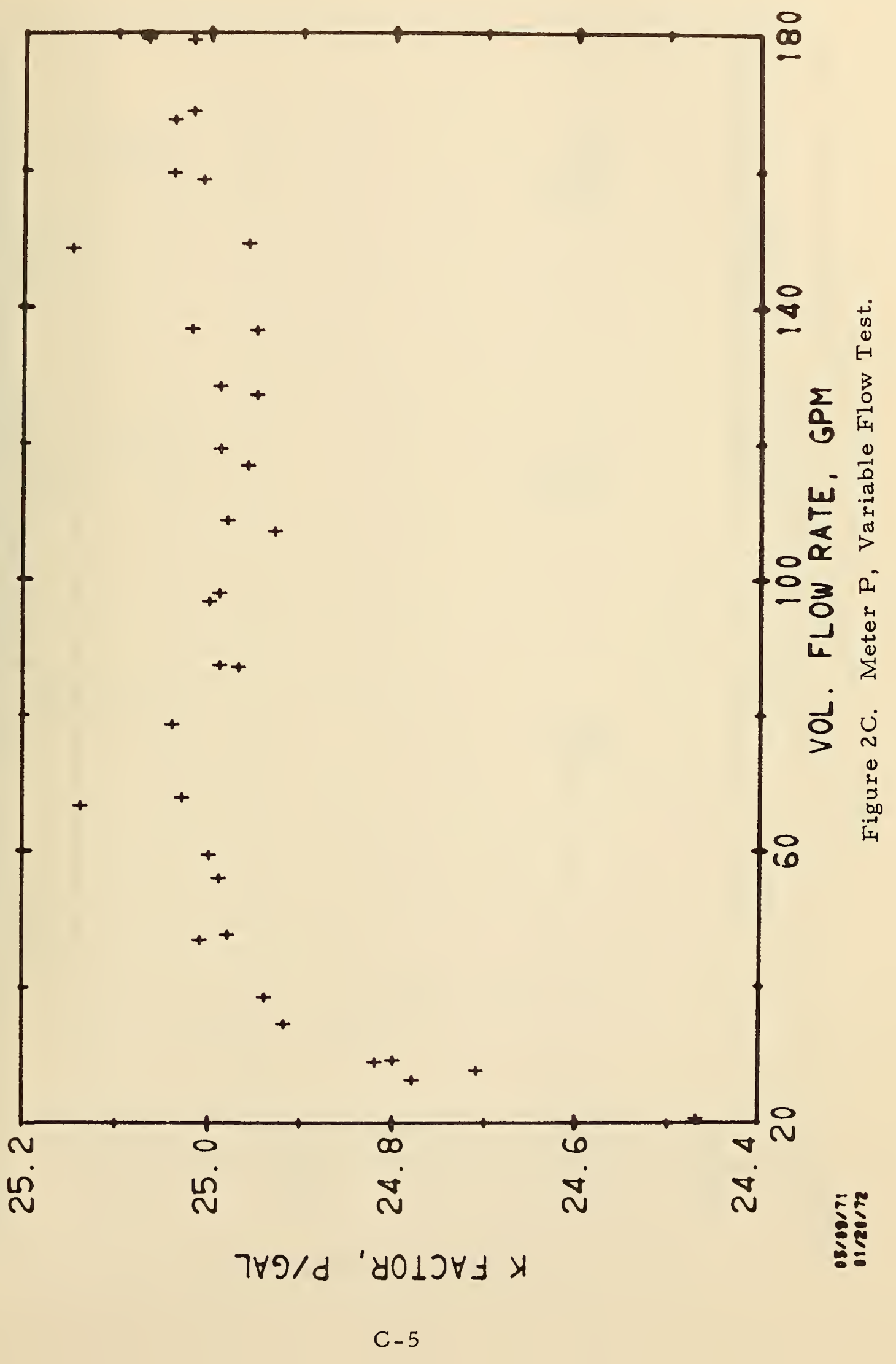




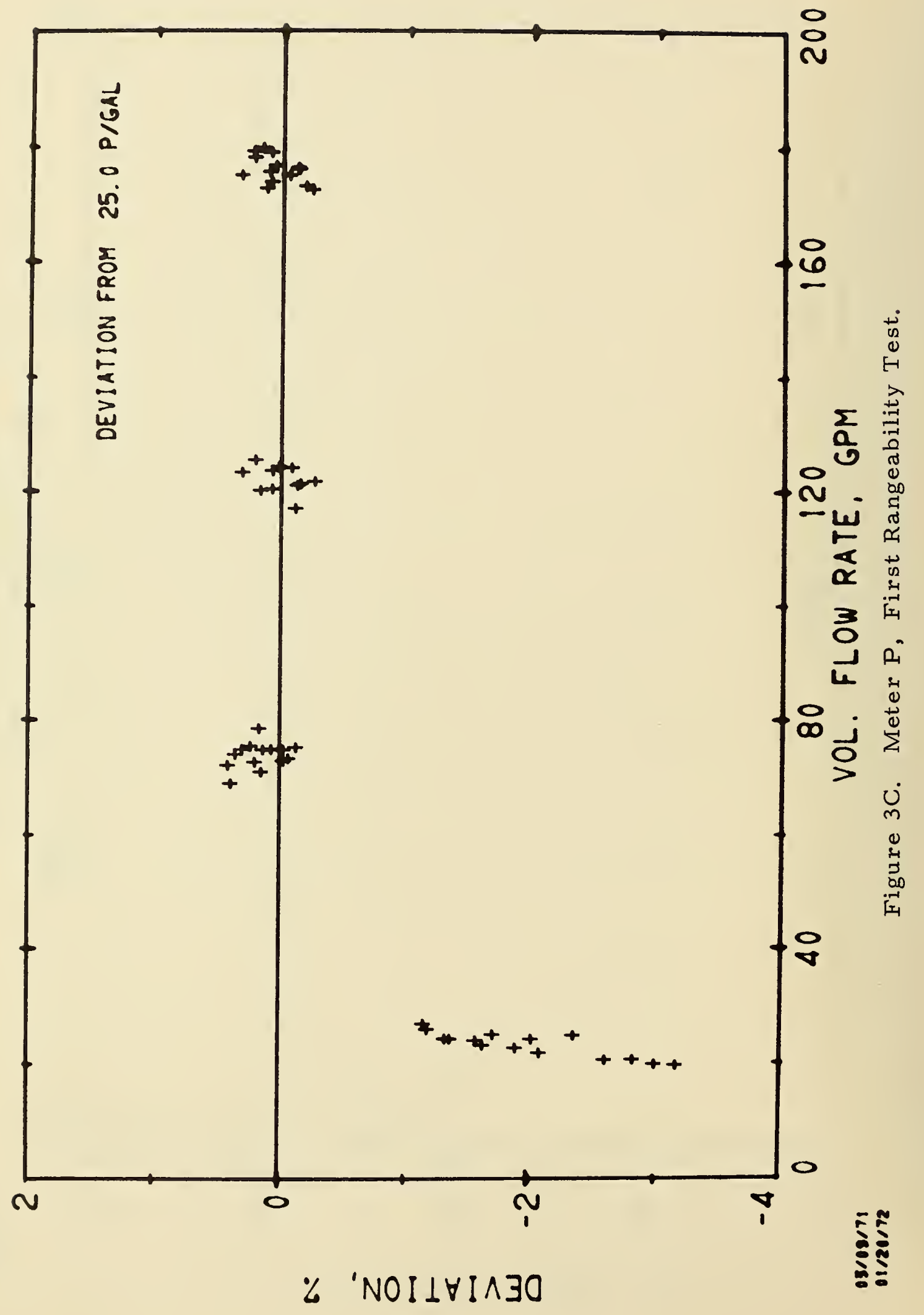




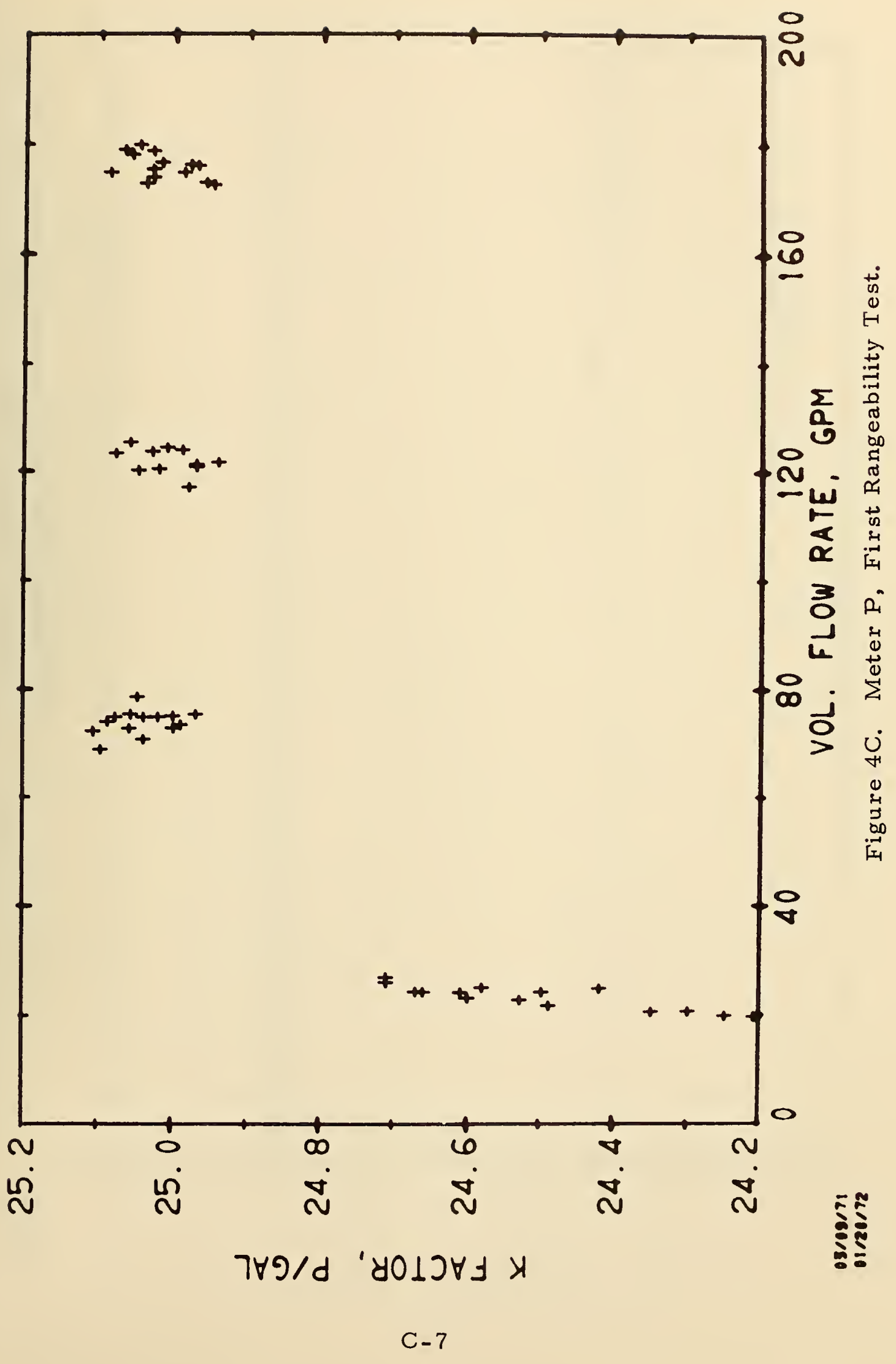




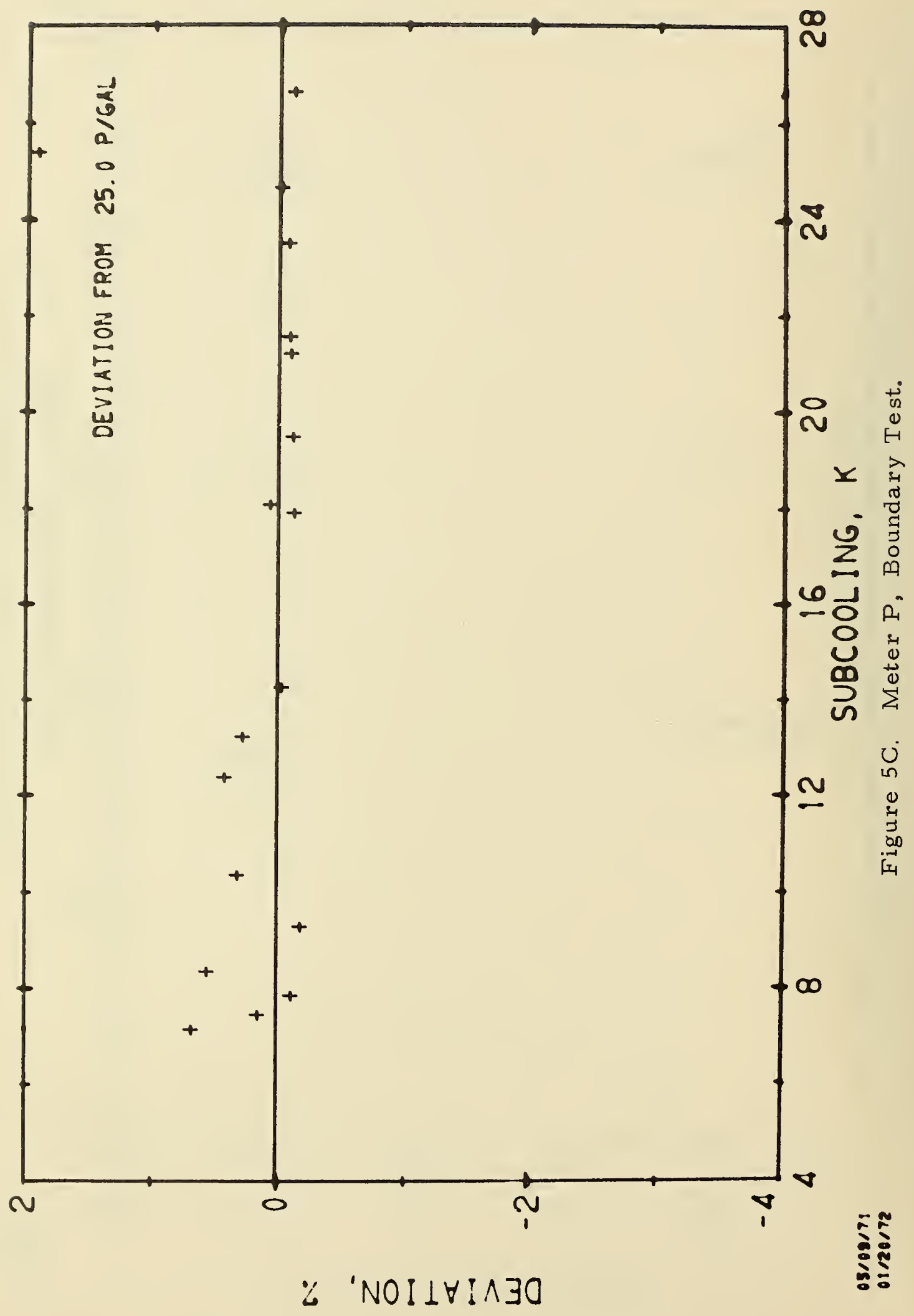

C -8 


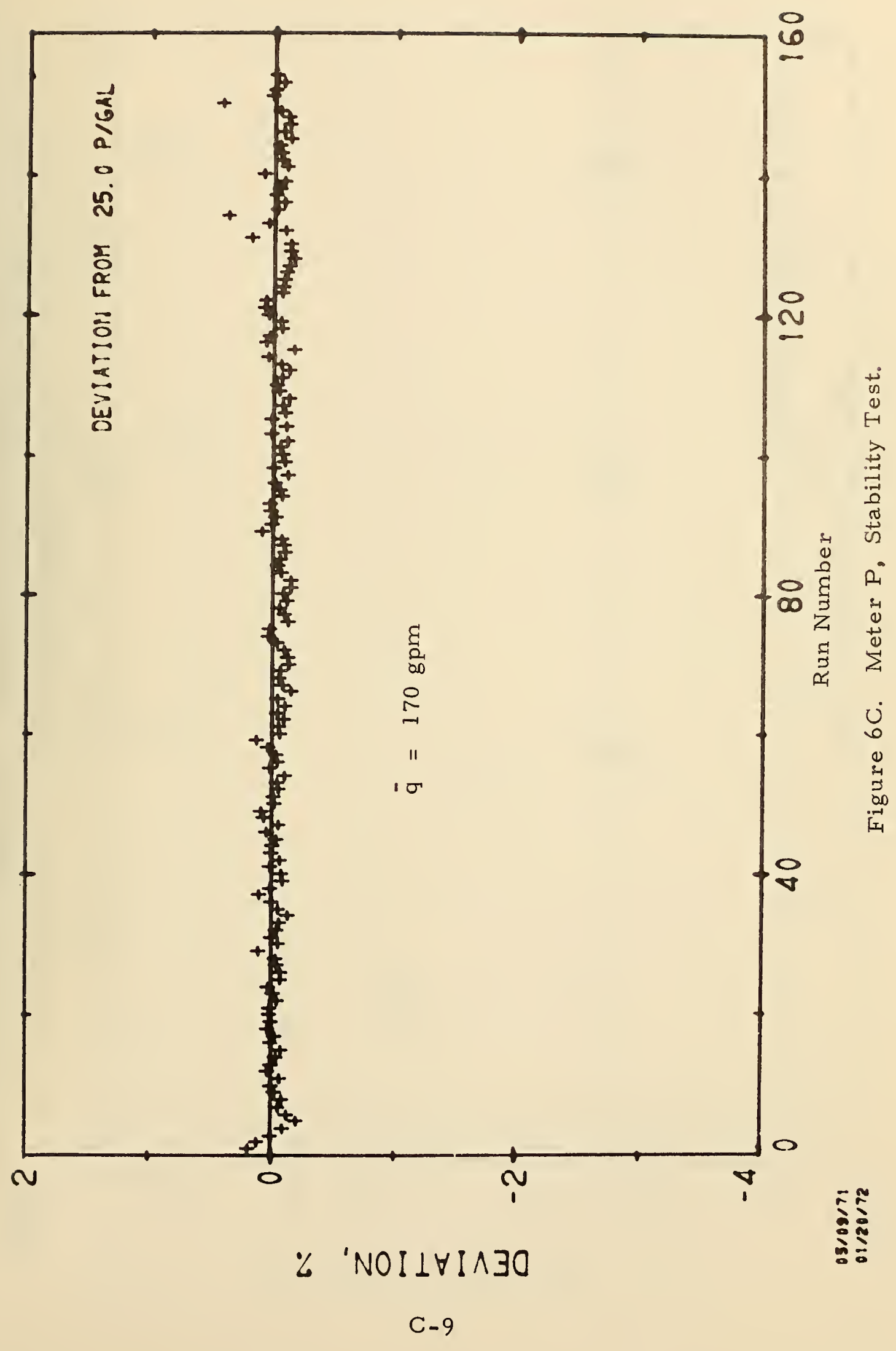




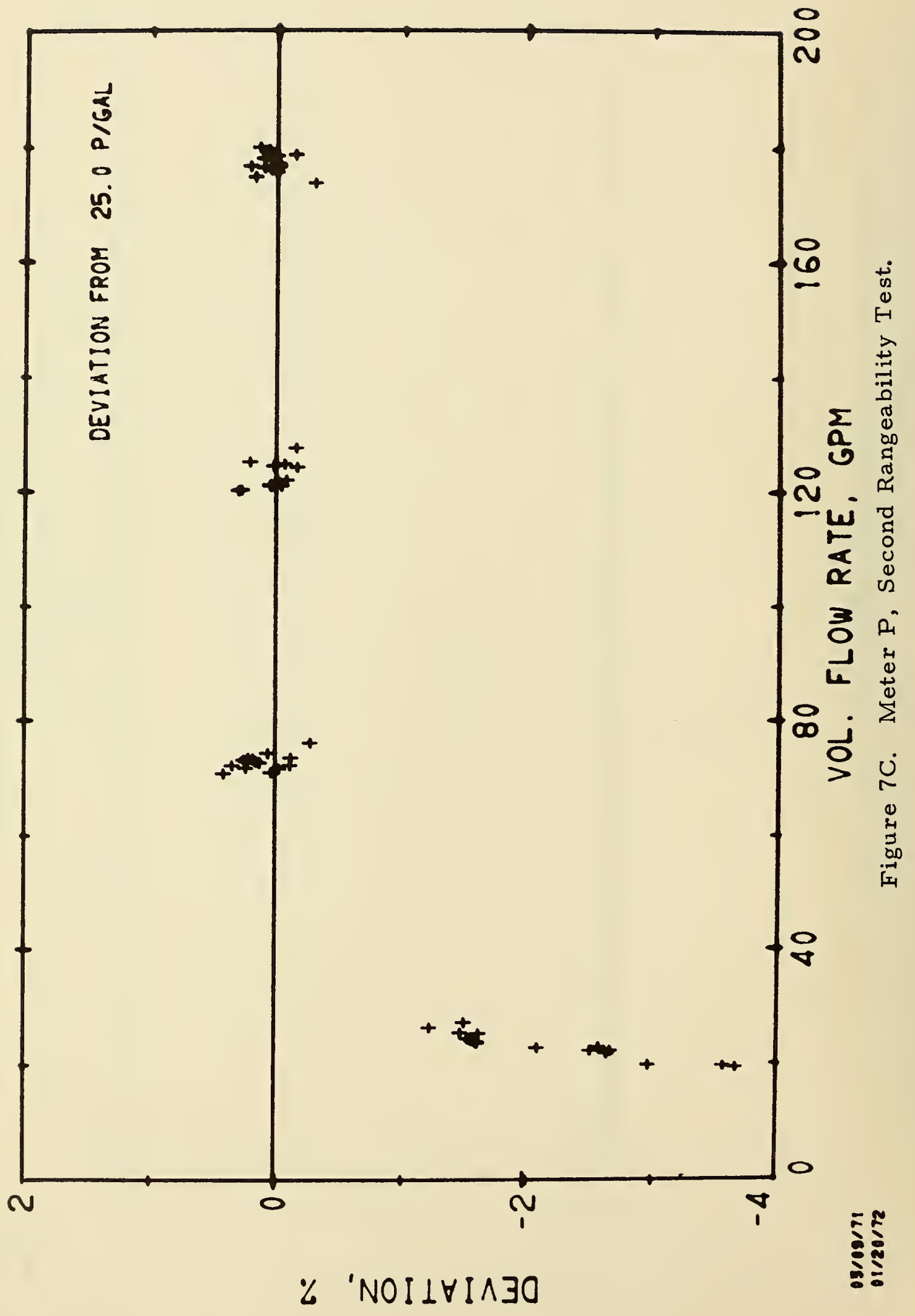

C -10 


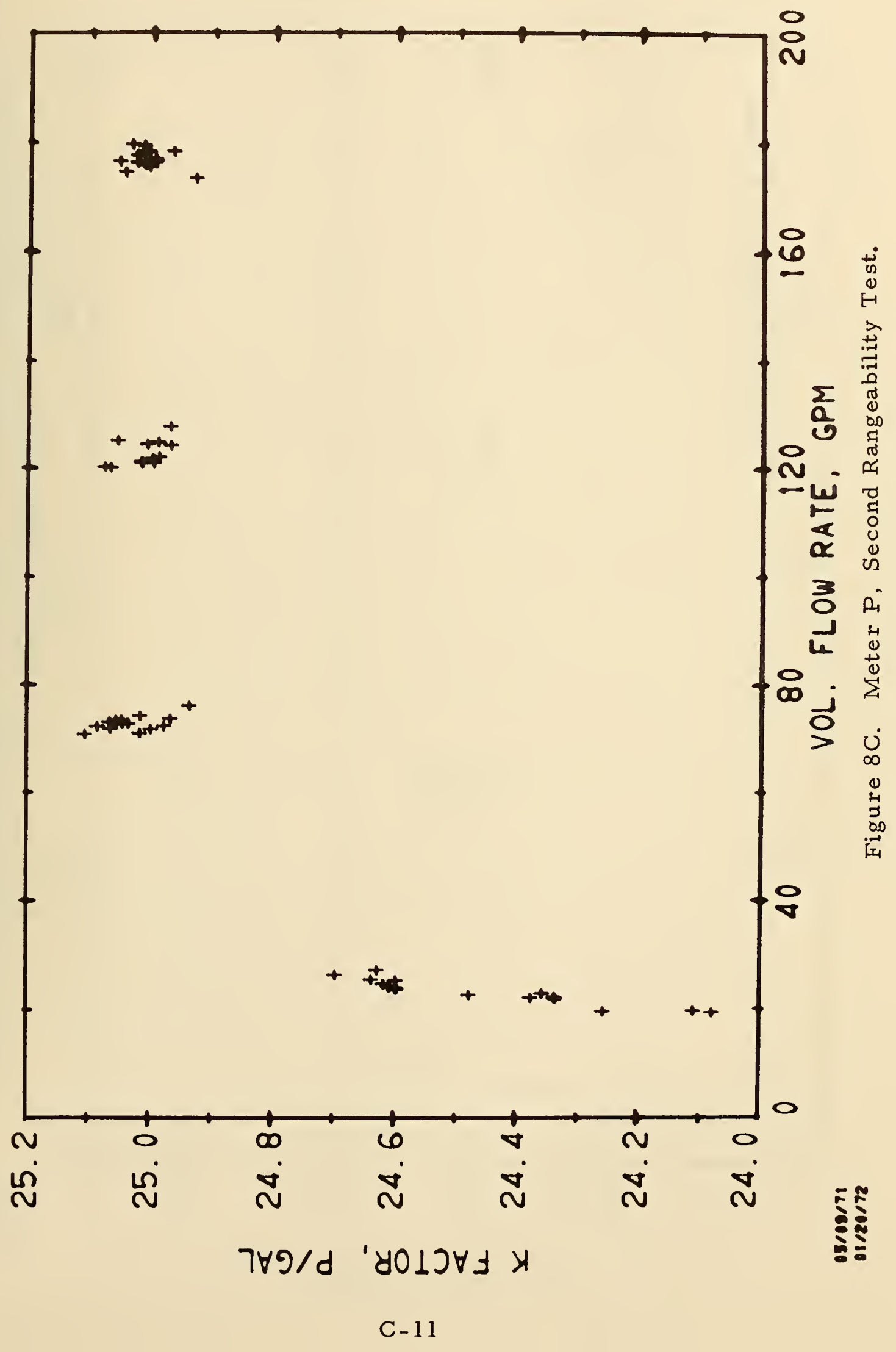




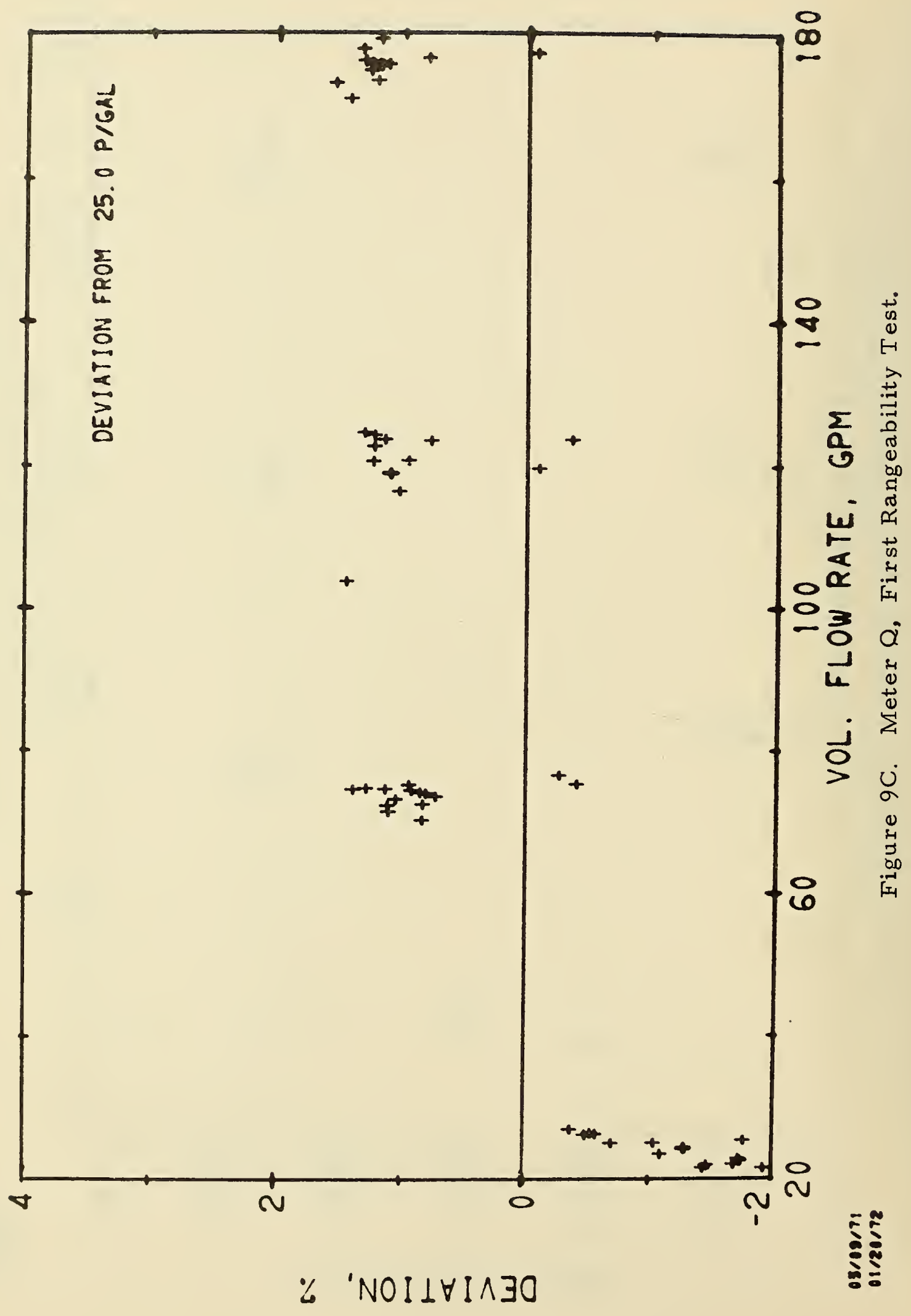




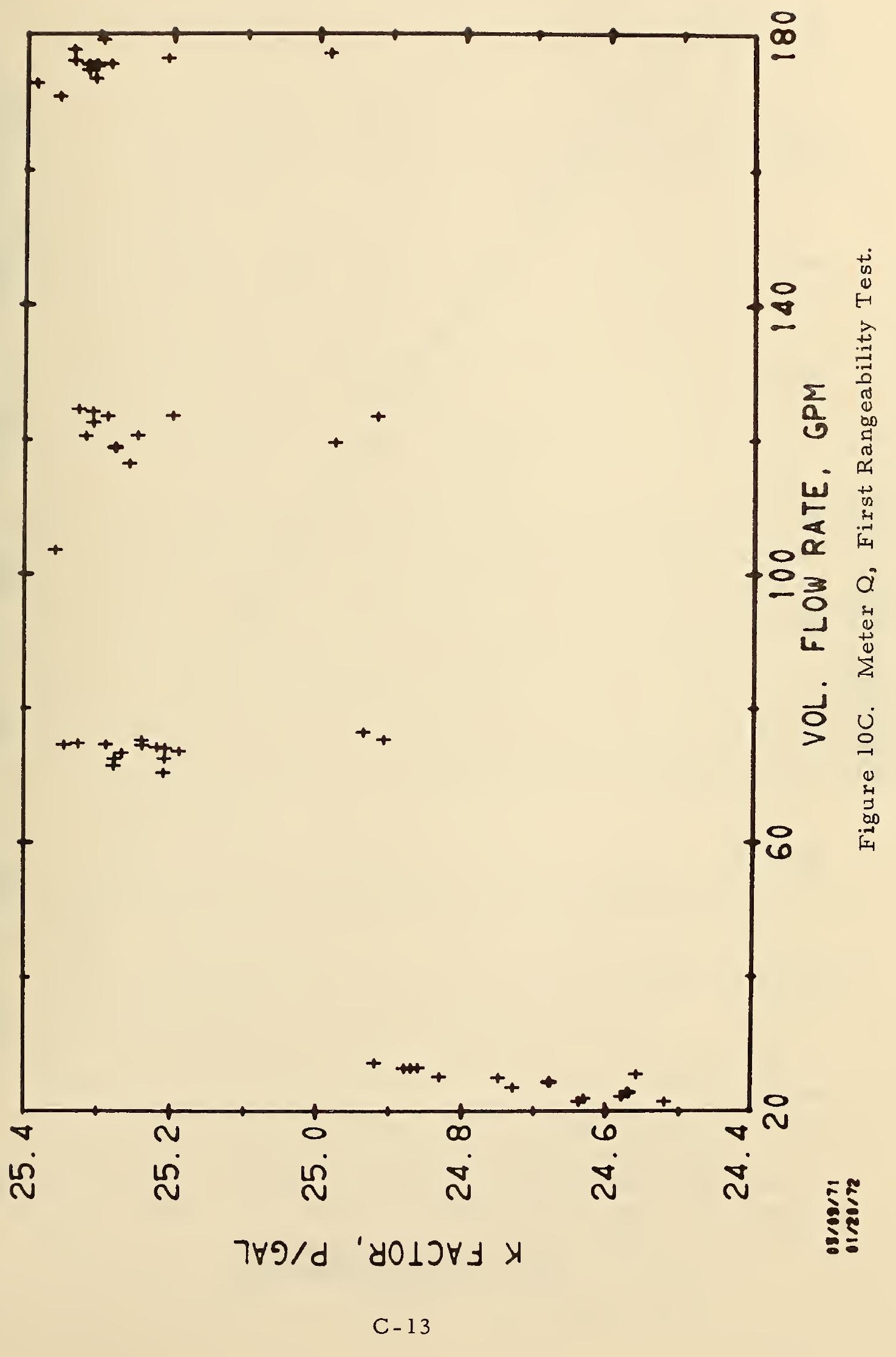




\section{APPENDIX D. Performance of a Volumetric}

Turbine Meter (Meters $R$ and $S$ )

This meter is a standard turbine flowmeter in which the rotor is actuated by the moving liquid. The volumetric flow rate is a function of the speed of rotation of the rotor. The rotor revolutions are translated into voltage pulses by a pickup coil mounted on the meter housing. This system includes an electronic package with a manually adjustable meter $\mathrm{K}$-factor and a digital register. By selecting the proper meter factor, the register will read directly in gallons.

The meter manufacturer's specifications are:

$$
\begin{aligned}
& \text { fluid - liquid nitrogen } \\
& \text { maximum flow rate }-120 \mathrm{gpm}(7.6 \mathrm{l} / \mathrm{s}) \\
& \text { minimum flow rate }-12 \mathrm{gpm}(0.8 \mathrm{l} / \mathrm{s}) \\
& \text { nominal size - } 1-1 / 2 \text { inch }(0.038 \mathrm{~m}) \\
& \text { Volumetric K-factor - Meter } \mathrm{R}-433 \mathrm{P} / \mathrm{gal} \\
& \text { Meter S }-425 \mathrm{P} / \mathrm{gal} .
\end{aligned}
$$

The test results of two meters ( $R$ and $S$ ) are reported. Both meters were a modified version of an earlier design. Two meters of the earlier design (meters $\mathrm{H}$ and I) were tested previously but are not reported. All four of these meters failed mechanically during the tests. The failure mode in all four cases was an apparent bearing failure which allowed the rotor blades to contact the meter housing. The meter failure was detected by a large underregistration accompanied by a high frequency audible response. In case of meter $\mathrm{R}$, the meter performed satisfactorily with no loss of accuracy up to the point of failure. Meter S showed a slight order dependency in the rangeability test data which may have been symptomatic of the ensuing failure.

Meter R

This meter was subjected to a variable flow test, a rangeability test, a boundary test, and a stability test.

The results of the variable flow test are shown in figures $1 \mathrm{D}$ and $2 \mathrm{D}$. The temperature was $80 \pm 0.2 \mathrm{~K}$ and the pressure was $99 \pm 2$ psia during this test.

The data were fitted to the model and the results are shown in table $1 \mathrm{D}$.

Table 1D. Fit of Model to Meter R, Variable Flow Test Data

Model y $=1.082+0.006578 \mathrm{q}$

Bias at $q=120 \mathrm{gpm}, y=1.87 \%$

Residual Standard Deviation $= \pm 0.10 \%$

Number of Points $=21$ 
This meter showed a significant dependency on volume flow rate, $q$ in $g$ pm, during this test, which is indicated by the model. The precision based upon three times the residual standard deviation is \pm 0.30 and the bias at a flow rate of $120 \mathrm{gpm}(7.6 \mathrm{l} / \mathrm{s})$ is +1.87 percent.

The mean bias of these data without fitting them to the model is +1.47 percent. The standard deviation of these data without the model is \pm 0.21 percent, and the precision based on three times this standard deviation is \pm 0.63 percent.

Since this meter has a signficiant flow rate dependency, the bias must be calculated from the model to obtain the precision of \pm 0.30 percent. If the bias is not calculated from the model, then the precision can not be better than \pm 0.63 percent.

The results of the first rangeability test are shown in figures $3 \mathrm{D}$ and $4 \mathrm{D}$. These data were fitted to the model and the results are shown in table $2 \mathrm{D}$.

Table 2D. Fit of Model to Meter R, Rangeability Test Data

Model $\mathrm{y}=1.139+0.006626 \mathrm{q}$

Bias at $\mathrm{q}=120 \mathrm{gpm}, \mathrm{y}=+1.93 \%$

Residual Standard Deviation $= \pm 0.34 \%$

Number of Points $=57$

The meter showed essentially the same flow rate dependency during this test as during the variable flow test. The precision based on three times the residual standard deviation was \pm 1.02 percent. This is significantly higher than the precision during the variable flow test; however, this is expected as all parameters are varied during this test while only flow rate is varied during the variable flow test.

When the data are not fitted to the model, the mean bias is \pm 1.56 percent. The standard deviation of these data without the model is \pm 0.42 percent and the precision based on three times the standard deviation is \pm 1.26 percent.

The results of the boundary test are shown in figure $5 \mathrm{D}$. A loss of precision and a tendency to overregister is evident below twenty degrees of subcooling.

The results of the stability test are shown in figure 6D. This test was terminated after approximately twenty hours when the meter failed. At the point of failure 280000 gallons ( $059900 \mathrm{l}$ ) of liquid nitrogen had been metered. The last data point taken on this meter had a deviation of minus twenty-five percent and is not shown on figure 6D.

\section{Meter S}

A rangeability test was completed on this meter, however, at the start of the boundary test the meter failed. 
The results of the rangeability test are shown in figures $7 \mathrm{D}$ and $8 \mathrm{D}$. These data were fitted to the model and the results are shown in table $3 \mathrm{D}$.

Table 3D. Fit of Model to Meter S, Rangeability Test Data

$$
\begin{aligned}
& \text { Model } y=2.166-0.01053 \theta \\
& \text { Bias at } \theta=57, y=+1.57 \% \\
& \text { Residual Standard Deviation }= \pm 0.26 \% \\
& \text { Number of Points }=57
\end{aligned}
$$

As noted previously, this meter has an order dependency which may have been a symptom of the failure which was to follow. The bias was calculated from the model at the last data point taken and was +1.57 percent. The bias at the beginning of the rangeability test, as calculated from the model, was +2.16 percent. The precision based on three times the residual standard deviation is \pm 0.78 percent.

The mean bias of these data without fitting them to the model is +1.86 percent. The standard deviation of these data without the model is \pm 0.31 percent and the precision based on three times the standard deviation is \pm 0.93 percent.

The pressure drop data for meters $R$ and $S$ are shown in figure $9 D$. 


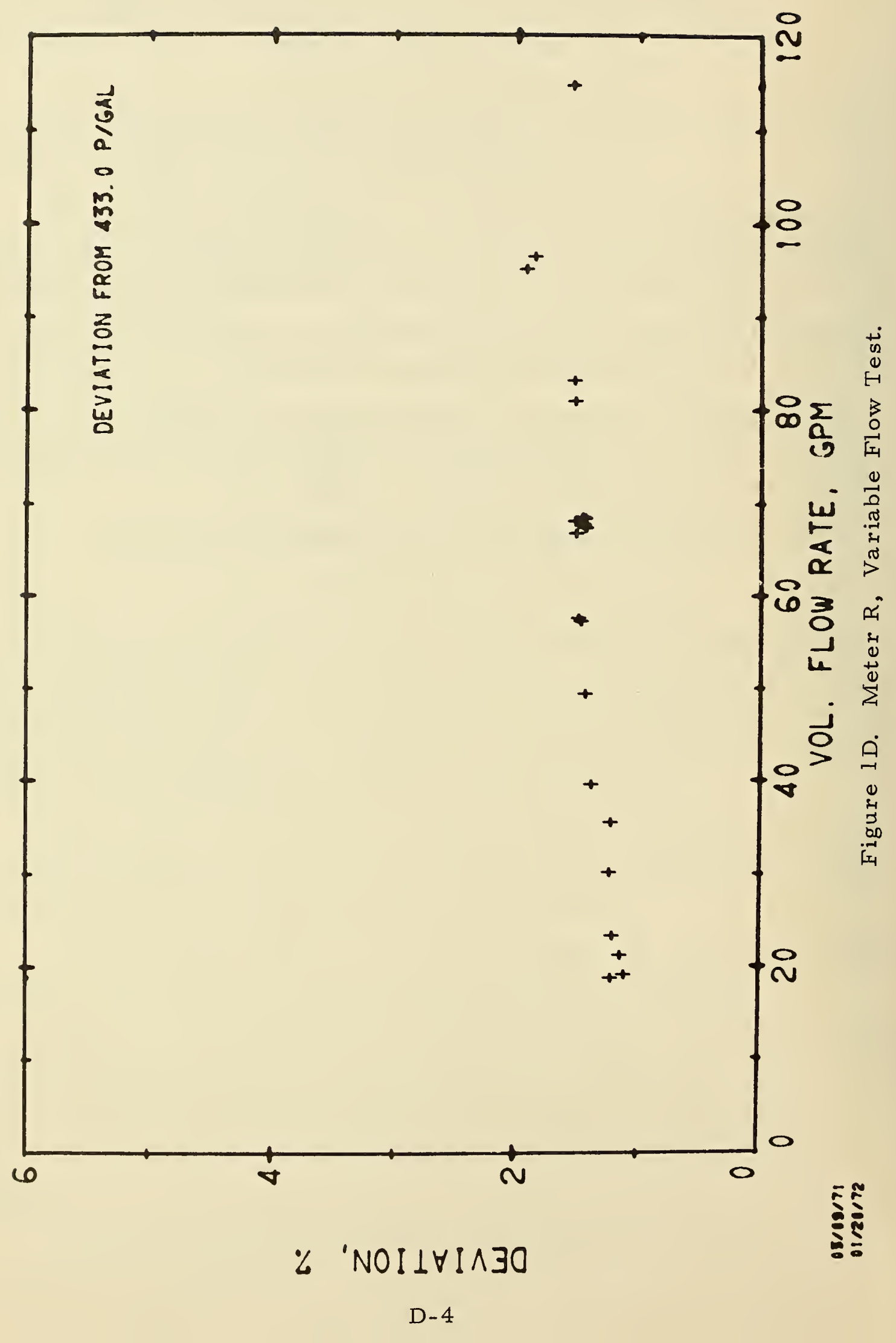




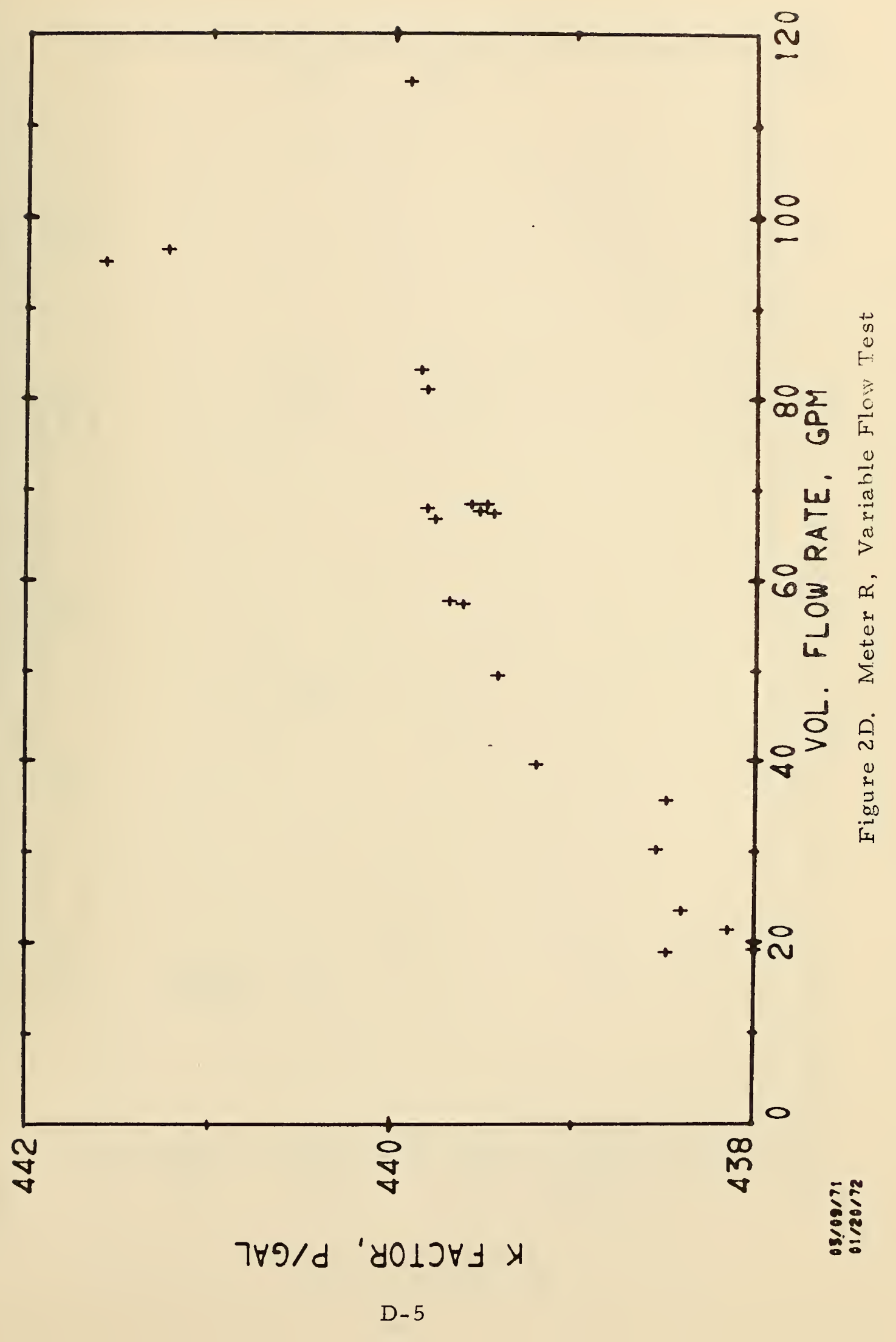




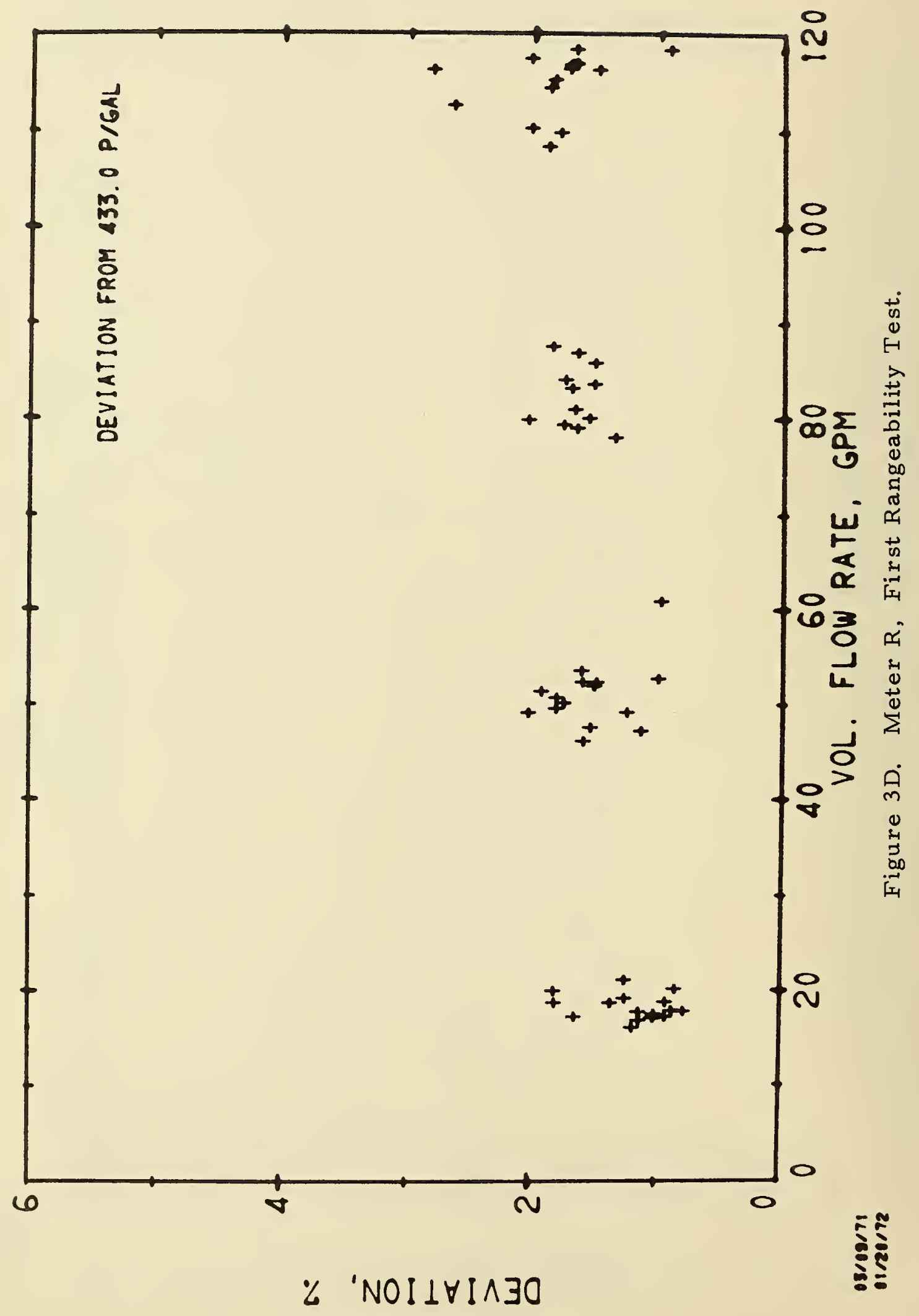

D- 6 


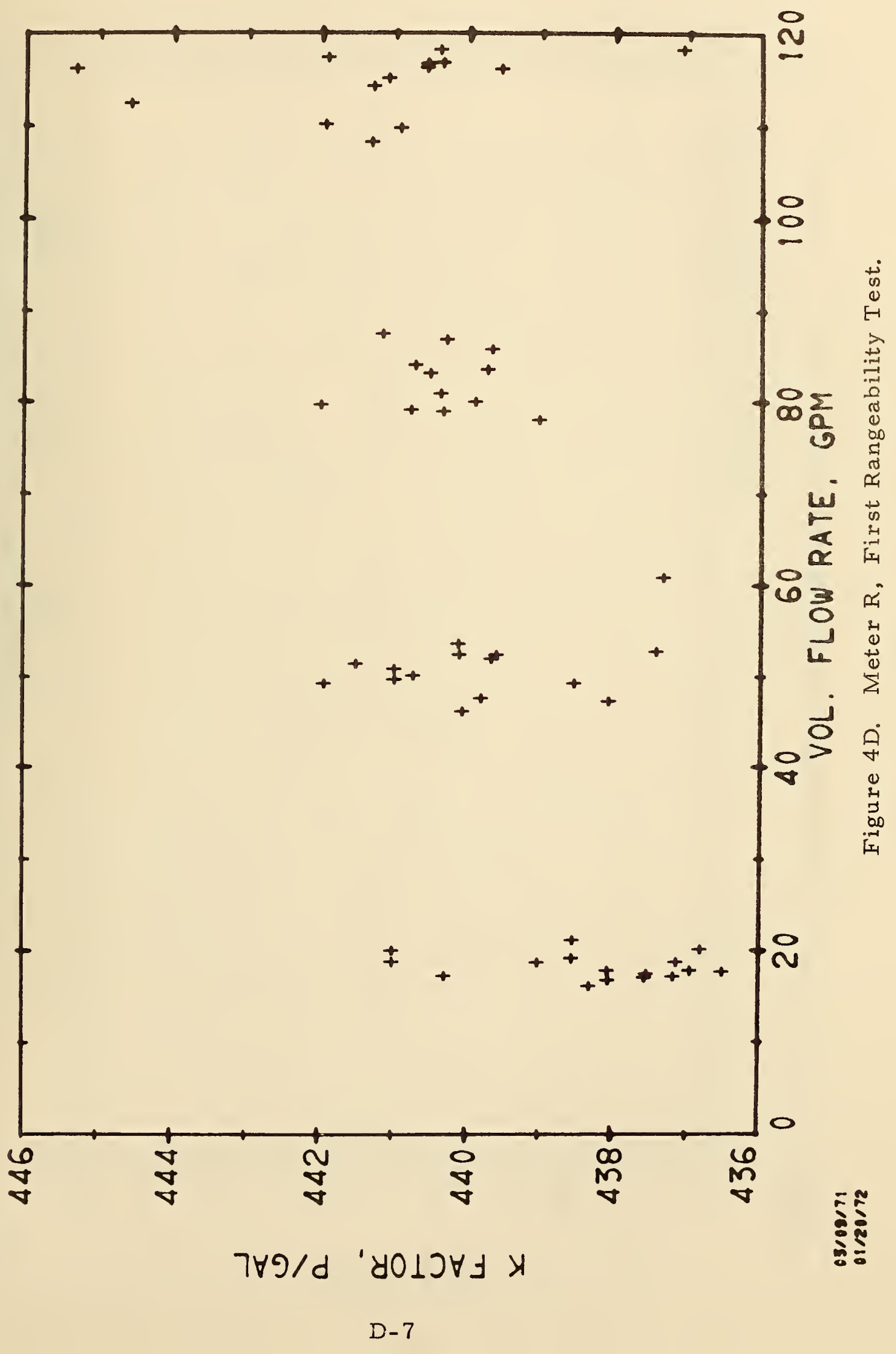




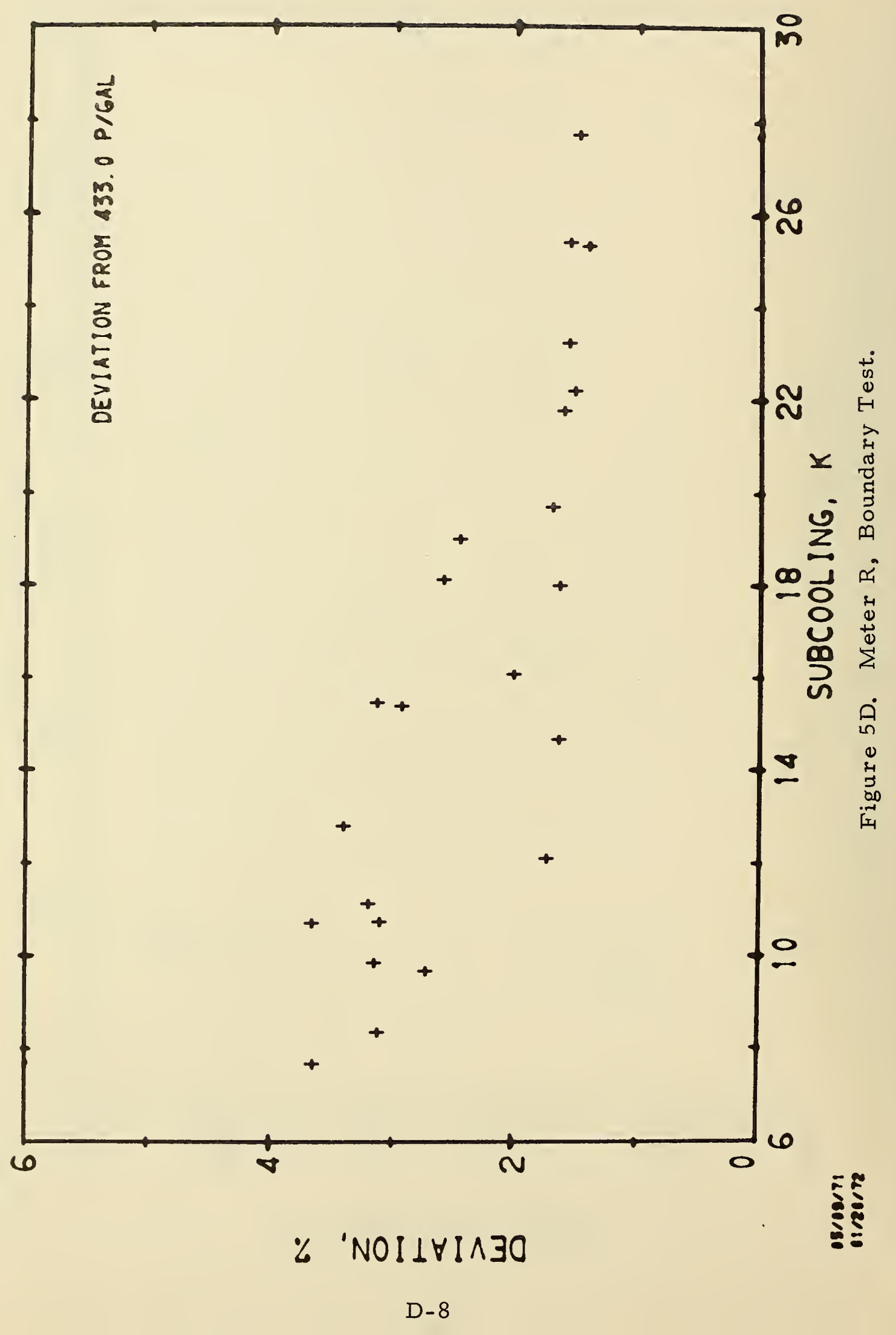




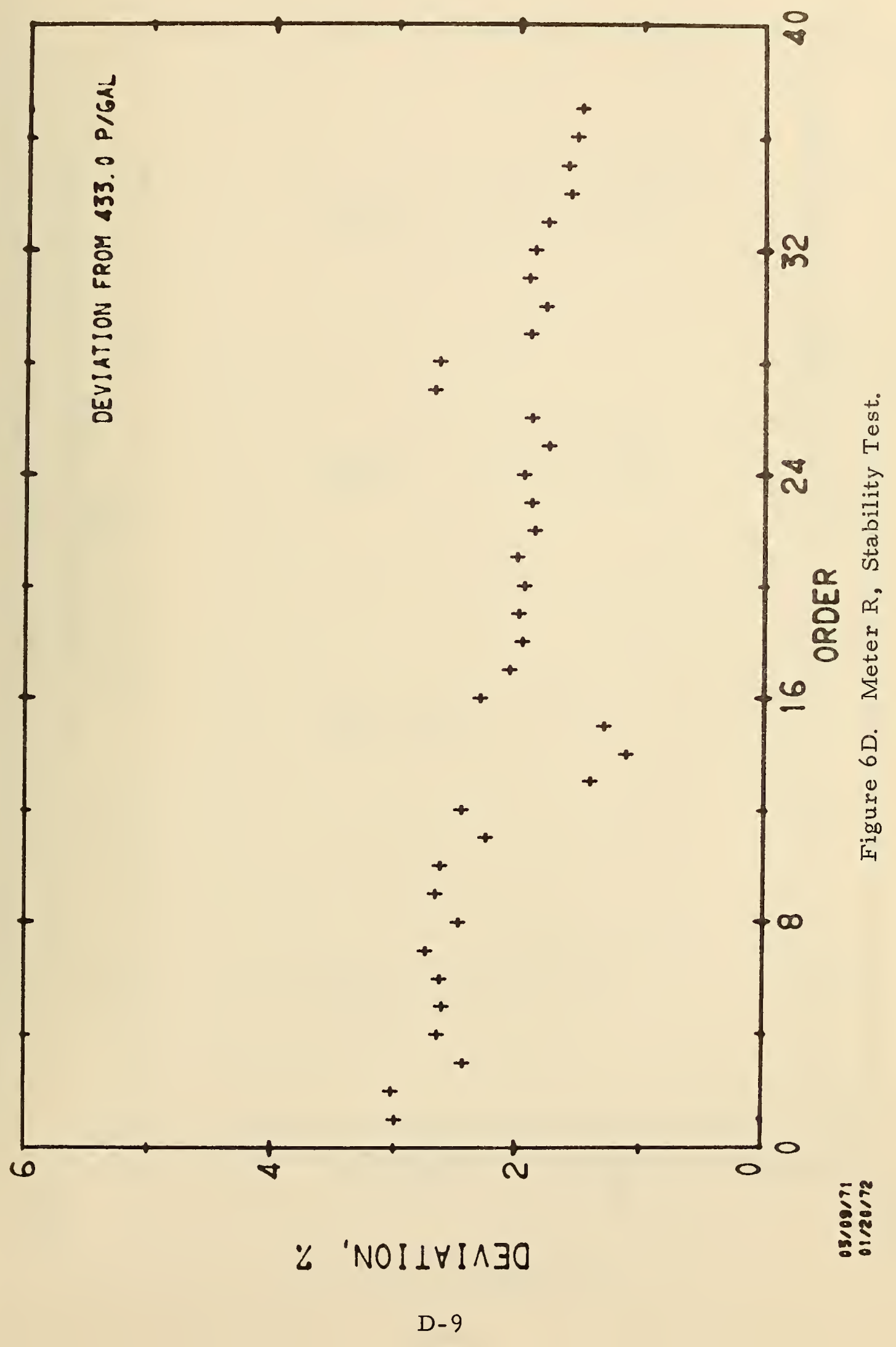




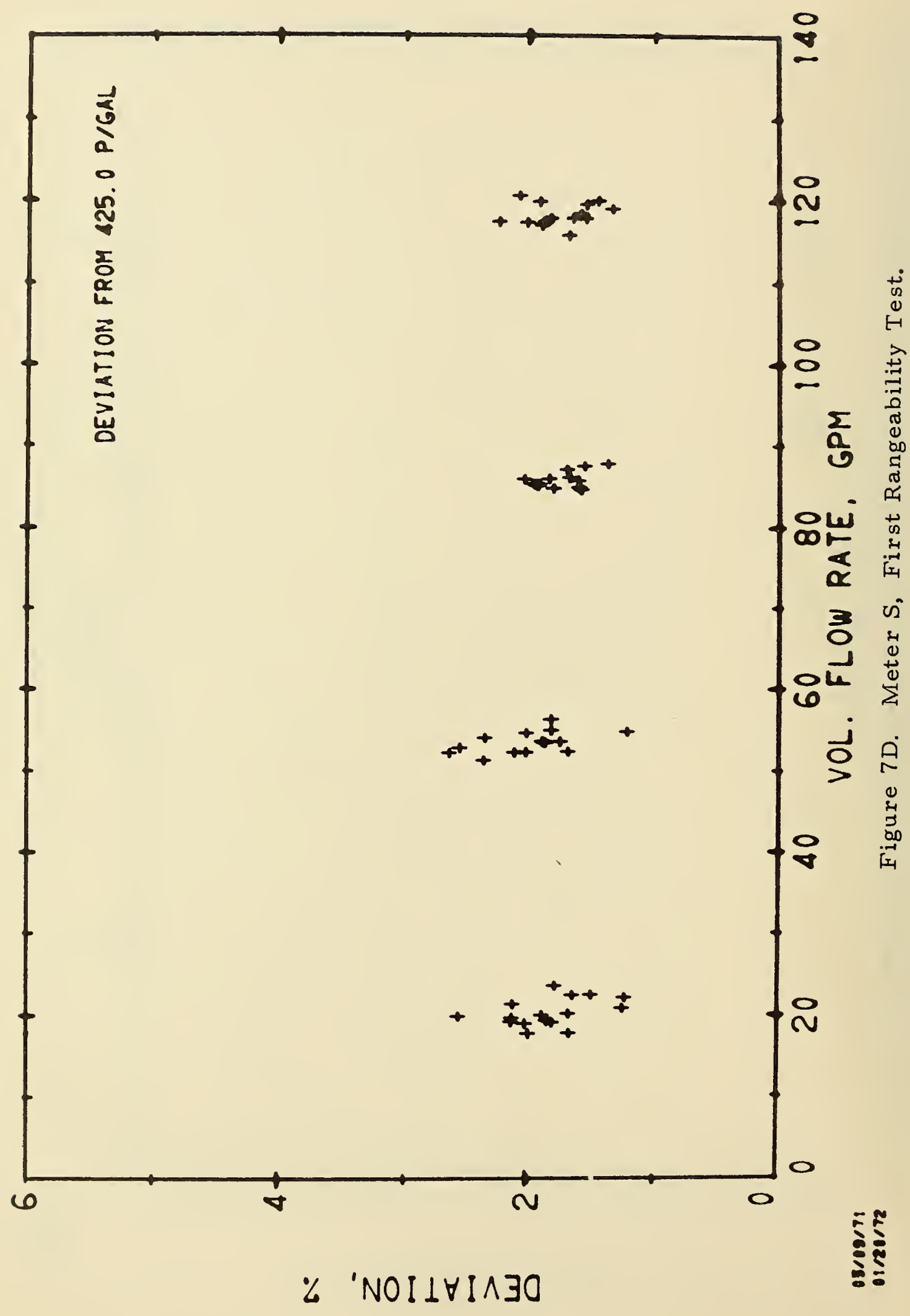

D -10 


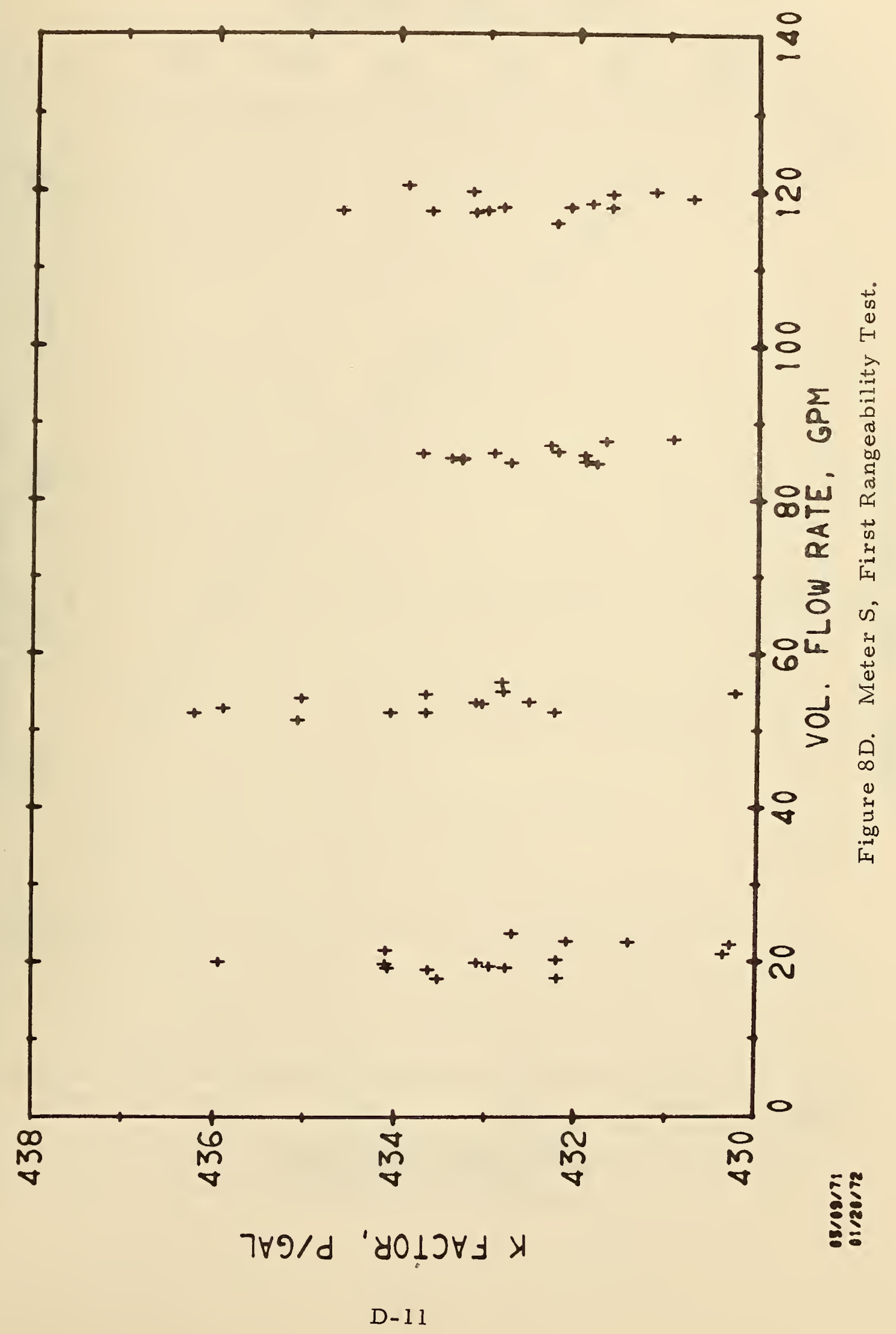




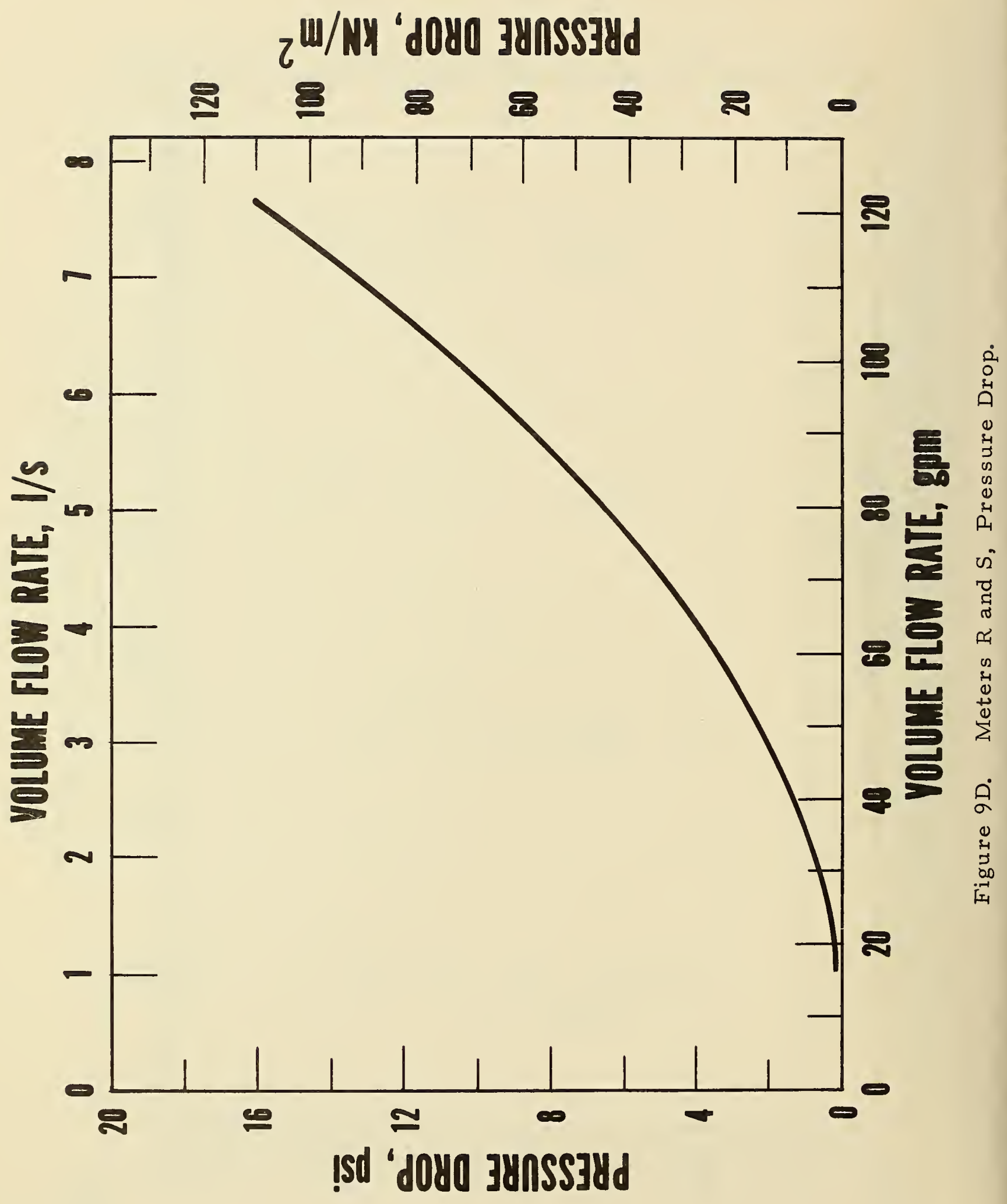




\section{APPENDIX E. Performance of Volumetric}

Turbine Meter (Meter'V)

This meter is a standard turbine flowmeter in which the rotor is actuated by the moving liquid. The volumetric flow rate is a function of the speed of rotation of the rotor. The rotor revolutions are translated into voltage pulses by a pickup coil mounted on the meter housing. This meter system was not equipped with a counter or a register. This system did include an integral signal conditioner which amplified the voltage pulses and re-shaped them from a sinusoidal to a square wave pulse form.

The meter manufacturer's specifications are:

$$
\begin{aligned}
& \text { fluid - liquid nitrogen } \\
& \text { maximum flow rate }-225 \mathrm{gpm}(14.2 \mathrm{l} / \mathrm{s}) \\
& \text { minimum flow rate }-22 \mathrm{gpm}(1.4 \mathrm{l} / \mathrm{s}) \\
& \text { volumetric } \mathrm{K} \text {-factor }-147.1 \mathrm{P} / \mathrm{gal} \\
& \text { nominal size }-2 \text { inch }(0.051 \mathrm{~m})
\end{aligned}
$$

The results of one meter (V) are reported. This meter was subjected to a rangeability test and a variable flow test.

The results of the rangeability test are shown in figures $1 \mathrm{E}, 2 \mathrm{E}$, and $3 \mathrm{E}$. These data were fitted to the mathematical model and the results are shown in table $1 \mathrm{E}$.

Table lE. Fit of Model to Meter V, Rangeability Test Data

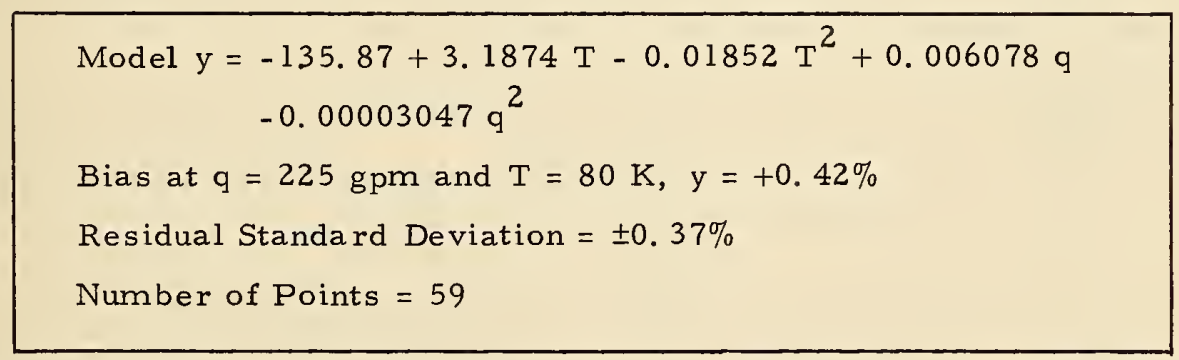

This meter shows significant dependencies on temperature, $\mathrm{T}$, temperature squared, volume flow rate, $\mathrm{q}$ in $\mathrm{gpm}$, and flow rate squared. The flow rate dependency is evident in figure $\mathrm{IE}$ and the temperature dependency can be seen in figure $3 \mathrm{E}$. The bias at a flow rate of $225 \mathrm{gpm}(14.2 \mathrm{l} / \mathrm{s})$ and $80 \mathrm{~K}$ is +0.42 percent. The precision based on three times the residual standard deviation is \pm 1.11 percent.

The mean bias of these data without fitting them to the model is +1.19 percent. The standard deviation of these data without the model is \pm 0.46 percent and the precision based on three times this standard deviation is \pm 1.38 percent. 
Since this meter has significant dependencies, the bias must be calculated from the model to obtain the precision of \pm 1.11 percent. If the bias is not calculated from the model, then the precision cannot be better than \pm 1.38 percent.

The results of the variable flow test are shown in figures $4 \mathrm{E}$ and $5 \mathrm{E}$. The temperature was held constant during this test at $82.5 \pm 0.2 \mathrm{~K}$ and the pressure at $108 \pm 4$ psia. These data were fitted to the model and the results are shown in table $2 \mathrm{E}$.

Table 2E. Fit of Model to Meter V, Variable Flow Test Data

$$
\begin{aligned}
& \text { Model } y=1.138+0.003148 \mathrm{q}-0.00001876 \mathrm{q}^{2} \\
& \text { Bias at } 225 \mathrm{gpm}, \mathrm{y}=+0.90 \% \\
& \text { Residual Standard Deviation }= \pm 0.055 \% \\
& \text { Number of Points }=17
\end{aligned}
$$

This meter shows a significant dependency on volume flow rate, $\mathrm{q}$ in $\mathrm{gpm}$, and on volume flow rate squared. The bias at a flow rate of $225 \mathrm{gpm}(14.2 \mathrm{l} / \mathrm{s})$ is +0.90 percent. The precision based on three times the residual standard deviation is \pm 0.16 percent. It should be noted that this variable flow test will only detect dependencies in order and flow rate. It is necessary to refer to the rangeability test data to examine the results or other dependencies such as temperature.

The mean bias of these data without fitting them to the model is +1.17 percent. The standard deviation of these data without the model is \pm 0.13 percent and the precision based on three times this standard deviation is \pm 0.39 percent.

Since this meter has significant dependencies, the bias must be calculated from the model to obtain the precision of \pm 0.16 percent. If the bias is not calculated from the model then the precision cannot be better than \pm 0.39 percent.

The pressure drop data for meter $\mathrm{V}$ are shown in figure $6 \mathrm{E}$. 


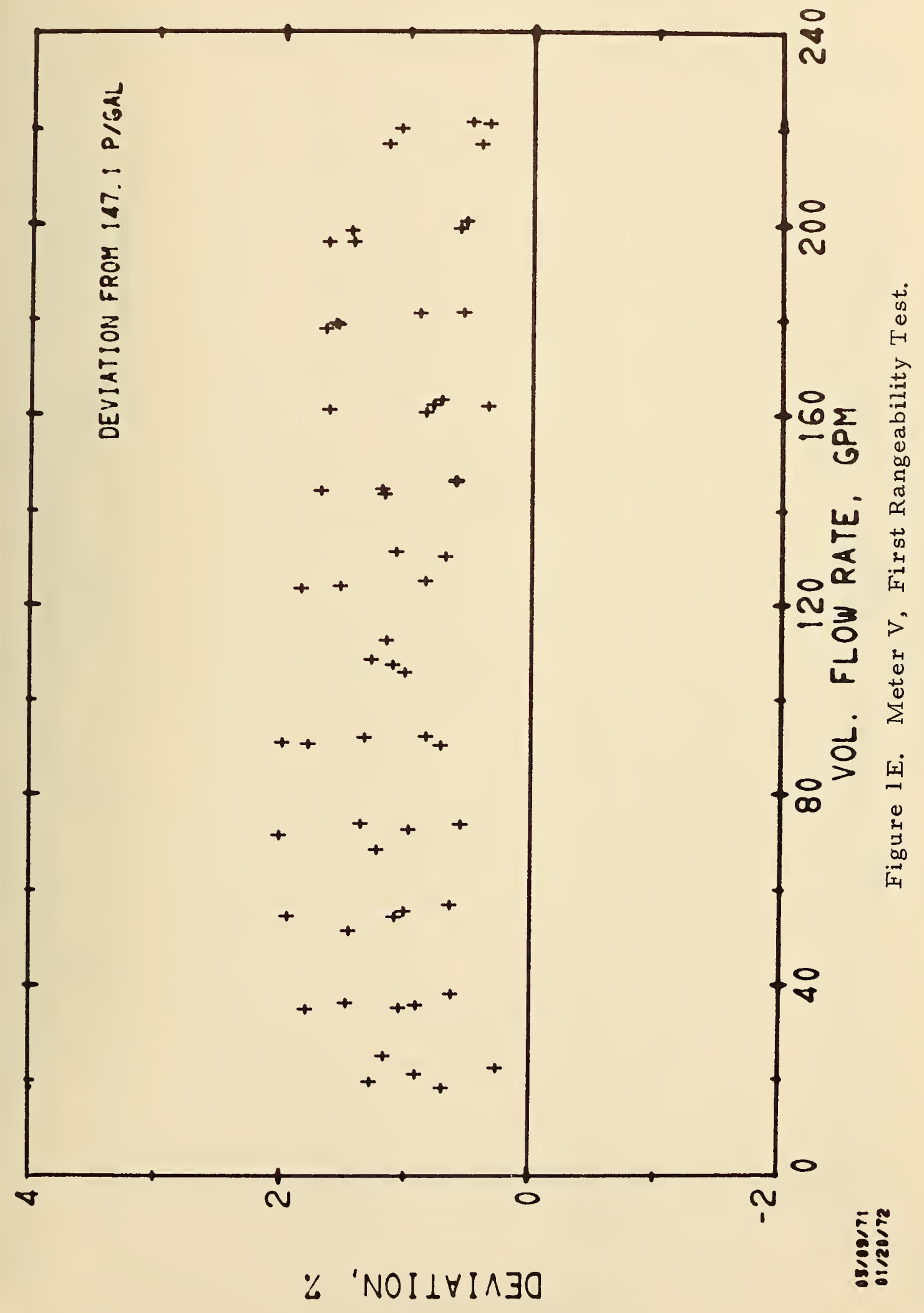

E-3 


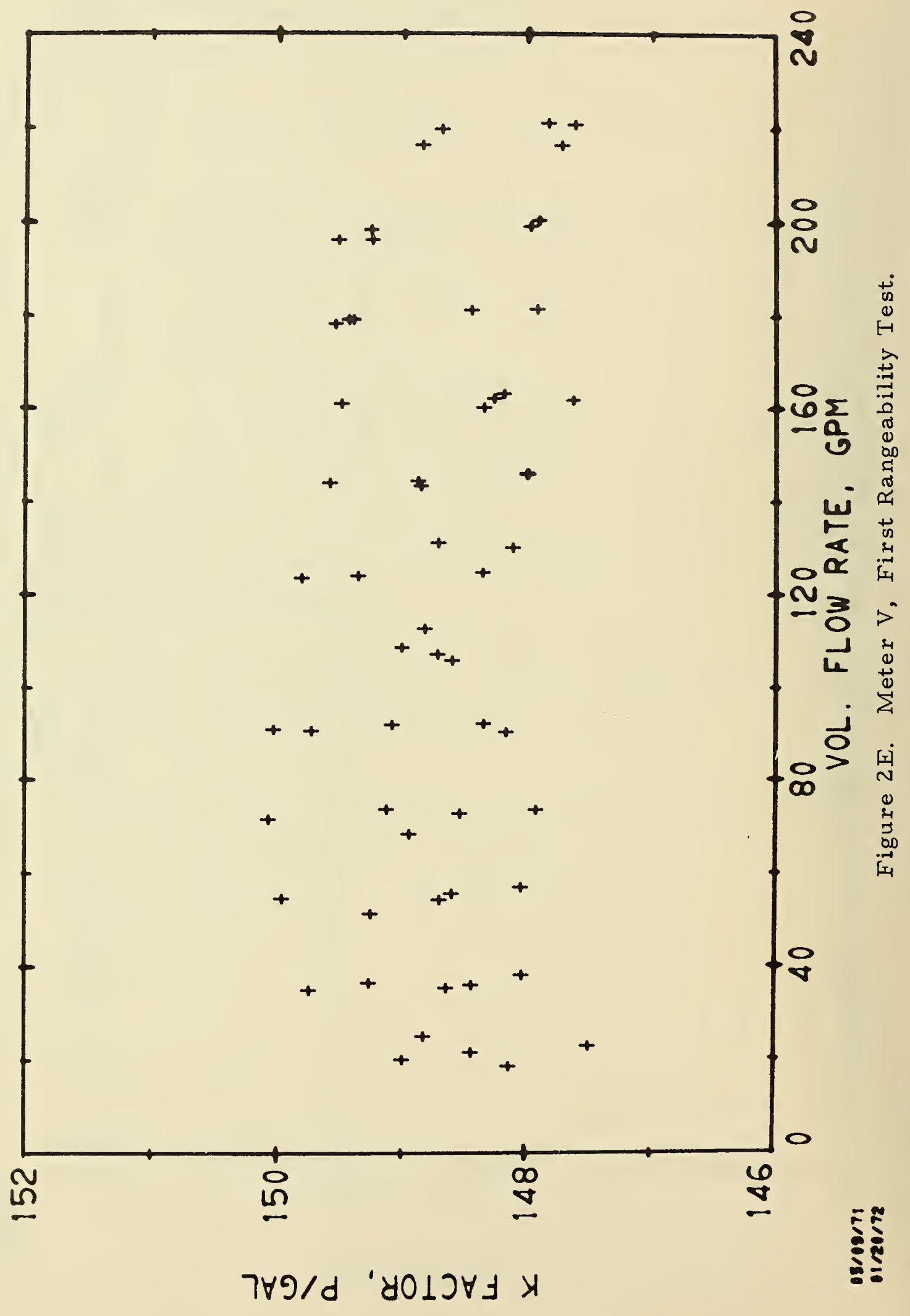




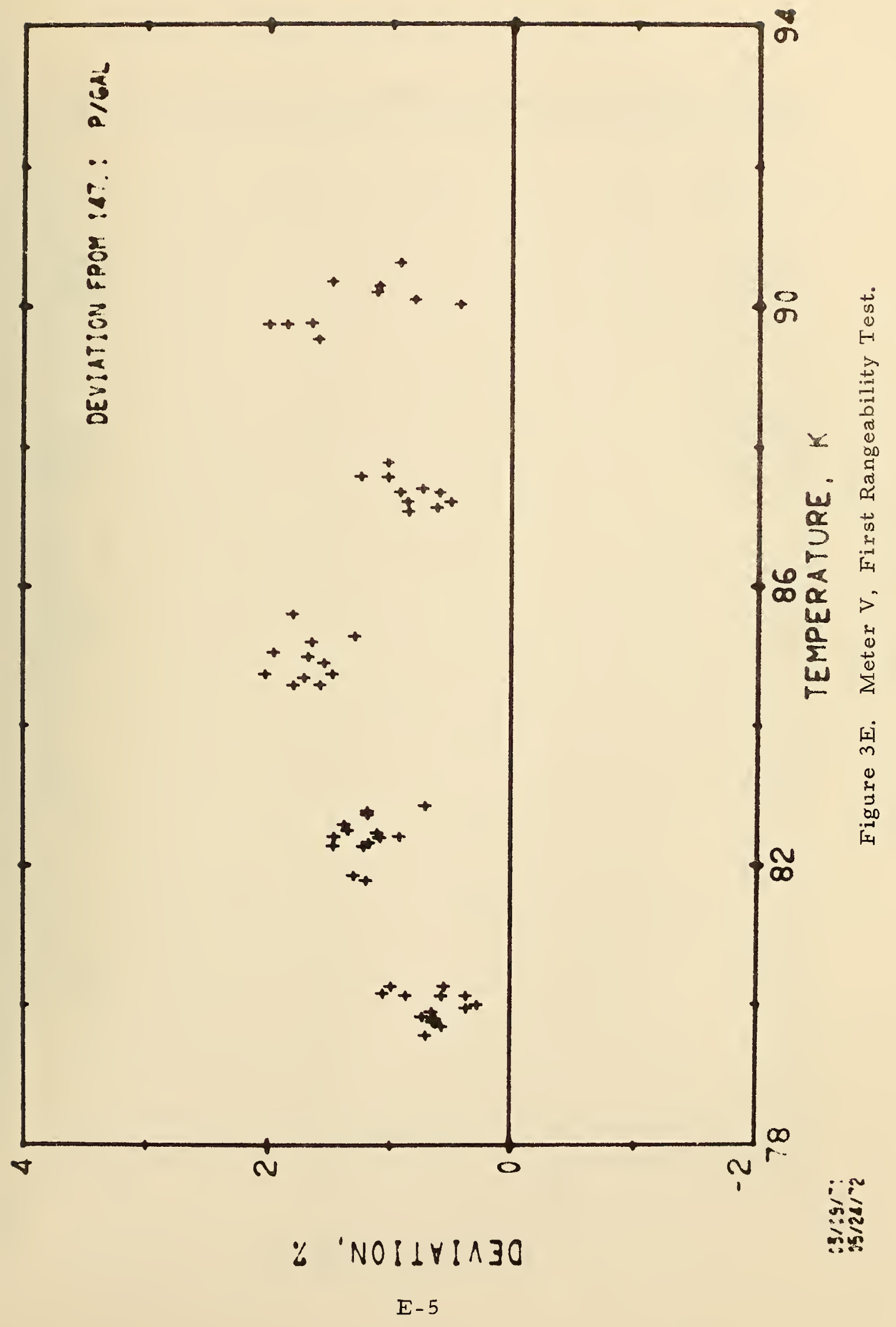




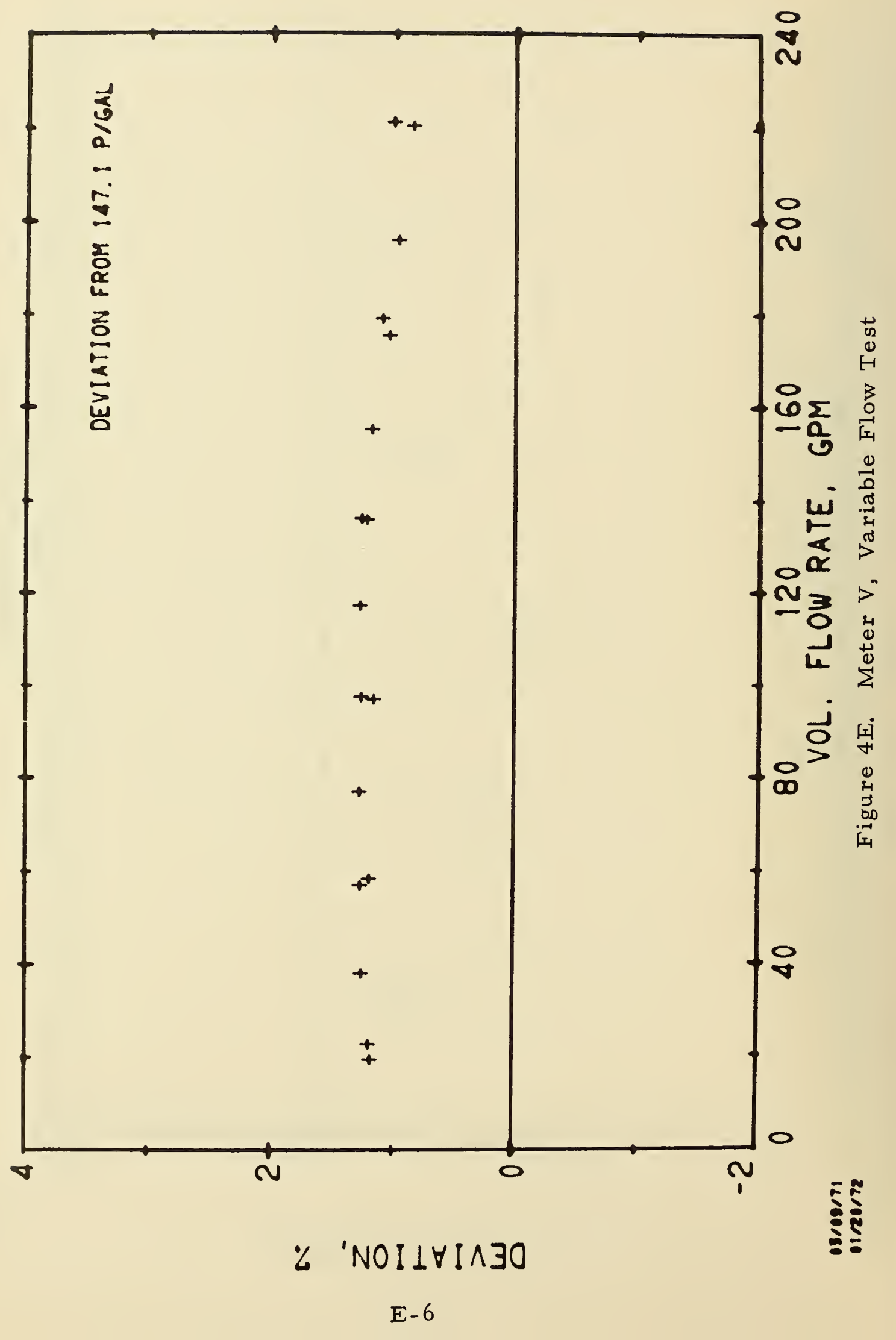




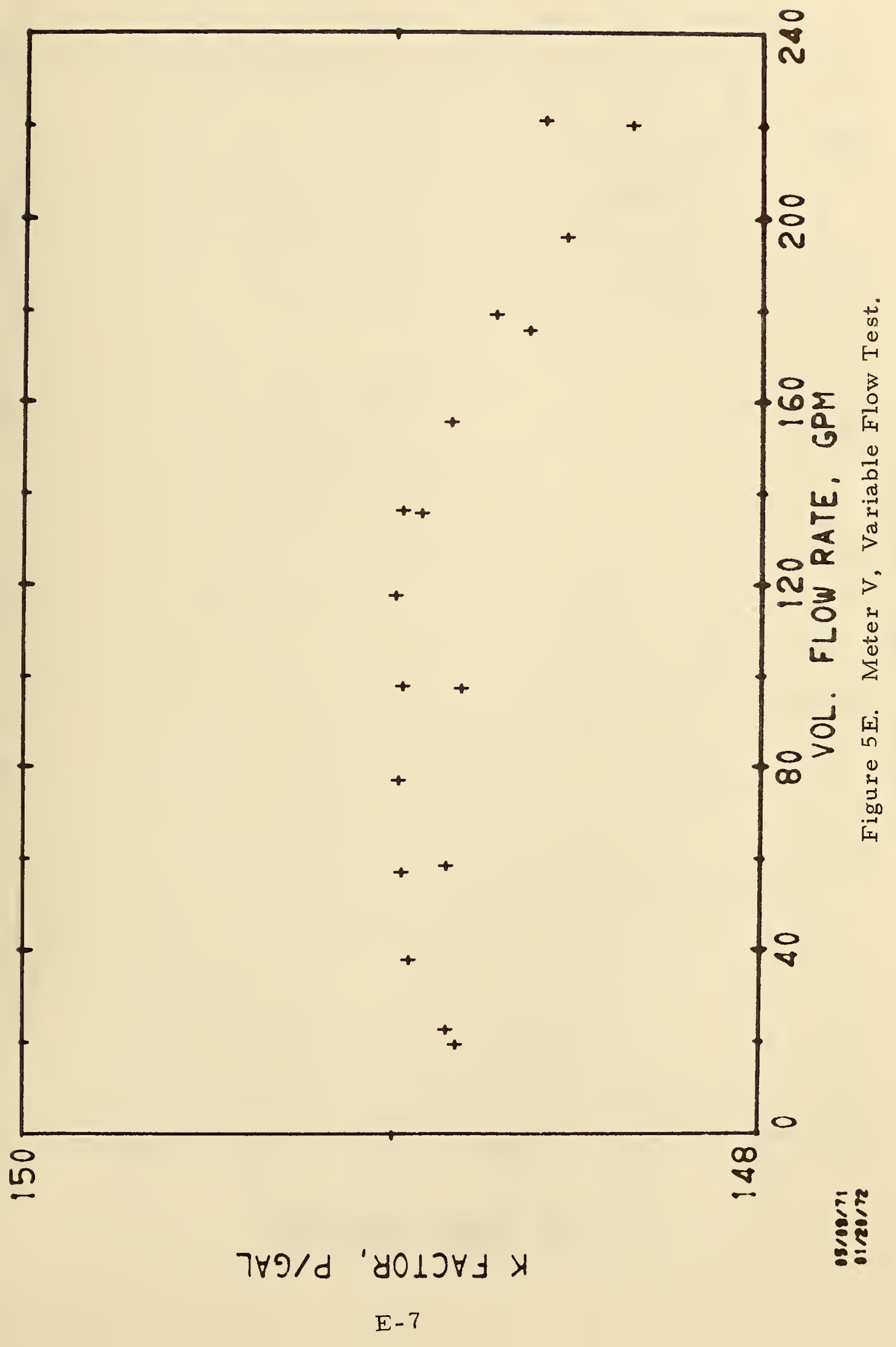




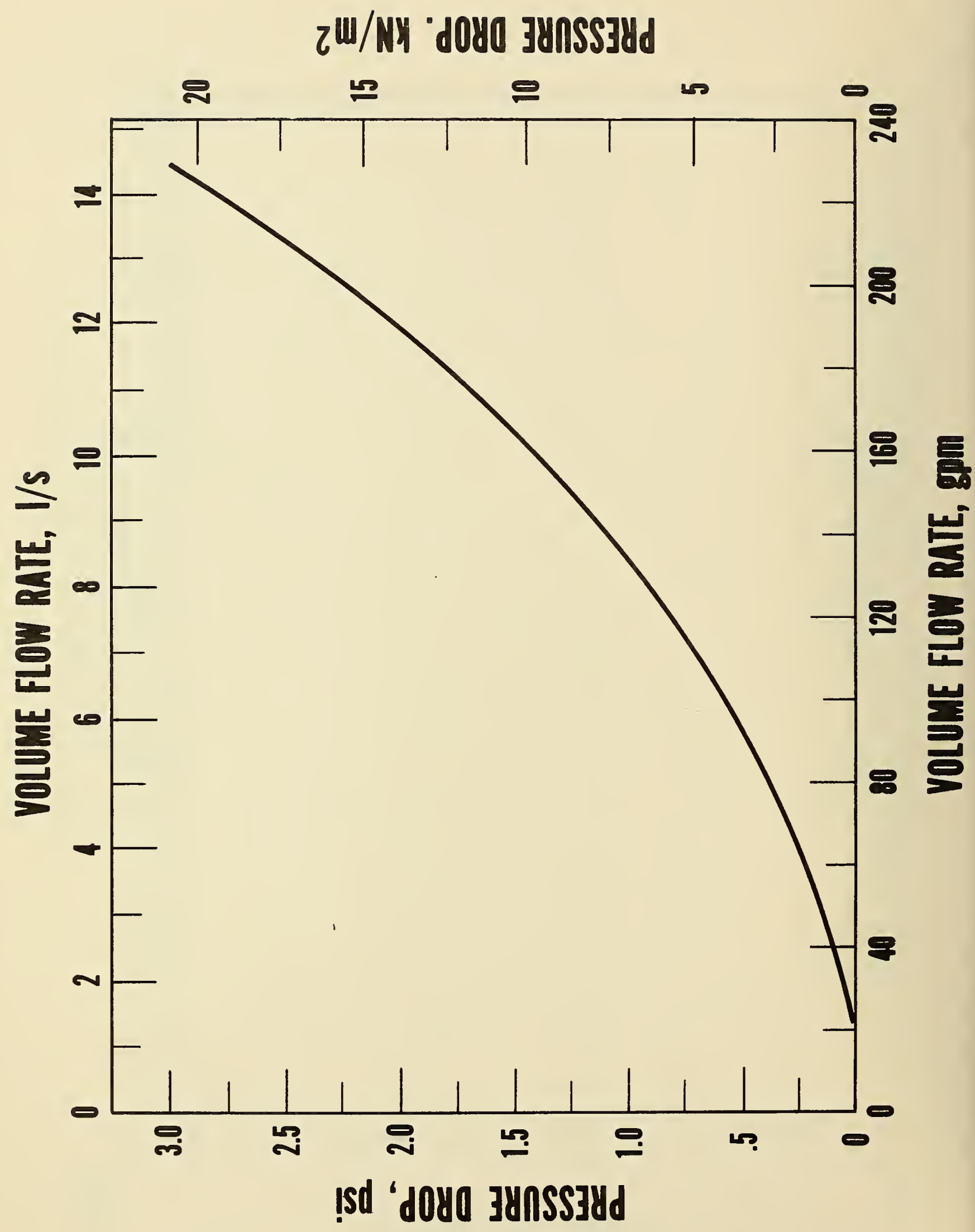

E-8 
This system consists of a standard turbine meter, an in-line densitometer, an electro-mechanical register and an electronics package. The turbine meter rotor speed is monitored by a pickup coil mounted on the meter housing. The volumetric flow rate is a function of the voltage pulse rate generated in the pickup coil. This voltage pulse is one input to the electronics package. The other input is the signal from the densitometer. This device measures density directly by monitoring the damping effect of the liquid on a vibrating element in the flowing liquid stream. The electronics package converts the volumetric pulse rate and the densitometer output to a pulse output that is proportional to the mass flow rate. This pulse output is converted to a direct reading in pounds by the electro-mechanical register.

The meter manufacturer's specifications are:

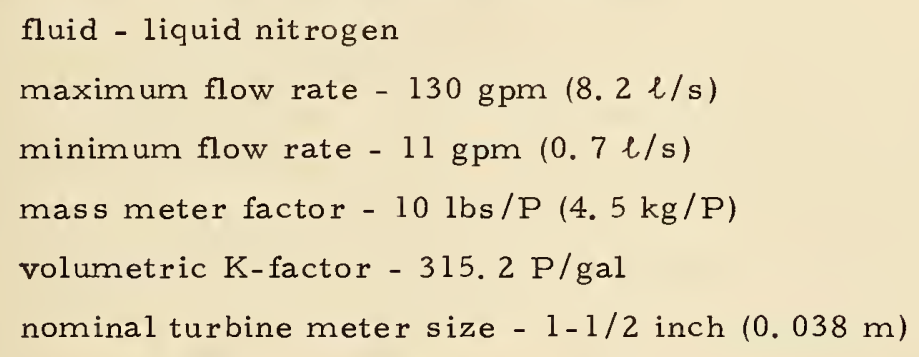

The test results of one meter are reported. Two meters were submitted for testing; however, one (meter $\mathrm{Y}$ ) of the two had been subjected to substantial preliminary tests at anothe $r$ facility and did not function satisfactorily at NBS.

The meter was subjected to a first rangeability test, a boundary test, a stability test, and a second rangeability test in that order.

Two sets of data were collected simultaneously during all tests. One set was volumetric data from the turbine meter only, and the other was mass flow rate data from the complete system. Both sets of results are reported.

\section{Meter Z (Volumetric System)}

The results of the first rangeability test are shown in figures $1 \mathrm{~F}$ and $2 \mathrm{~F}$. These data were fitted to the mathematical model and the results are shown in table $1 \mathrm{~F}$. The four outlying points were removed from the data prior to the fit because it was felt these points may have been influenced by the malfunctioning densitometer. 
Table 1F. Fit of Model to Meter Z (Volumetric System), First Rangeability Test Data
Model $y=-2.353+0.04287 \mathrm{~T}$
Bias at $\mathrm{T}=80 \mathrm{~K}, \mathrm{y}=+1.08 \%$
Residual Standard Deviation $= \pm 0.19 \%$
Number of Points $=54$

This volumetric meter displayed a significant temperature dependency. The bias at a temperature of $80 \mathrm{~K}$ is +1.08 percent. The precision based on three times the residual standard deviation is \pm 0.57 percent.

The mean bias of these data without fitting them to the model is +1.27 percent. The standard deviation of these data without the model is \pm 0.24 percent and the precision based on three times this standard deviation is \pm 0.72 percent.

The results of the boundary test are shown in figure 3E. The accuracy seems to remain unaffected by subcooling above approximately sixteen degrees of subcooling. Below that point there is a noticeable change in bias and a loss of precision. The amount of subcooling was determined at the inlet to the metering system; therefore, the turbine meter performance may have been affected by the pressure drop across the densitometer and the interconnecting piping.

The results of the stability test are shown in figure 4F. Approximately 624000 gallons (2 $362100 \ell$ ) of liquid nitrogen were metered during this test with no apparent wear occurring.

The results of the second rangeability test are shown in figures $5 \mathrm{~F}$ and $6 \mathrm{~F}$.

These data were fitted to the model and the results are shown in table $2 \mathrm{~F}$. Two points with the highest deviation were removed before fitting because of possible influence of the densitometer.

Table 2F. Fit of Model to Meter Z (Volumetric System), Second Rangeability Data

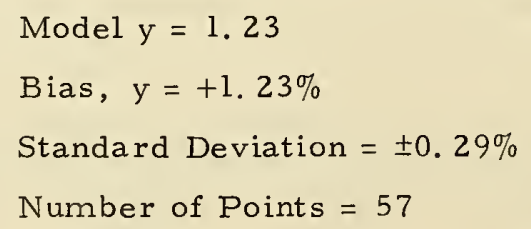

There were no significant dependencies exhibited during this test. The bias is \pm 1.23 percent and the precision based on three times the standard deviation is \pm 0.87 percent. 
Typical pressure drop data for meter $\mathrm{Z}$ is shown in figure $11 \mathrm{~F}$.

Meter Z (Mass System)

The results of the first rangeability test are shown in figure $7 \mathrm{~F}$. The data above $4 \mathrm{lbs} / \mathrm{s}(1.8 \mathrm{~kg} / \mathrm{s})$ were fitted to the model and the results are shown in table $3 \mathrm{~F}$. The data below $4 \mathrm{lbs} / \mathrm{s}(1.8 \mathrm{~kg} / \mathrm{s})$ were removed from the model because of the strong flow rate dependency and the loss of precision. One other point was removed at $14 \mathrm{lbs} / \mathrm{s}$ $(6.3 \mathrm{~kg} / \mathrm{s})$ and 6 percent deviation because the densitometer was not functioning properly at that time.

Table 3F. Fit of Model to Meter Z (Mass System), First Rangeability Data, for flow rates above $4 \mathrm{lbs} / \mathrm{s}(1.8 \mathrm{~kg} / \mathrm{s})$

Model y $=156.62-3.5366 \mathrm{~T}+0.019865 \mathrm{~T}^{2}$

Bias at $\mathrm{T}=80 \mathrm{~K}, \mathrm{y}=+0.83 \%$

Residual Standard Deviation $= \pm 0.60 \%$

Number of Points $=48$

These data show significant dependencies on temperature, $T$, and temperature squared. The bias at a temperature of $80 \mathrm{~K}$ is +0.83 percent and the precision based on three times the residual standard deviation is \pm 1.80 percent.

The mean bias of these data without fitting them to the model is -0.147 percerit. The standard deviation of these data without the model is \pm 0.84 percent and the precision based on three times the standard deviation is \pm 2.52 percent.

There appeared to be a calibration error in the densitometer which can be seen in figure $8 \mathrm{~F}$. Since the density is relatively insensitive to pressure, this calibration error appears in the model as a temperature dependency.

The results of the boundary test a re shown in figure $9 \mathrm{~F}$. The eight high deviation points at approximately eight degrees of subcooling are the result of the turbine meter subcooling dependency observed on figure $3 \mathrm{~F}$. The three high deviation points at approximately twenty-four degrees subcooling are a result of the behavior of the densitometer. Below a liquid temperature of $74 \mathrm{~K}$ (high subcooling), the densitometer became er ratic and gave erroneous data.

The results of the stability test are shown in figure $10 \mathrm{~F}$. The imprecision was due in large part to the erratic behavior of the densitometer. There did not appear to be any change in the turbine meter during this test.

The results of the second rangeability test are shown in figure $11 \mathrm{~F}$. The data below $4 \mathrm{lbs} / \mathrm{s}$ did not exhibit the same los of precision as was observed during the first range- 
ability test and they were included in the fit to the model. The results of the fit are presented in table $4 \mathrm{~F}$.

Table 4F. Fit of Model to Meter Z (Mass System), Second Rangeability Test Data

Model $\mathrm{y}=15.29-0.1786 \mathrm{~T}-0.1136 \dot{\mathrm{m}}$

Bias at $\mathrm{T}=80 \mathrm{~K}$ and $\dot{\mathrm{m}}=14.5 \mathrm{lbs} / \mathrm{s}, \mathrm{y}=-0.64 \%$

Residual Standard Deviation $= \pm 0.80 \%$

Number of Points $=58$

During this test, the mass meter system shows significant dependencies on temperature, $T$, and mass flow rate, $\dot{m}$. The bias at a flow rate of $14.5 \mathrm{lbs} / \mathrm{s}$ and a temperature of $80 \mathrm{~K}$ is -0.64 percent. The precision based on three times the residual standard deviation is \pm 2.40 percent.

The mean bias of these data without fitting them to the model is -0.69 percent. The standard deviation of these data without the model is \pm 1.10 percent and the precision based on three times the standard deviation is \pm 3.30 percent.

Since this meter has significant. dependencies, the bias must be calculated from the model to obtain the precision of \pm 2.40 percent. If the bias is not calculated from the model then the precision can be no better than \pm 3.30 percent.

The density dependency is shown in figure $12 \mathrm{~F}$. 


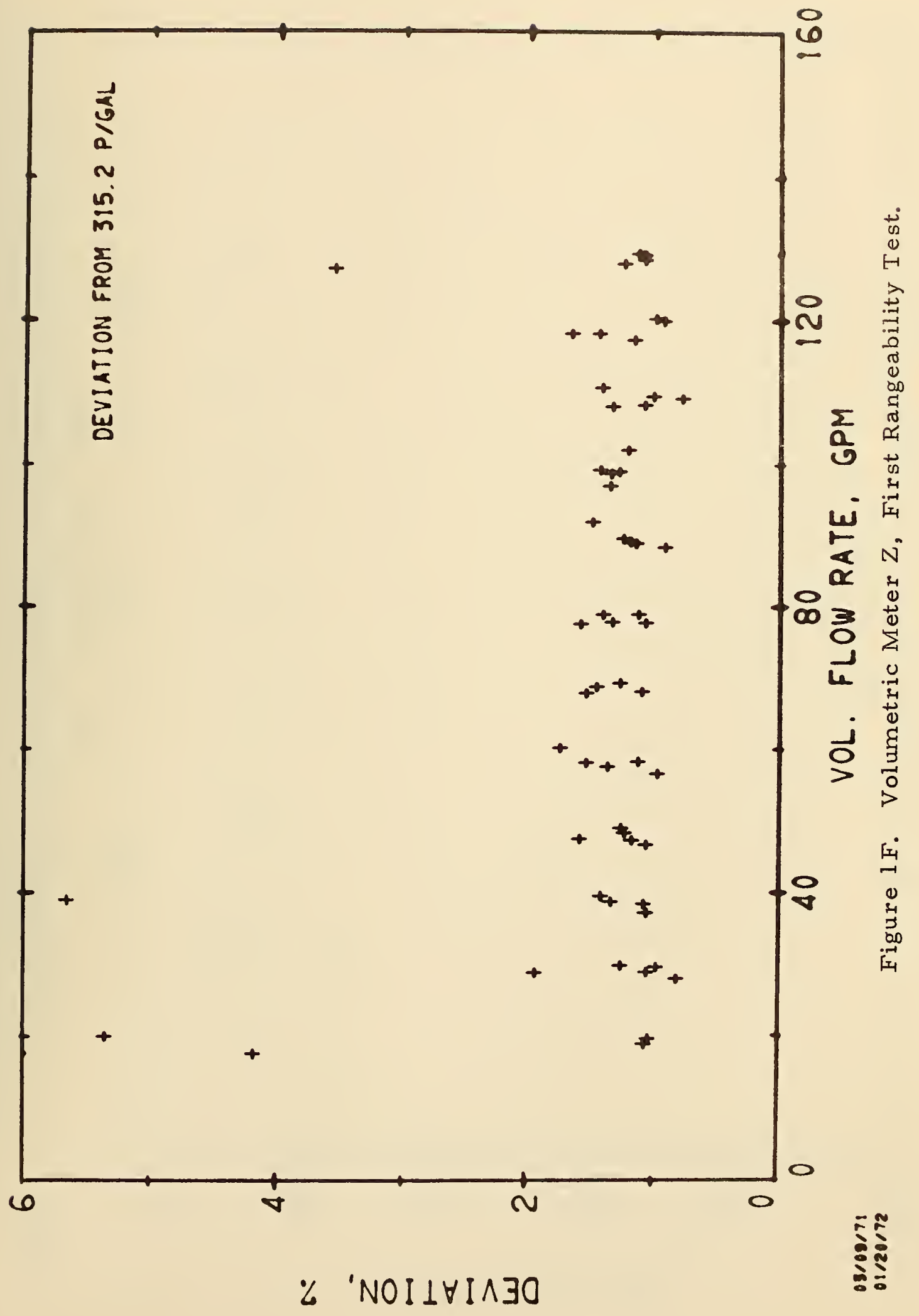

F-5 


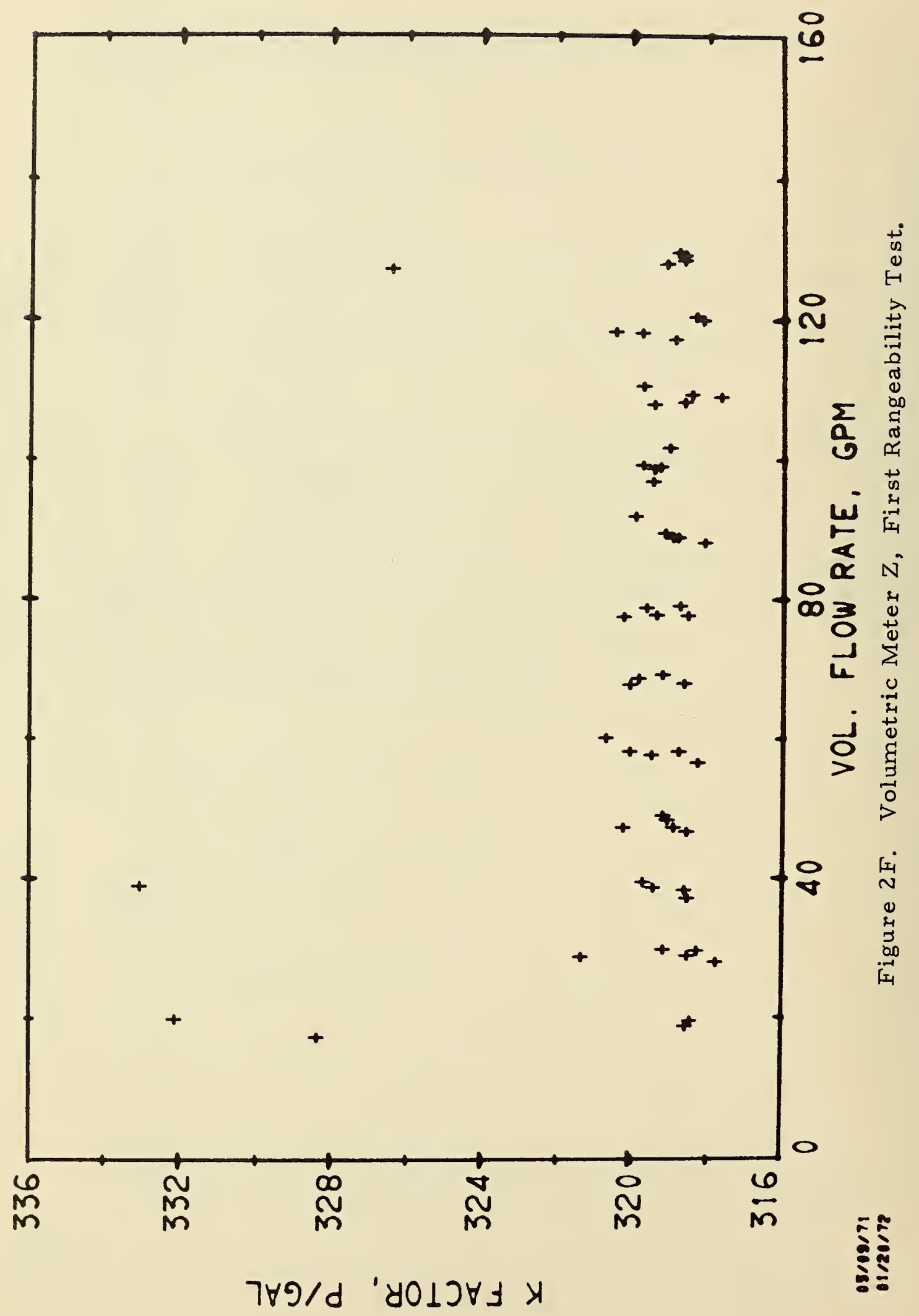

F-6 


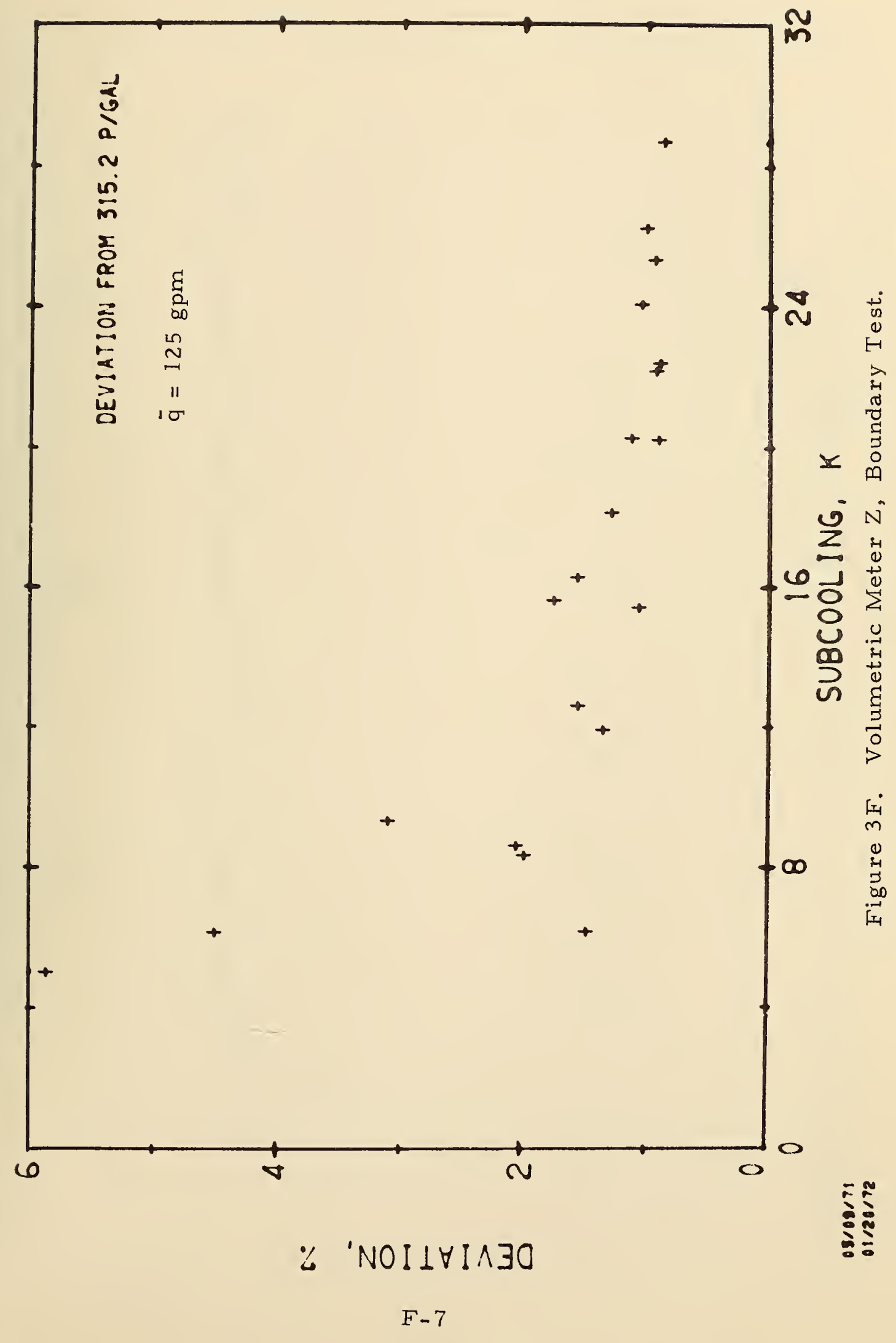




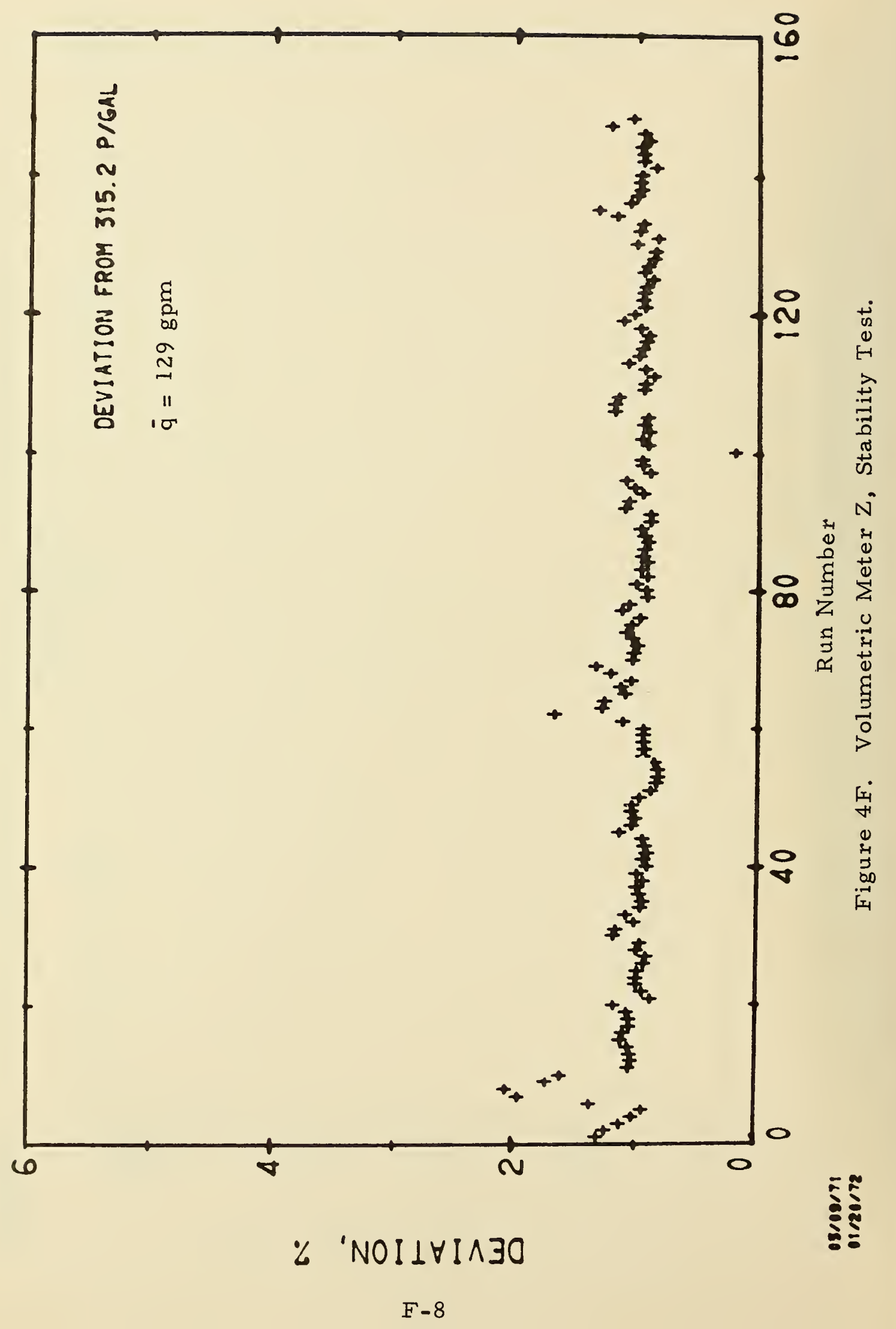




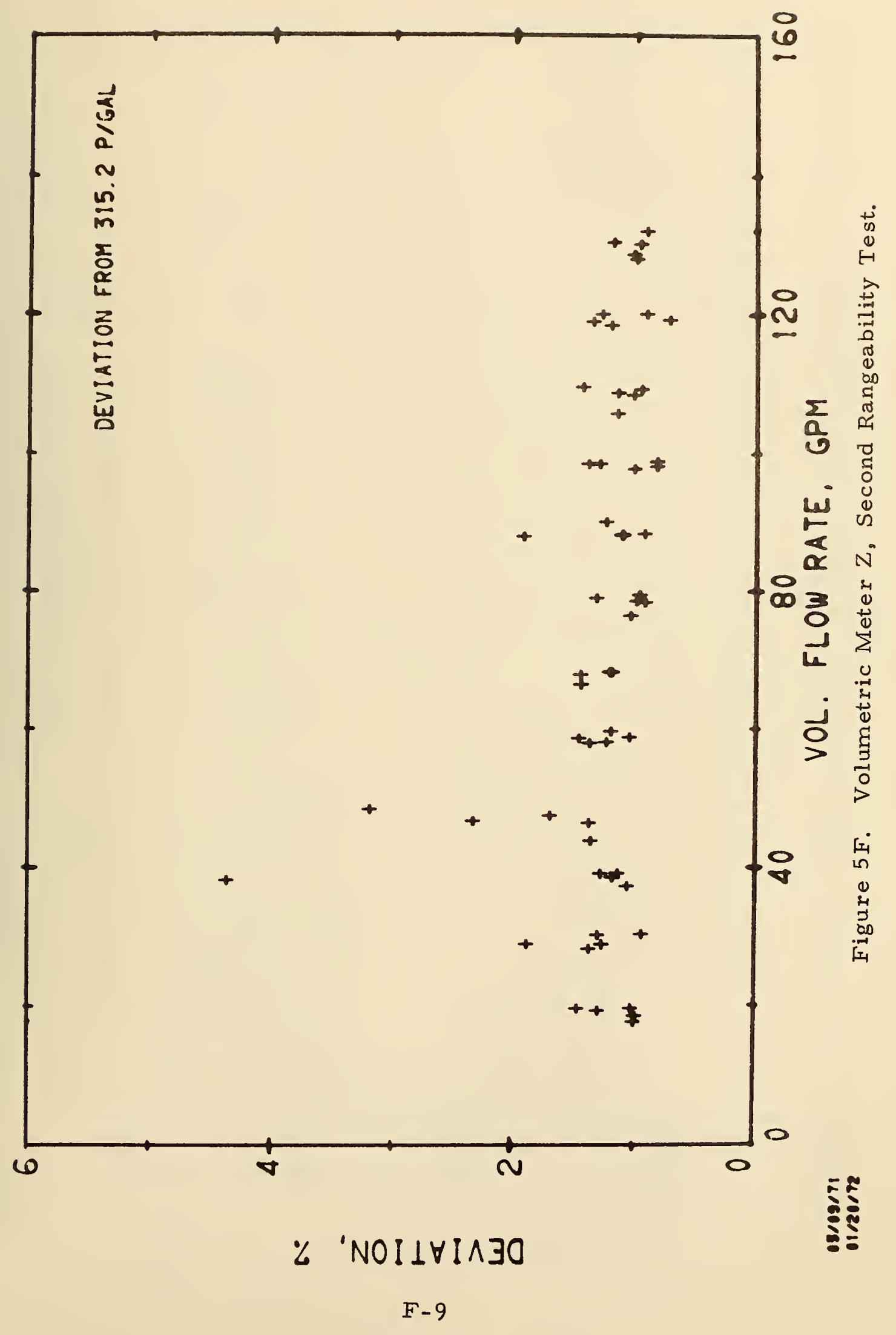




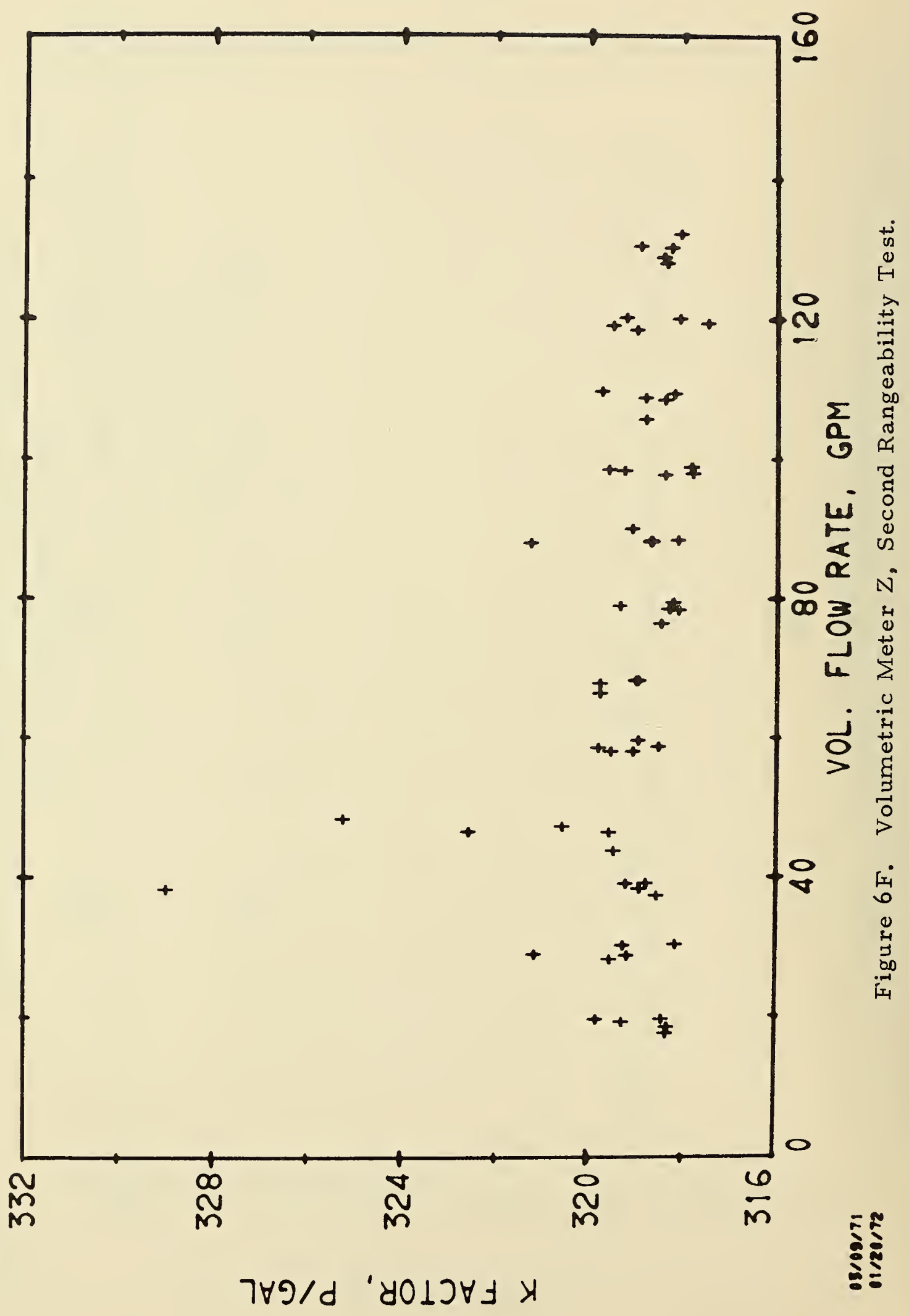




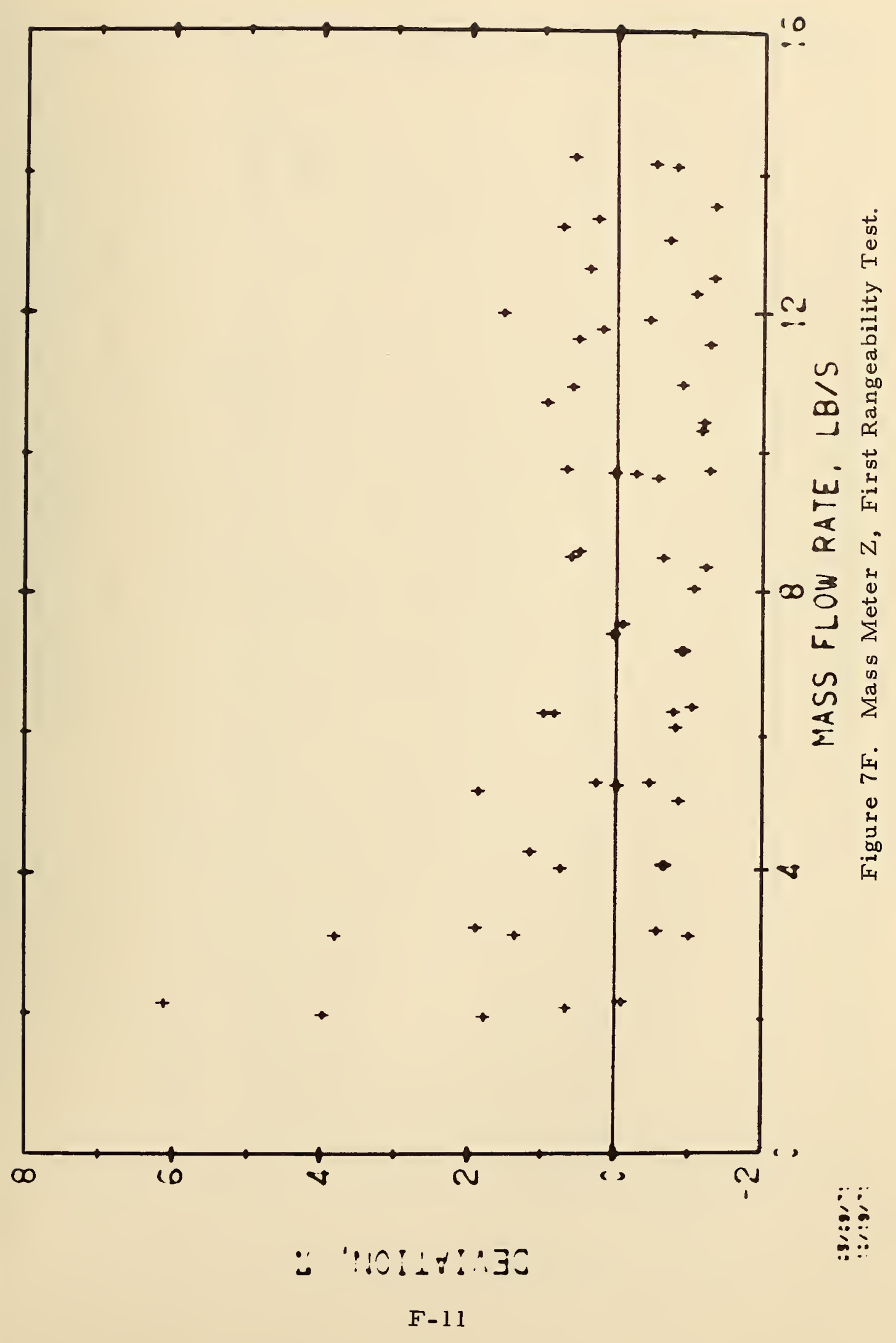




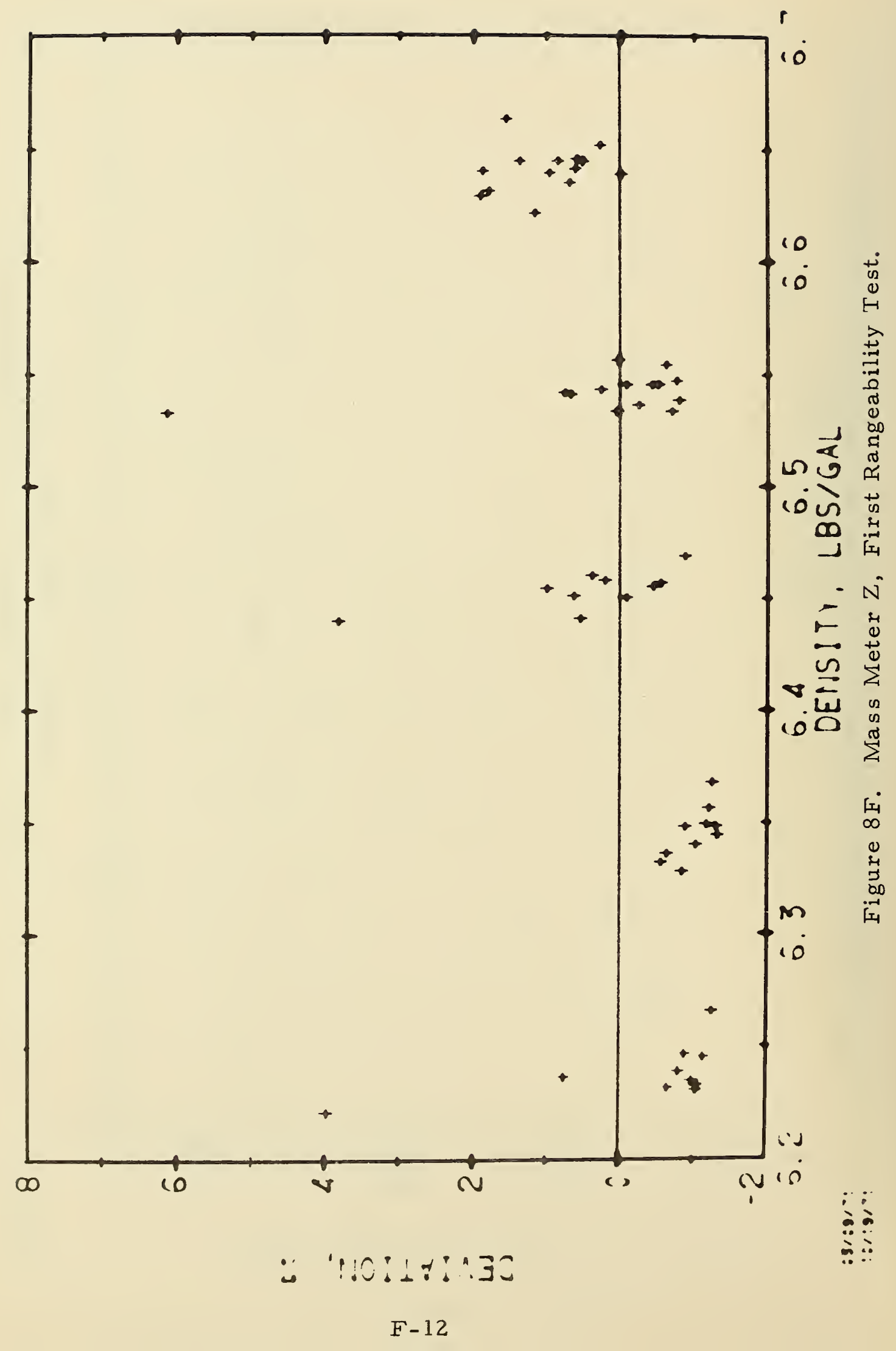




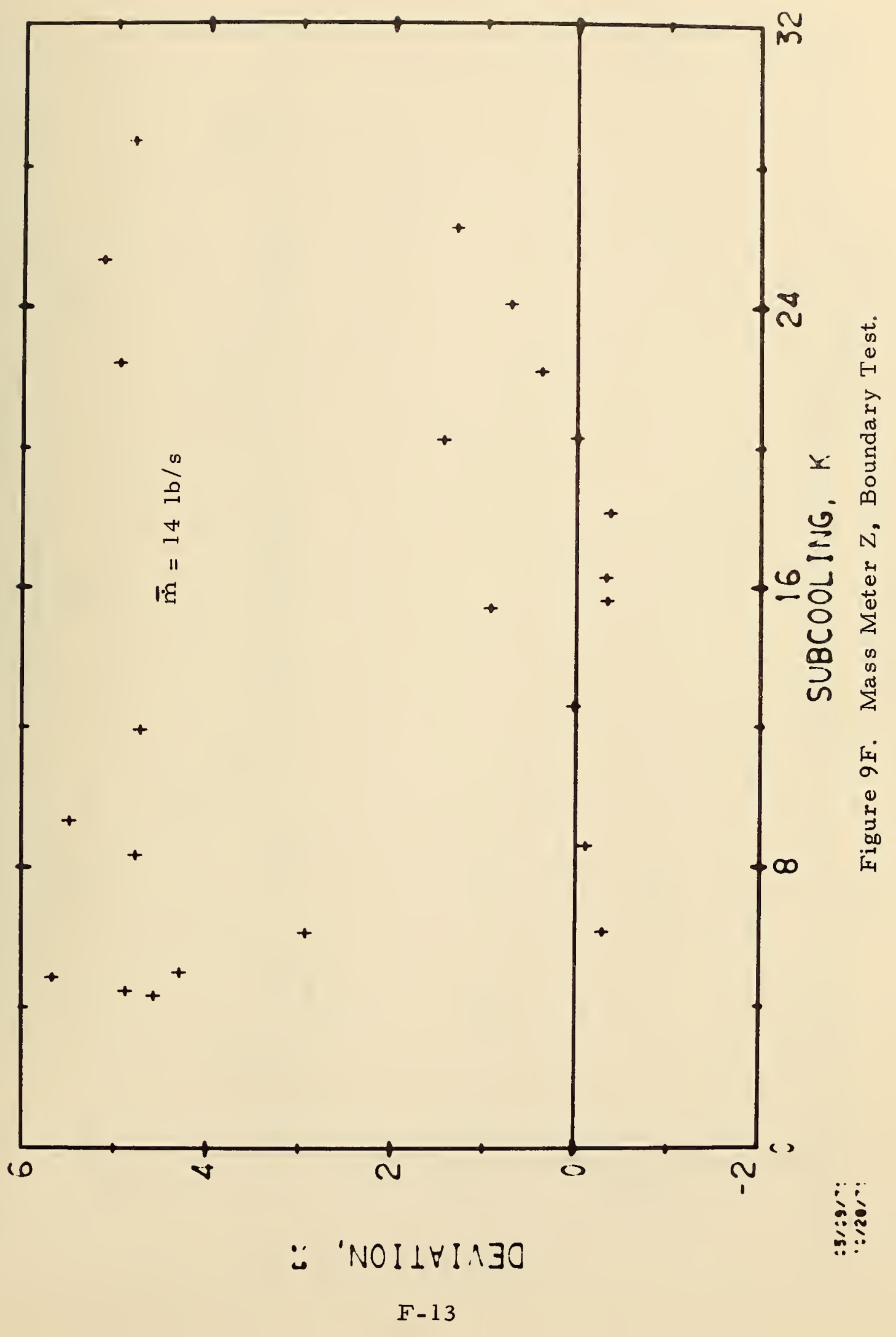




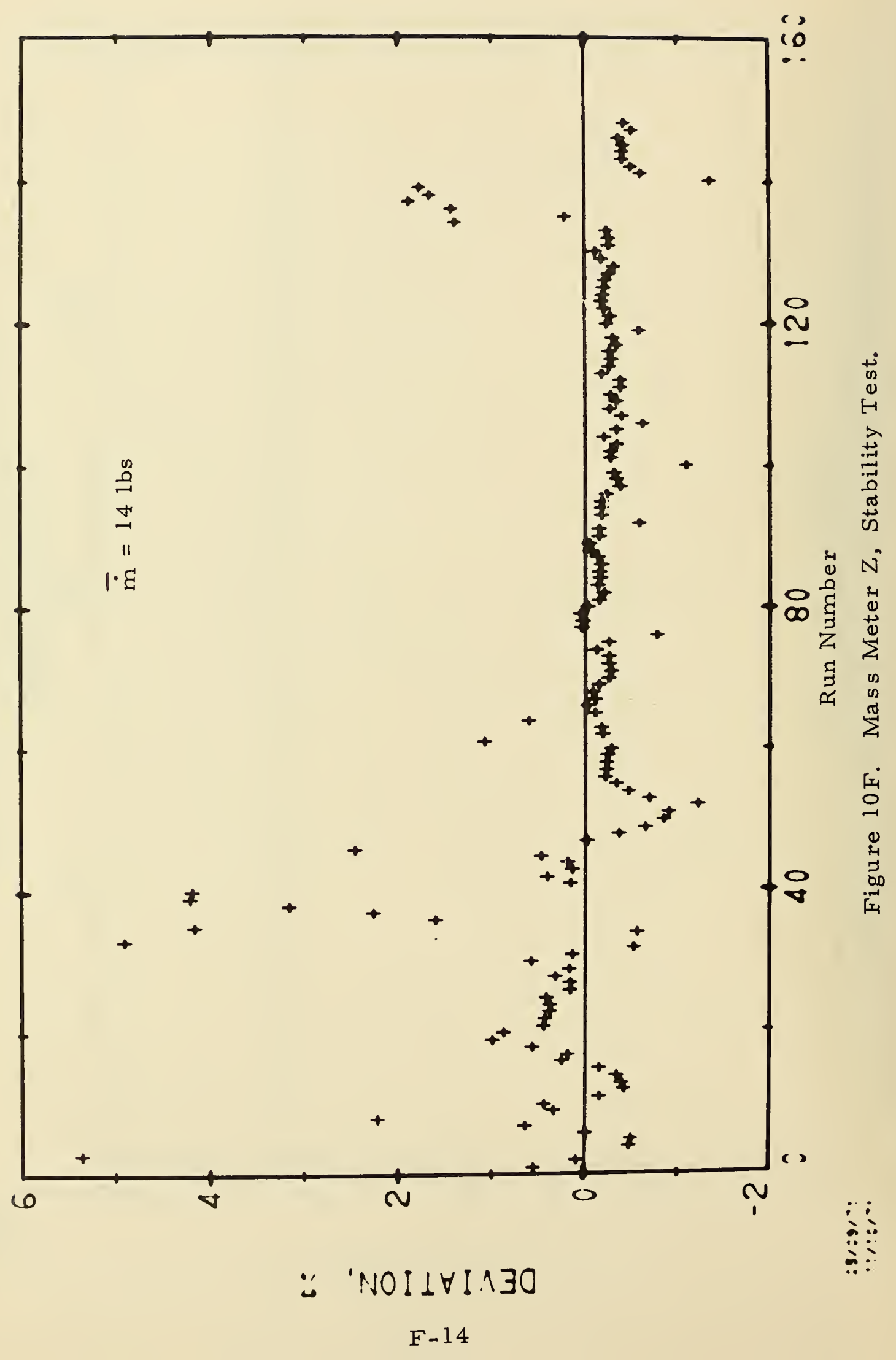




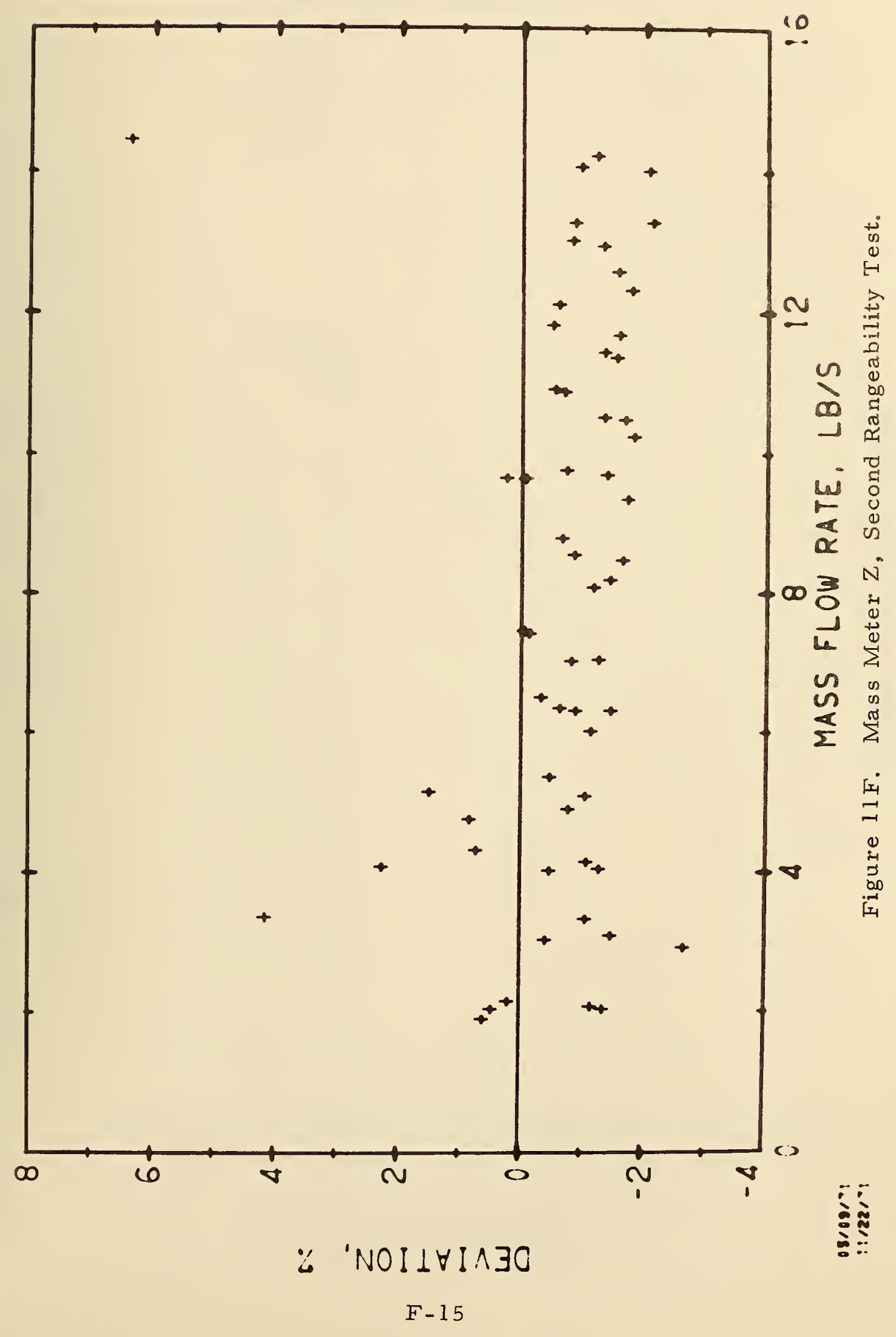




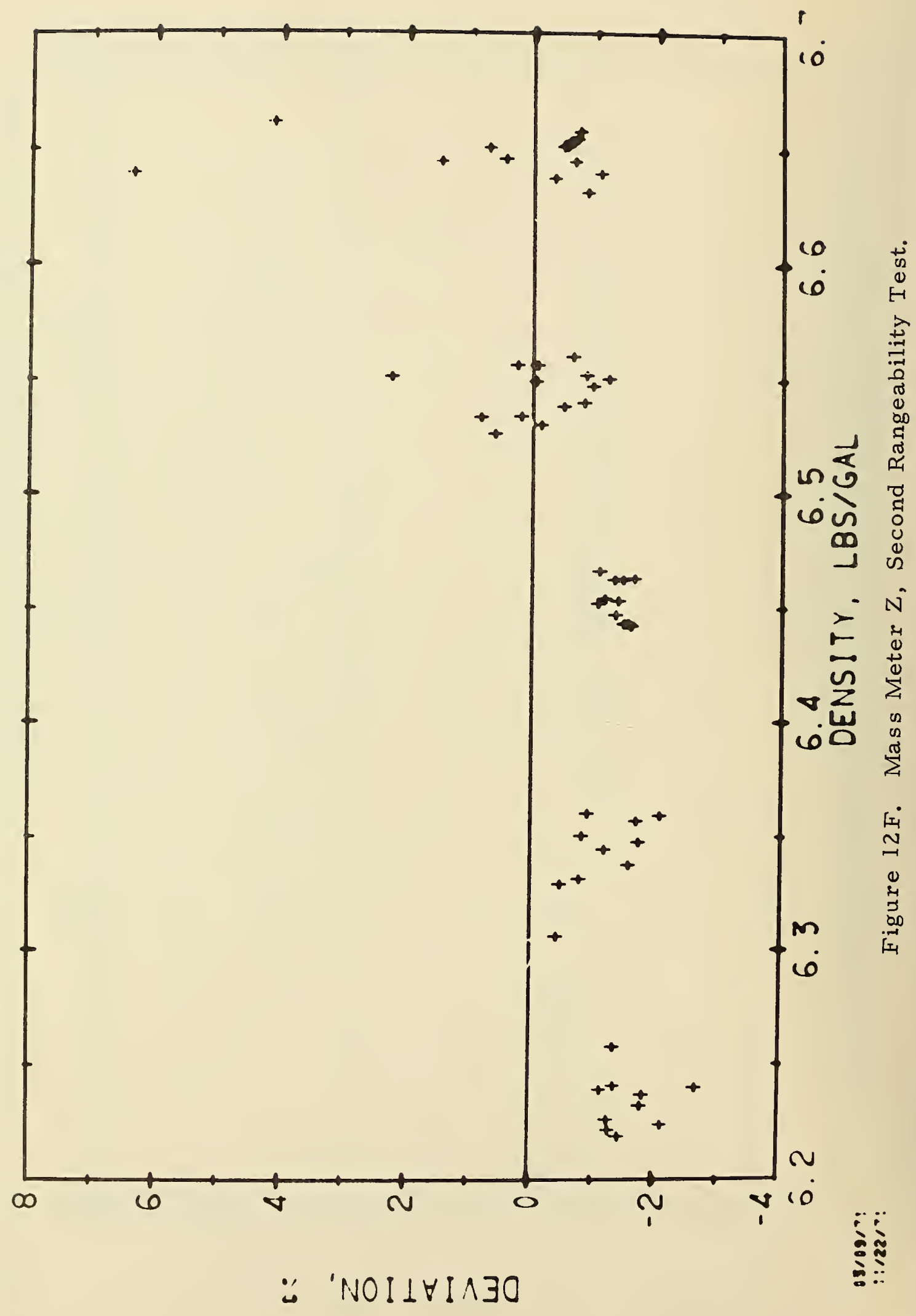




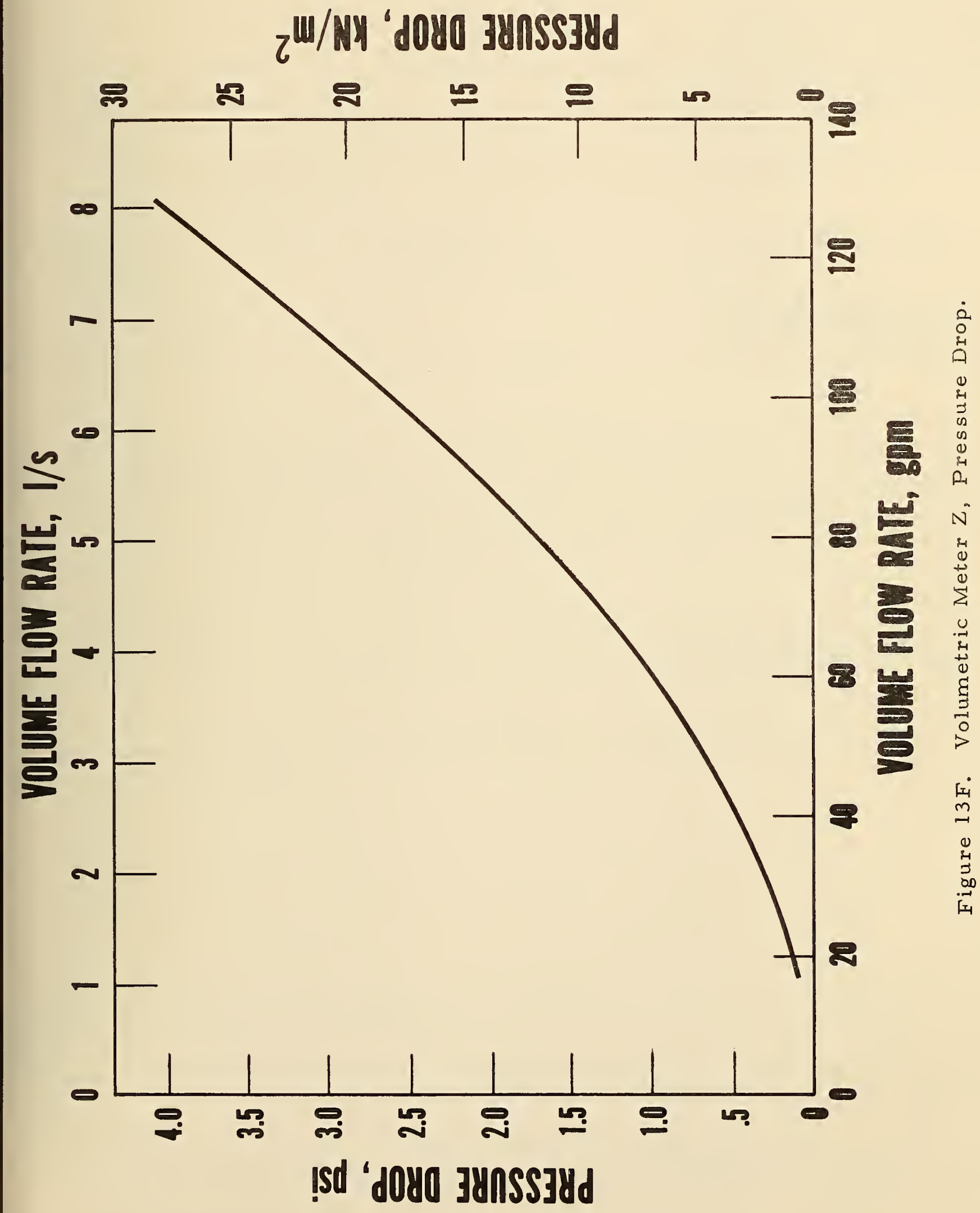





\begin{tabular}{|c|c|c|}
\hline $\begin{array}{c}\text { J.S. DEPT. OF COMM. } \\
\text { BIBLIOGRAPHIC DATA } \\
\text { SHEET }\end{array}$ & $\begin{array}{c}\text { 1. PUBLICATION OR REPORT NO. } \\
\text { NBS TN 624 }\end{array}$ & $\begin{array}{l}\text { 2. Gov't Accession } \\
\text { No. }\end{array}$ \\
\hline
\end{tabular}
1. TITLE AND SUBTITLE

An Evaluation of Several Cryogenic Turbine Flowmeters

3. Recipient's Accession No.

5. Publication Date

October 1972

6. Performing Organization Code

8. Performing Organization C. H. Kneebone

- AUThOR(s) J.A. Brennan, R.W. Stokes, D. B. Mann, and

. PERF ORMING ORGANIZATION NAME AND ADDRESS

NATIONAL BUREAU OF STANDARDS, Boulder Labs. DEPARTMENT OF COMMERCE

Boulder, Colorado 80301

10. Project/Task/Work Unit No. 2750360

11. Contract/Grant No.

1. Sponsoring Organization Name and Address

Co-Sponsored by

The Compressed Gas Association, Incorporated

500 Fifth Avenue

New York, New York 10036

13. Type of Report \& Period Covered

Interim - 1971

14. Sponsoring A gency Code

SUP PLEMENT ARY NOTES

- ABSTRACT (A 200-word or less factual summary of most significant information. If document includes a significant bibliography or literature survey, mention it here.)

he National Bureau of Standards (NBS) and the Compressed Gas Association (CGA) zve jointly sponsored a research program on cryogenic flow measurement. A cryoenic flow research facility was constructed and has been used to evaluate cryogenic owmeters operating on several different principles.

he operation and the accuracy of the flow facility is briefly described. The perforance of the flowmeters in liquid nitrogen is described by reporting the precision and as of the meters before and after an 80 -hour stability test and by defining the existende temperature, pressure, flow rate, subcooling, and time order (wear) dependencies.

eters were evaluated with flow rates ranging from 20 to $210 \mathrm{gpm}(1.3$ to 13.2 (s), pressures ranging from 32 to 112 psia $\left(0.22\right.$ to $0.77 \mathrm{MN} / \mathrm{m}^{2}$ ), and with temperares ranging from 72 to $90 \mathrm{~K}$.

KEY WORDS (Alphabetical order, separated by semicolons)

:yogenic; flow; liquid nitrogen; mass; mass flowmeters; measurement; turbine Jwmeters; volume flowmeters.

AVAILABILITY ST ATEMENT

[X] UNLIMIT ED.

FOR OFFICIAL DISTRIBUTION. DO NOT RELEASE TO NTIS.

\begin{tabular}{|c|c|}
\hline $\begin{array}{c}\text { 19. SECURITY CLASS } \\
\text { (THIS REPURT) }\end{array}$ & 21. NO. OF PAGES \\
UNCL ASSIFIED & 90 \\
\hline $\begin{array}{l}\text { 20. SECUR ITY CLASS } \\
\text { (THIS P AGE) }\end{array}$ & $\begin{array}{c}\text { 22. Price } \\
\$ 1.00\end{array}$ \\
UNCL ASSIFIED & \\
\hline
\end{tabular}

USCOMM-DC $66244 . P 7$ 



\section{NBS TECHNICAL PUBLICATIONS}

\section{PERIODICALS}

JOURNAL OF RESEARCH reports National Bureau of Standards research and development in physics, mathematics, and chemistry. Comprehensive scientific papers give complete details of the work, including laboratory data, experimental procedures, and theoretical and mathematical analyses. Illustrated with photographs, drawings, and charts. Includes listings of other NBS papers as issued.

Published in two sections, available separately:

\section{- Physies and Chemistry}

Papers of interest primarily to scientists working in these fields. This section covers a broad range of physical and chemical research, with major emphasis on standards of physical measurement, fundamental constants, and properties of matter. Issued six times a year. Annual subscription: Domestic, $\$ 9.50 ; \$ 2.25$ additional for foreign mailing.

\section{- Mathematical Sciences}

Studies and compilations designed mainly for the mathematician and theoretical physicist. Topics in mathematical statistics, theory of experiment design, numerical analysis, theoretical physics and chemistry, logical design and programming of computers and computer systems. Short numerical tables. Issued quarterly. Annual subscription: Domestic, \$5.00; $\$ 1.25$ additional for foreign mailing.

\section{TECHNICAL NEWS BULLETIN}

The best single source of information concerning the Bureau's measurement, research, developmental, cooperative, and publication activities, this monthly publication is designed for the industry-oriented individual whose daily work involves intimate contact with science and technology-for engineers, chemists, physicists, research managers, product-development managers, and company executives. Includes listing of all NBS papers as issued. Annual subscription: Domestic, $\$ 3.00 ; \$ 1.00$ additional for foreign mailing.

\section{Bibliographic Subscription Services}

The following current-awareness and literaturesurvey bibliographies are issued periodically by the Bureau: Cryogenic Data Center Current Awareness Service (weekly), Liquefied Natural Gas (quarterly), Superconducting Devices and Materials (quarterly), and Electromagnetic Metrology Current Awareness Service (monthly). Available only from NBS Boulder Laboratories. Ordering and cost information may be obtained from the Program Information Office, National Bureau of Standards, Boulder, Colorado 80302 .

\section{HOMPERIODICALS}

Applied Mathematics Series. Mathematical tables, manuals, and studies.

Building Science Series. Research results, test methods, and performance criteria of building materials, components, systems, and structures.

Handbooks. Recommended codes of engineering and industrial practice (including safety codes) developed in cooperation with interested industries, professional organizations, and regulatory bodies.

Special Publications. Proceedings of NBS conferences, bibliographies, annual reports, wall charts, pamphlets, etc.

Monographs. Major contributions to the technical literature on various subjects related to the Bureau's scientific and technical activities.

National Standard Reference Data Series. NSRDS provides quantitative data on the physical and chemical properties of materials, compiled from the world's literature and critically evaluated.

Product Standards. Provide requirements for sizes, types, quality, and methods for testing various industrial products. These standards are developed cooperatively with interested Government and industry groups and provide the basis for common understanding of product characteristics for both buyers and sellers. Their use is voluntary.

Technical Notes. This series consists of communications and reports (covering both other-agency and NBS-sponsored work) of limited or transitory interest.

Federal Information Processing Standards Publications. This series is the official publication within the Federal Government for information on standards adopted and promulgated under the Public Law 89-306, and Bureau of the Budget Circular A-86 entitled, Standardization of Data Elements and Codes in Data Systems.

Consumer Information Series. Practical information, based on NBS research and experience, covering areas of interest to the consumer. Easily understandable language and illustrations provide useful background knowledge for shopping in today's technological marketplace.

\section{CATALOGS OF NBS PUBLICATIONS}

NBS Special Publication 305, Publications of the NBS. 1966-1967. When ordering, include Catalog No. C13.10:305. Price $\$ 2.00 ; 50$ cents additional for foreign mailing.

NBS Special Publication 305, Supplement 1, Publications of the NBS, 1968-1969. When ordering, include Catalog No. C13.10:305/Suppl. 1. Price $\$ 4.50 ; \$ 1.25$ additional for foreign mailing.

NBS Special Publication 305, Supplement 2, Publications of the NBS, 1970. When ordering, include Catalog No. C13.10:305/Suppl. 2. Price $\$ 3.25$; 85 cents additional for foreign mailing. 
U.S. DEPARTMENT OF COMMERCE

National Bureau of Standards

Washington, 0.C. 20234

OFFICIAL BUSINESS

U.S. OEPARTMENT OF COMMERCE

215

Penalty for Private Use, $\$ 300$ 